SiMuS - Uma arquitetura de referência para sistemas multirrobóticos de serviço 



\title{
SiMuS - Uma arquitetura de referência para sistemas multirrobóticos de serviço
}

\author{
Daniel Feitosa
}

Orientadora: Profa. Dra. Elisa Yumi Nakagawa

Dissertação apresentada ao Instituto de Ciências Matemáticas e de Computação - ICMC-USP, como parte dos requisitos para obtenção do título de Mestre em Ciências - Ciências de Computação e Matemática Computacional. VERSÃO REVISADA 
Ficha catalográfica elaborada pela Biblioteca Prof. Achille Bassi e Seção Técnica de Informática, ICMC/USP, com os dados fornecidos pelo(a) autor(a)

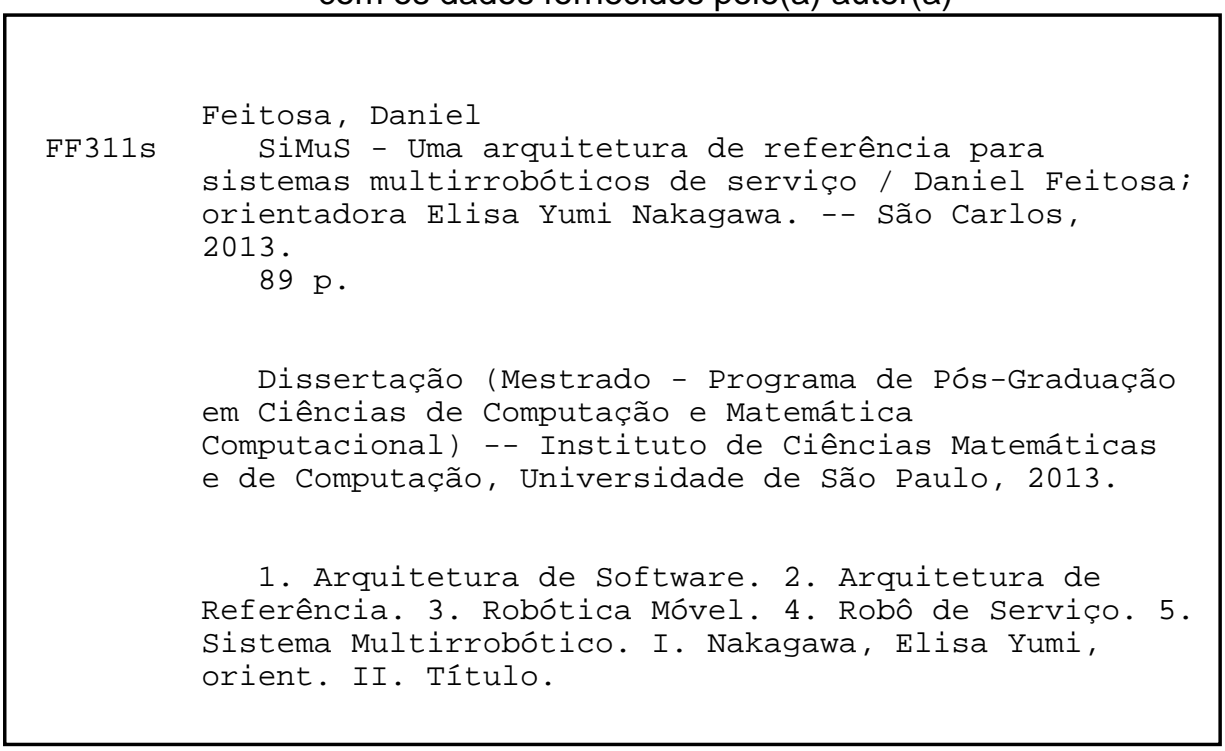


À fonte de minhas motivações, meus pais, Marciana Menezes Feitosa e Joaquim Duarte Feitosa 



\section{Agradecimentos}

A minha mãe, Marciana Menezes Feitosa, por tudo e mais um pouco. Agradeço pela dedicação, carinho, educação e até pelas broncas. Agradeço por ter sido forte e se tornado um pai na situação em que ser mãe foi mais difícil. A meu pai, Joaquim Duarte Feitosa, pelo carinho e pelos ensinamentos, mesmo após sua partida.

À orientadora Profa. Dra. Elisa Yumi Nakagawa, pelos ensinamentos, conselhos e dedicação durante o desenvolvimento deste trabalho. Você foi mais que uma orientadora nessa minha fase, foi uma amiga. Obrigado pelo seu otimismo e empenho.

A meus irmãos Leon, Sabrina e Bruno. Obrigado pelo apoio incondicional e carinho. Não existe uma relação que defina todos os laço que possuímos. Serei eternamente grato por tê-los comigo.

Aos melhores amigos da Bahia: Raul e Rodrigo. Agradeço por me acolherem como irmão e manter o mesmo laço forte de amizade, independente da distância e do tempo.

Aos grandes amigos que fiz em São Carlos Maria Lydia, Arthur (Querosene), Diego (Goiás) e Fábio (Zomona). Agradeço por tudo que me ensinaram e passaram ao meu lado.

Aos camaradas Santiago (Tia), Luís (Garça), Eder (Zero2), Marcos Vinicius (Cirilo), Marcos Nascimento (Markinho), Marco Aurélio (Marcão) e Douglas (Douglão), agradeço por tudo que passamos e que ainda passaremos.

A minha esposa Renata, que em tão pouco tempo se tornou a pessoa com a qual não me arrependo por cada segundo que passei ao seu lado e com a qual sei que poderei contar sempre. Obrigado pelo amor e conselhos.

Ao Alojamento da USP-São Carlos, no qual tive experiências com as quais aprendi muito e continuarei aprendendo. Aos amigos que fiz enquanto 
lá estive, tantos que não me atrevo a escrevê-los aqui. Muito obrigado por fazerem parte da minha vida e ter me permitido fazer parte da de vocês.

Aos amigos do LabES, pelo apoio, brincadeiras e conselhos: Lucas, Rafael (Frota), Vinícius, Milena, Adriano (D'), David, Maria Adelina, Paulo Nardi, Katia, Rafael Messias, Rodolfo, Draylson, Arineiza, Joice, Eduardo, Thiago e Harry.

Aos professores dos campi da USP-São Carlos que acompanharam e contribuíram para minha formação, desde o ingresso na graduaa̧ão até o fim deste trabalho. Em especial aos professores Thiago Pardo, Cristina Ciferri, Elisa Yumi, Ellen Francine, Denis Wolf, Fernando Osório e Paulo Sergio, que contribuŕam de formas singulares para meu crescimento pessoal e acadêmico.

A todos os funcionários do ICMC, pela excelência nos serviços prestados. Em especial, às funcionarias da secretaria da pós-graduação, sempre prestativas e atenciosas.

Obrigado a todos que, de alguma forma, contribuíram para o desenvolvimento deste trabalho.

À Universidade de São Paulo. Ao CNPq, CAPES, e INCT-SEC pelo apoio financeiro. 
Somos o que repetidamente fazemos.

A excelência, portanto, não é um feito, mas um hábito.

Aristóteles 

Atualmente, os sistemas robóticos têm sido necessários para uma diversidade de novos produtos, como em robôs de serviço e em robôs para ambientes perigosos. Como consequência, um aumento da complexidade desses sistemas é observada, exigindo também atenção considerável para a qualidade e a produtividade. Vale destacar que a complexidade de parte desses sistemas decorre, parcial ou totalmente, da necessidade de se utilizar diversos robôs para compor a solução. Em outra perspectiva, arquiteturas de referência surgiram como um tipo especial de arquitetura de software que consegue agregar conhecimento de domínios específicos, facilitando o desenvolvimento, padronização e evolução de sistemas de software. Nessa perspectiva, arquiteturas de referência foram também propostas para o domínio de robótica e de têm sido consideradas como um elemento importante para o desenvolvimento de sistemas para esse domínio. No entanto, existe uma falta de arquiteturas de referência especializadas em sistemas multirrobóticos de serviço. Assim, a principal contribuição desse trabalho é o apoio ao desenvolvimento de sistemas multirrobóticos de serviço. Para isso, o principal resultado, aqui apresentado, é o estabelecimento da SiMuS, uma arquitetura de referência que agrega o conhecimento e a experiência de como organizar sistemas multirrobóticos de serviço, visando a escalabilidade, evolução e reúso. Para o estabelecimento dessa arquitetura, foi utilizado o ProSA-RA, um processo que sistematiza o projeto, representação e avaliação de arquiteturas de referência. Resultados alcançados por uma inspeção, por meio de checklist, e estudo de caso conduzidos evidenciam que a SiMuS é uma arquitetura de referência viável e reusável para o desenvolvimento de sistemas multirrobóticos de serviço. 

Currently, robotic systems have been more and more required for a diversity of new products, such as in service robots and in robots for dangerous environments. As a consequence, an increase in the complexity of these systems is observed, requiring also considerable attention to their quality and productivity. One of the main complexities faced by systems is the problem of control multiple robots to complete a task. In another perspective, reference architectures have emerged as a special type of software architecture that achieves well-recognized understanding of specific domains, facilitating the development, standardization, and evolution of software systems. In this perspective, reference architectures have also been proposed for the robotic domain and they have been considered an important element to the development of systems for that domain. However, there is a lack of reference architectures specialized in multi-robotic systems for service robots. Thus, the main contribution of this work is to support the development of multi-robotic for service robots. For that, the main result presented here is the establishment of SiMuS, a reference architecture that combines the knowledge and experience of how to organize multi-robotic systems for service robots, aiming at scalability, evolution and reuse. For establishing this architecture, was used the ProSA-RA, a process that systematizes the design, representation and evaluation of reference architectures. Results achieved by a checklist inspection and case study conduction, show that the SiMuS is a viable and reusable reference architecture for developing multi-robotic systems service robots. 

1 Introdução 1

1.1 Contextualização . . . . . . . . . . . . . . . . . . . . . . 1

1.2 Motivação . . . . . . . . . . . . . . . . . . . . . . 3

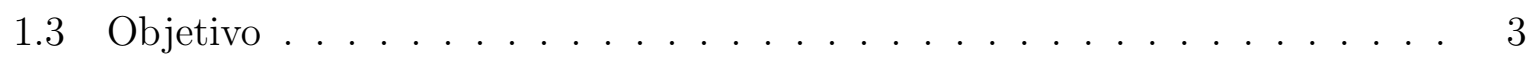

1.4 Organização . . . . . . . . . . . . . . . . . . 4

2 Sistemas Embarcados e Robótica Móvel $\mathbf{5}$

2.1 Considerações Iniciais . . . . . . . . . . . . . . . . . . . . . . . . . . . . . . . . . . .

2.2 Sistemas Embarcados . . . . . . . . . . . . . . . . . . 5

2.3 Robótica Móvel . . . . . . . . . . . . . . . . . . . . . . . . . . . . . . . . . . .

2.3.1 Arquiteturas de Controle . . . . . . . . . . . . . . . 8

2.3.2 Sistemas Multirrobóticos . . . . . . . . . . . . . . . . . . . . . . . . . . . . 10

2.3.3 Robôs de Serviço . . . . . . . . . . . . . . . . . . . . . . . 10

2.4 Frameworks para Desenvolvimento e Simulação de Sistemas Robóticos . . . 11

2.4 .1 Player, Stage e Gazebo . . . . . . . . . . . . . . . . . . . . . . . 12

$2.4 .2 \quad \mathrm{ORCA} \ldots \ldots \ldots \ldots \ldots \ldots$

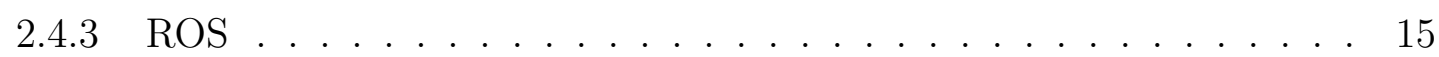

2.5 Considerações Finais . . . . . . . . . . . . . . . . . . . . 16

3 Arquitetura de Software e Arquitetura de Referência $\quad 17$

3.1 Considerações Iniciais . . . . . . . . . . . . . . . . . . . . . . . . . . . . . . . . . . . .

3.2 Arquitetura de Software . . . . . . . . . . . . . . . . . . . . . . . . . . . . . . 18

3.2.1 Representação de Arquiteturas de Software . . . . . . . . . . . . . . 19

3.3 Arquitetura de Referência . . . . . . . . . . . . . . . . . . . 21

3.3.1 Classificações de Arquiteturas de Referência . . . . . . . . . . . . . 22

3.3.2 Processo para o Estabelecimento de Arquiteturas de Referência . . 24

3.4 Arquiteturas de Referência para Sistemas Robóticos . . . . . . . . . . . . 25

3.4.1 Planejamento e Condução . . . . . . . . . . . . . . . 26

3.4.2 Relato dos Resultados . . . . . . . . . . . . . . . . 29

3.5 Considerações Finais . . . . . . . . . . . . . . . . . . . 31 
4 Estabelecimento da SiMuS 33

4.1 Considerações Iniciais . . . . . . . . . . . . . . . . . . . . . . . . . . 33

4.2 Passo RA-1: Investigação das Fontes de Informação . . . . . . . . . . . . . 34

4.2.1 Grupo 1: Padronizações Aplicáveis à Produção de Software para Robôs Móveis . . . . . . . . . . . . . . . . . . . . . . . 34

4.2.2 Grupo 2: Arquiteturas de Referência para o Domínio de Robótica Móvel e Aplicações . . . . . . . . . . . . . . . . . . . . . . . 35

4.3 Passo RA-2: Estabelecimento dos Requisitos Arquiteturais . . . . . . . . 36

4.3.1 Requisitos Arquiteturais para Robôs Móveis . . . . . . . . . . . . . 36

4.3.2 Requisitos Arquiteturais para Sistemas Multirrobóticos . . . . . . . 37

4.3.3 Requisitos Arquiteturais para Robôs de Serviço . . . . . . . . . . . 37

4.4 Passo RA-3: Projeto Arquitetural . . . . . . . . . . . . . . . . . 38

4.4.1 Objetivos, Stakeholders e Interesses . . . . . . . . . . . . . . . 38

4.4.2 Ponto de Vista Transversal . . . . . . . . . . . . . . . . . . . . . . . 40

4.4.3 Ponto de Vista de Implantação . . . . . . . . . . . . . . . . . . . . 44

4.4 .4 Ponto de Vista Estrutural . . . . . . . . . . . . . . . . . . . . . 46

4.4.5 Ponto de Vista em Tempo de Execução . . . . . . . . . . . . . . . . 53

4.5 Passo RA-4: Avaliação da Arquitetura de Referência . . . . . . . . . . . 56

4.6 Considerações Finais . . . . . . . . . . . . . . . . . . . . 57

5 Estudo de Caso: Utilização da SiMuS 59

5.1 Considerações Iniciais . . . . . . . . . . . . . . . . . . . . . . . . . . . 59

5.2 Descrição do Sistema . . . . . . . . . . . . . . . . . . . . . . 60

5.3 Instanciação da SiMuS . . . . . . . . . . . . . . . . . . . . . . 62

5.3.1 Requisitos Arquiteturais, Stakeholders e Interesses . . . . . . . . . . 62

5.3.2 Ponto de Vista Transversal . . . . . . . . . . . . . . . . . . . . . . . 64

5.3.3 Ponto de Vista de Implantação . . . . . . . . . . . . . . . . . . 67

5.3.4 Ponto de Vista Estrutural . . . . . . . . . . . . . . . . . . . . 68

5.3.5 Ponto de Vista em Tempo de Execução . . . . . . . . . . . . . . . . . . . 74

5.4 Perspectivas para a Implementação do Sistema . . . . . . . . . . . . . . 75

5.5 Discussões . . . . . . . . . . . . . . . . . . . . . . . . 76

5.6 Considerações Finais . . . . . . . . . . . . . . . . . . . . 77

6 Conclusão $\quad 79$

6.1 Caracterização da Pesquisa Realizada . . . . . . . . . . . . . . . . . . 79

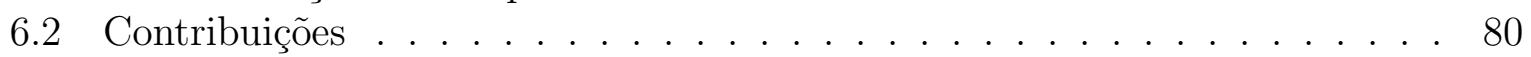

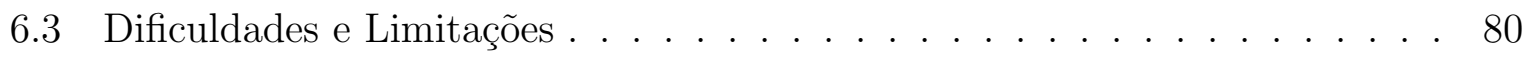

6.4 Trabalhos Futuros . . . . . . . . . . . . . . . . . . . . . . . . . . 81

$\begin{array}{lr}\text { Referências } & 89\end{array}$ 
2.1 Percepção e Ação Realizados pelo Robô no Ambiente . . . . . . . . . . . . 9

2.2 Interação entre Servidores e Clientes do Player . . . . . . . . . . . . . . . . 13

2.3 Ideia do Framework ORCA (ORCA Robotics, 2009) . . . . . . . . . . . . . 14

2.4 Relação entre Componentes do ORCA, Interface ICE, Driver do Hydro e Driver de Dispositivo Gearbox (Mirisola, 2009) . . . . . . . . . . . . . . . . 14

3.1 Relacionamento entre Modelo de Referência, Padrão Arquitetural, Arquitetura de Referência e Arquitetura Concreta (Bass et al., 2003) . . . . . . . 22

3.2 Interação de Stakeholders e Contextos entre Arquiteturas Concretas e de Referência (Angelov et al., 2008) . . . . . . . . . . . . . 23

3.3 Passos do ProSA-RA (Nakagawa et al., 2009b) . . . . . . . . . . . . 25

3.4 Passos da Revisão Sistemática (Adaptado de Kitchenham (2004)) . . . . 26

4.1 Visão Conceitual da SiMuS . . . . . . . . . . . . . . . . . . . . 42

4.2 Visão Global da SiMuS . . . . . . . . . . . . . . . . . . . . . . . . . 43

4.3 Visão de Implantação da SiMuS . . . . . . . . . . . . . . . . . . . . . . . . 45

4.4 Formas de Orquestração da SiMuS . . . . . . . . . . . . . . . . . . . . 46

4.5 Visão Estrutural (Geral) da SiMuS . . . . . . . . . . . . . . . . . . . 49

4.6 Visão Estrutural (Devices Manager) da SiMuS . . . . . . . . . . . . . . . 50

4.7 Visão Estrutural (Evolution Manager) da SiMuS . . . . . . . . . . . . . 51

4.8 Visão Estrutural (Controller) da SiMuS . . . . . . . . . . . . . . . 52

4.9 Visão de Processos da SiMuS . . . . . . . . . . . . . . . . . . . 55

5.1 Robô Pioneer-3DX Equipado com Laser Sick LMS-200 . . . . . . . . . . . 60

5.2 Exemplo de Utilização do Sistema de Vigilância . . . . . . . . . . . . . . . 61

5.3 Relação entre Conceitos do Sistema de Vigilância . . . . . . . . . . . . . . 66

5.4 Visão Global do Sistema de Vigilância . . . . . . . . . . . . . . . . . . 67

5.5 Visão de Implantação do Sistema de Vigilância . . . . . . . . . . . . . . . . 68

5.6 Visão Estrutural (Geral) do Sistema de Vigilância . . . . . . . . . . . . . . 70

5.7 Visão Estrutural (Devices Manager) do Sistema de Vigilância . . . . . . . 71

5.8 Visão Estrutural (Controller) do Sistema de Vigilância . . . . . . . . . . . 72

5.9 Visão de Funcionalidades do Sistema de Vigilância . . . . . . . . . . . . . . 73

5.10 Visão de Processos do Sistema de Vigilância . . . . . . . . . . . . . . . . . 75 



\section{Lista de Tabelas}

2.1 Tipos, Funções e Exemplos de Sensores (Adaptado de Wolf et al. (2009)) • 7

2.2 Tipos, Funções e Exemplos de Atuadores (Adaptado de Wolf et al. (2009)) 8

3.1 Arquiteturas de Referência para Robôs Móveis . . . . . . . . . . . . . . . . 27

3.2 Contexto de Desenvolvimento das Arquiteturas de Referência . . . . . . . . 30

3.3 Nível de Maturidade das Arquiteturas de Referência . . . . . . . . . . . . . 30

3.4 Funcionalidades Contidas nas Arquiteturas de Referência . . . . . . . . . . 31

4.1 Histórico de Alterações do Ponto de Vista Transversal . . . . . . . . . . . . . 44

4.2 Histórico de Alterações do Ponto de Vista de Implantação ....... 46

4.3 Histórico de Alterações do Ponto de Vista Estrutural . . . . . . . . . . . . 53

4.4 Histórico de Alterações do Ponto de Vista em Tempo de Execução . . . . . 56 



\section{Lista de Abreviaturas e Siglas}

4D/RCS 4D Real-time Control System Reference Model Architecture

ACROSET Arquitectura de Control para Robots de Servicio Teleoperados

ADL Architectural Description Language

AIS Adaptive Intelligent Systems

API Application Programming Interface

ICE Internet Communications Engine

JAUS Joint Architecture for Unmanned Systems

MLP Multi-Layer Perceptron

ORCA Open Robot Components API

QA Quality Assurance

ROS Robot Operating System

RMA Robô Móvel Autônomo

RNA Redes Neurais Artificiais

SEI Software Engineering Institute

SiMuS arquitetura de referência para Sistemas Multirrobóticos de Serviço

SMAS Situated Multiagent Systems Architecture

SysML Systems Modeling Language

TCP Transmission Control Protocol

UML Unified Modeling Language 


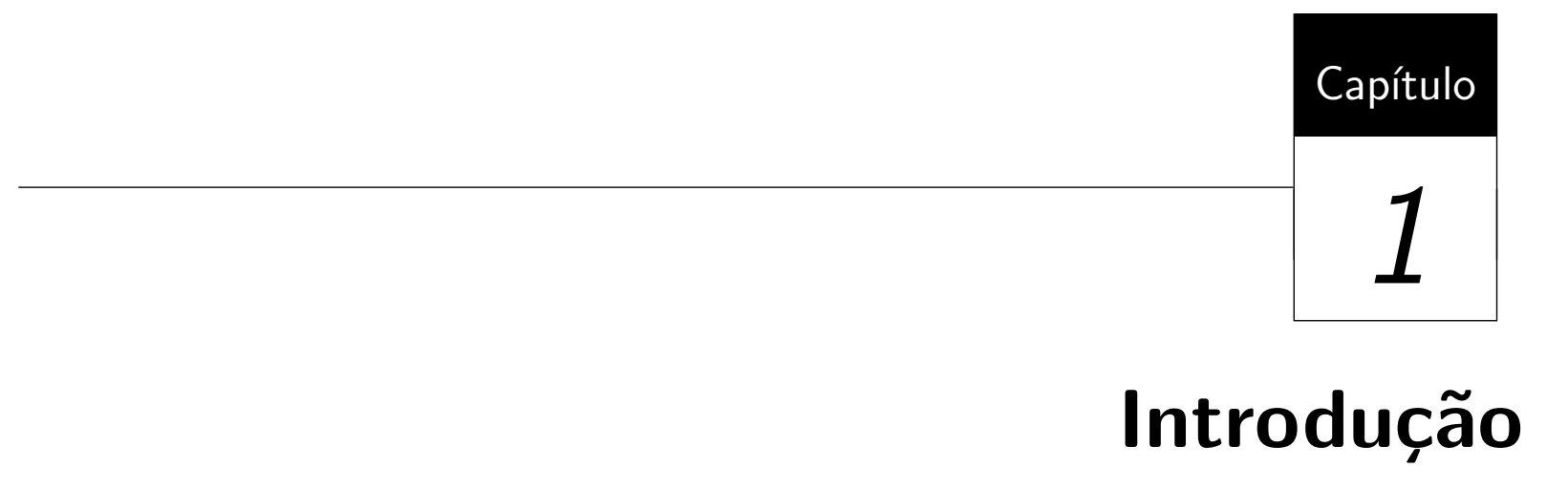

\subsection{Contextualização}

Segundo Vahid e Givargis (2002), sistemas embarcados são aqueles de propósito específico, criados para executar uma ou mais funções específicas. Tais sistemas são geralmente incorporados como parte de um dispositivo completo, incluindo hardware e peças mecânicas. Nesse tipo de sistema, software e hardware possuem características peculiares tais como, restrições rigorosas de energia e desempenho. Atualmente, observa-se que uma diversidade de dispositivos são controlados por sistemas embarcados, como por exemplo, relógios digitais, semáforos, impressoras, robôs, entre outros. Contudo, apesar de sistemas embarcados poderem ser utilizados em robôs, é importante entender que Robótica e Sistemas Embarcados são comumente consideradas duas áreas de pesquisa distintas. Existem robôs que são controlados por computadores e não por um sistema embarcado. Por exemplo, tem-se o braço robótico de uma linha de produção de carros que é controlado por um computador que centraliza todo o processamento. Observa-se, no entanto, que existe uma interseção entre essas duas áreas, na qual se encontra, também, a Robótica Móvel (Wolf et al., 2009), subárea da Robótica, que se utiliza de sistemas embarcados em robôs para prover determinada independência a esses robôs. Um importante tipo de robô móvel é o robô de serviço, pois é caracterizado por auxiliar o homem em tarefas tais como trabalhos domésticos ou de vigilância, sendo capaz de conviver com ele (Bekey e Junku, 2008). Ao se tratar de aplicações de maior escala ou mais complexas, tais como a vigilância de um 
ambiente ou a busca realizada numa vasta área, existe a necessidade de se utilizar vários robôs de serviço, dando origem a sistemas multirrobóticos de serviço. Deve-se lembrar que esses sistemas, mesmo sendo capazes de controlar vários robôs, também devem ser capazes de controlar um único robô em sua tarefa.

Em paralelo, para tarefas complexas e críticas que envolvem, por exemplo, vidas humanas, existe um tipo de sistema embarcado denominado Sistema Embarcado Crítico. Trata-se de sistemas computacionais empregados, por exemplo, em veículos autônomos e aeronaves não-tripuladas para a realização de missões de monitoramento e controle, missões essas que, muitas vezes, envolvem vidas humanas. Nesse contexto, tem-se o Instituto Nacional de Ciência e Tecnologia em Sistemas Embarcados Críticos ${ }^{1}$ (INCT-SEC), que faz parte de um programa conduzido pelo Ministério da Ciência e Tecnologia (MCT) que visa a criação de diversos INCTs. O INCT-SEC, em especial, é um projeto que tem a missão de agregar habilidades, competências e infraestrutura necessárias para o desenvolvimento de sistemas embarcados críticos, com ênfase em veículos autônomos móveis. Dessa forma, o INCT-SEC visa capacitar a academia e a indústria brasileira no ensino, treinamento, pesquisa e desenvolvimento científico-tecnológicos em aplicações de relevância e de alto impacto econômico-social em áreas estratégicas do país, a exemplo de aplicações na agricultura, segurança e defesa nacional, aviação e meio ambiente. É também de interesse do INCT-SEC a colaboração da área de Engenharia de Software para a sistematização no desenvolvimento de sistemas embarcados críticos. Dessa forma, ressalta-se que o presente trabalho de mestrado está sendo conduzido no contexto do INCT-SEC. Ressalta-se que este projeto também faz parte do projeto "ProSA-RAES: Subsídios para o Estabelecimento de Arquiteturas de Referência para Sistemas Embarcados" (Fapesp, Processo N:2011/23316-8) e do projeto "Uma Contribuição ao Estabelecimento e Avaliação de Arquiteturas de Referência para Sistemas Embarcados" (CNPq, Processo N:474720/2011-0). Esses projetos maiores visam contribuir para o estabelecimento de arquiteturas de referência de sistemas embarcados.

No contexto de Engenharia de Software, a subárea de Arquitetura de Software tem se destacado nos últimos anos uma vez que a arquitetura de software é considerada como tendo principal papel na determinação da qualidade e da manutenibilidade do software (Wasserman, 1996), na mesma linha da $\mathrm{SEI}^{2}$ (Software Engineering Institute) que afirma que os atributos de qualidade dos sistemas de software são estreitamente relacionados às suas arquiteturas. De acordo com Garlan (2000) e Software Engineering Institute (2009), a arquitetura de software é uma estrutura de componentes de um programa/sistema, os relacionamentos entre esses componentes, os princípios e diretrizes que governam os pro-

\footnotetext{
${ }^{1}$ http://www.inct-sec.org/ — FAPESP Processo N. 08/57870-9 e CNPQ Processo N. 573963/2008-8

${ }^{2}$ http://www.sei.cmu.edu
} 
jetos e a evolução dos softwares. Nesse contexto, uma arquitetura de referência pode ser vista como uma estrutura que provê uma caracterização das funcionalidades dos sistemas de software de um dado domínio de aplicação, promovendo, assim, o reúso do projeto arquitetural e o entendimento de um domínio de aplicação específico. Pode-se encontrar arquiteturas de referência de diversos domínios (Arsanjani et al., 2007; Eklund et al., 2005; Nakagawa et al., 2007; Sandkuhl e Messer, 2000) e essas tem se mostrado bastante relevantes para o desenvolvimento de sistemas desses domínios. Para facilitar e sistematizar o estabelecimento de arquiteturas de referência, processos e guidelines têm sido propostos (Bayer, 2004; Eklund et al., 2005; Muller, 2008). Por exemplo, o ProSA-RA (Nakagawa et al., 2009b) é um processo que sistematiza o projeto, representação e avaliação de arquiteturas de referência.

\subsection{Motivação}

Apesar de já haver diversas iniciativas de utilização de atividades de Engenharia de Software para o desenvolvimento de sistemas robóticos (Graaf et al., 2003), há uma carência de trabalhos que investigam o estabelecimento de arquiteturas de referência para o domínio de Robótica, em especial, para sistemas multirrobóticos de serviço. O surgimento cada vez mais frequente de aplicações tanto multirrobóticas quanto aquelas envolvendo robôs de serviço reforça a necessidade de arquiteturas de referência para tal domínio.

Além disso, observa-se também que, de um modo geral, o desenvolvimento de sistemas robóticos maiores ocorrem por meio da implementação de módulos independentes que se integram somente no final do projeto. Existe uma preocupação em testar e agregar qualidade a cada um desses módulos; porém, não existe uma forma pré-estabelecida de integração desses módulos, sendo que o desenvolvimento deles é realizado, em geral, de forma separada e individual. Dessa forma, pesquisas que envolvam arquiteturas de referência para o domínio de robótica móvel poderiam contribuir para uma melhor estruturação, modularização e, consequentemente, reúso de módulos, aumento de produtividade (com a diminuição do número de módulos a serem implementados) e capacidade de evolução dos sistemas desse domínio.

\subsection{Objetivo}

O principal objetivo deste trabalho é apoiar o desenvolvimento de sistemas robóticos móveis, especificamente para sistemas multirrobóticos de serviço, ou seja, para sistemas caracterizados por um grupo de robôs de serviço que trabalham na realização de uma tarefa, como por exemplo, robôs para monitoramento de um espaço físico. Para isso, foi estabele- 
cida e avaliada uma arquitetura de referência para esse tipo de sistema. Utilizando-se essa arquitetura, visa-se o aumento na produtividade, na manutenibilidade e na capacidade de evolução dos sistemas desenvolvidos, bem como diminuição nos esforços de desenvolvimento.

Além disso, visando observar a viabilidade da arquitetura proposta, realizou-se a condução de um estudo de caso envolvendo a utilização dessa arquitetura como base para a instanciação de arquitetura de software para um sistema composto de múltiplos robôs de vigilância (monitoramento de ambientes fechados - indoor). Isso permitiu uma avaliação das vantagens que a arquitetura de referência pode prover aos sistemas desenvolvidos com base nela. A fim de divulgar os resultados alcançados neste trabalho, pretende-se também publicar artigos em eventos da área e periódicos pertinentes.

\subsection{Organização}

Neste capítulo foi apresentado o contexto no qual esta proposta de mestrado se insere, a motivação para desenvolver o trabalho proposto, bem como os objetivos deste trabalho. O restante desta monografia está organizada da seguinte forma. No Capítulo 2 são apresentados conceitos relacionados a Sistemas Embarcados (SE) e Robótica Móvel, dando-se especial atenção a robôs de serviço e sistemas multirrobóticos. No Capítulo 3 são discutidos conceitos e terminologias relacionadas à arquitetura de software, dando ênfase à arquitetura de referência. A arquitetura de referência proposta é apresentada no Capítulo 4. Em seguida, o estudo de caso realizado é apresentado no Capítulo 5. Por fim, no Capítulo 6 são apresentados as conclusões sobre todo o trabalho desenvolvido. 


\section{Sistemas Embarcados e Robótica Móvel}

\subsection{Considerações Iniciais}

Atualmente, observa-se que uma diversidade de dispositivos são controlados por sistemas embarcados, como por exemplo, relógios digitais, semáforos, impressoras, robôs, entre outros. Por sua vez, os robôs têm recebido amplo destaque junto à mídia e à sociedade de um modo geral (Wolf et al., 2009). Em especial os robôs móveis vêm ganhando espaço, podendo-se notar o surgimento de aplicações em diversos setores como, por exemplo, doméstico (com robôs cortadores de grama, entre outros) e militar (com robôs para desarmar bombas).

Na Seção 2.2 são apresentados conceitos básicos relacionados aos sistemas embarcados. Na Seção 2.3 são discutidos conceitos e termos relacionados à robótica móvel. Os frameworks de apoio para o desenvolvimento de sistemas robóticos são apresentados na Seção 2.4. Por fim, na Seção 2.5, são discutidas as considerações finais deste capítulo.

\subsection{Sistemas Embarcados}

Muitos dos dispositivos usados comumente são controlados por sistemas embarcados, por exemplo, relógios digitais, semáforos, impressoras, robôs, aviões, entre outros. É característica desses sistemas possuírem um propósito específico, sendo criados para executar uma ou mais funções específicas. Sistemas embarcados são geralmente incorporados como 
parte de um dispositivo completo, incluindo hardware e peças mecânicas (Vahid e Givargis, 2002).

Esse tipo de sistema é composto tanto por software quanto por hardware, sendo que cada parte tem suas características peculiares. O software, geralmente, é altamente configurável, tem um menor ciclo de desenvolvimento, atualizações facilitadas em versões, é mais barato; porém, fica restrito à velocidade do processador, que pode ter que satisfazer à aplicação em tempo real ou não. Em contrapartida, o hardware tem um ciclo de desenvolvimento mais longo, mas pode ser personalizado para aplicações específicas e apresentar melhor desempenho em aplicações de alta velocidade em tempo real (Vahid e Givargis, 2002).

Há diversos tipos de sistemas embarcados que são objetos de estudo de diversos grupos de pesquisa, no Brasil e em nível internacional. Dentre eles, pode-se citar os sistemas embarcados de tempo real e sistemas embarcados críticos (Vahid e Givargis, 2002), que interagem com outras tipos de sistema como robóticos móveis e aviônicos.

\subsection{Robótica Móvel}

A área de robótica engloba diversos tipos aplicações, tais como braços mecânicos em linhas montagens, robôs domésticos e robôs militares. Contudo, nem todas as aplicações desenvolvidas dentro da robótica envolvem sistemas embarcados. Nos sistemas robóticos móveis, assim como nos sistemas embarcados, é possível identificar os projetos de software e hardware, bem como as características dessa área. Segundo Wolf et al. (2009), o hardware é responsável pela implementação física de sensores, atuadores (responsáveis pelo deslocamento e ações do robô) e do processamento dos dados (componentes básicos para autonomia parcial ou total dos robôs) por meio do uso de um processador embarcado, enquanto o software implementa o sistema de controle robótico, responsável pela análise dos sinais dos sensores, planejamento e tomada de decisões bem como o controle dos atuadores.

Os sensores são os componentes de hardware responsáveis por passar ao robô a "visão" do mundo, representando alguns sentidos como visão e audição, e permitindo que eles interpretem o ambiente. A Tabela 2.1 apresenta uma relação com tipos e exemplos de sensores, na qual a primeira coluna é a categoria de sensor, a segunda coluna é a função do sensor, e a terceira coluna os exemplos (para sensores de posição e orientação que determinam posição absoluta ou orientação do robô — pode-se citar a bússola ou inclinômetro). Já os atuadores possibilitam ao robô interagir com o meio, permitindo que eles se locomovam e executem diferentes ações, tais como pegar ou empurrar um objeto. A Tabela 2.2 apresenta uma relação com tipos e exemplos de atuadores, na qual 


\section{CAPÍTULO 2. SISTEMAS EMBARCADOS E ROBÓTICA MÓVEL}

a primeira coluna é a categoria do atuador, a segunda coluna possui os principais tipos, e a terceira coluna os exemplos (para atuadores com base móvel utilizando rodas, mais especificamente duas rodas, pode-se citar o robô Pioneer P3-DX $\left.{ }^{1}\right)$.

Tabela 2.1: Tipos, Funções e Exemplos de Sensores (Adaptado de Wolf et al. (2009))

\begin{tabular}{|c|c|c|}
\hline Sensor & Principal Função & Exemplos \\
\hline Posição e Orientação & $\begin{array}{l}\text { Determinar a posição absoluta } \\
\text { ou direção de orientação do robô }\end{array}$ & $\begin{array}{l}\text { GPS, } \\
\text { Bússola, } \\
\text { Inclinômetro, } \\
\text { Triangulação usando marcas }\end{array}$ \\
\hline Obstáculos & $\begin{array}{l}\text { Determinar a distância até um } \\
\text { objeto ou obstáculo }\end{array}$ & $\begin{array}{l}\text { Sensor Infravermelho, } \\
\text { Ultrassom (Sonar), } \\
\text { Sensor laser, } \\
\text { Sistema de Visão Estéreo }\end{array}$ \\
\hline Contato & $\begin{array}{l}\text { Determinar o contato com um objeto } \\
\text { ou posição de contato com marcação }\end{array}$ & $\begin{array}{l}\text { Sensores de Contato (Bumbers, Switches) } \\
\text { Antenas e "bigodes" (Animal whiskers) } \\
\text { Marcações (barreiras óticas e magnéticas) }\end{array}$ \\
\hline $\begin{array}{l}\text { Deslocamento } \\
\text { e Velocidade }\end{array}$ & $\begin{array}{l}\text { Medir o deslocamento do robô } \\
\text { Realizar medidas relativas da } \\
\text { posição e orientação do robô }\end{array}$ & $\begin{array}{l}\text { Inercial (Giroscópio, Acelerômetro) } \\
\text { Odômetro (Encoders: Optical, Brush) } \\
\text { Potenciômetros (angular) } \\
\text { Sensores Baseados em Visão }\end{array}$ \\
\hline Comunicação & $\begin{array}{l}\text { Enviar e receber dados e sinais } \\
\text { externos (troca de informação) }\end{array}$ & $\begin{array}{l}\text { Sistemas de Visão e Sensores Óticos } \\
\text { Sistemas de Comunicação (rádio) }\end{array}$ \\
\hline Outros tipos & \multicolumn{2}{|c|}{$\begin{array}{l}\text { Sensores magnéticos, indutivos, capacitivos, reflexivos } \\
\text { Sensores de temperatura, carga (bateria), pressão e força, entre outros. } \\
\text { Detectores: detector de movimento, de marcações e de gás/odores }\end{array}$} \\
\hline
\end{tabular}

Nesse contexto, introduzem-se um dos tipos mais importantes de robôs móveis, os RMAs (Robôs Móvel Autônomo) (Siegwart e Nourbakhsh, 2004). Eles possuem como características fundamentais as capacidades de locomoção e de operação de modo semi ou completamente autônomo. Aspectos como capacidade de percepção, robustez e inteligência, podem levar o robô a maiores níveis de autonomia (Jung et al., 2005). Um conhecido exemplo de RMA é o Automower ${ }^{2}$.

Com relação ao software do robô, esse software capacita o robô a desenvolver atividades complexas e inteligentes, como localização, mapeamento e navegação robótica, bem como atividades essenciais para o robô, como o controle da tarefa a ser executada (Wolf et al., 2009). Tais atividades serão detalhadas a seguir:

- Localização: consiste em estimar a posição de um robô no ambiente. Para que qualquer tarefa de navegação seja executada, determinar sua própria posição é uma capacidade básica. É importante que um robô consiga determinar exatamente a posição em que se encontra dentro de um ambiente para que o mesmo possa planejar

\footnotetext{
${ }^{1}$ http://www.mobilerobots.com/ResearchRobots/ResearchRobots.aspx

${ }^{2}$ http://www.automower.com/
} 


\section{CAPÍTULO 2. SISTEMAS EMBARCADOS E ROBÓTICA MÓVEL}

uma trajetória até o seu destino e cumprir as tarefas que lhe forem alocadas (Fox et al., 1999);

Tabela 2.2: Tipos, Funções e Exemplos de Atuadores (Adaptado de Wolf et al. (2009))

\begin{tabular}{|c|c|c|}
\hline Atuador & Principais Tipos & Exemplos \\
\hline Base Fixa & "Braço Robótico com base fixa & Robôs industriais PUMA $^{1}$ \\
\hline Base Móvel: Rodas & $\begin{array}{l}2 \text { rodas independentes } \\
3 \text { rodas (triciclo, omnidirecionais) } \\
4 \text { rodas (veículos robóticos - ackermann) }\end{array}$ & $\begin{array}{l}\text { Robôs Khepera }{ }^{2} \text { e Pioneer P3-DX } \\
\text { Robôs BrainStem PPRK } \\
\text { Stanley }^{4} \text { - Stanford (Darpa Challenge }\end{array}$ \\
\hline Base Móvel: Esteira & Esteira (Slip/Skid locomotion - tracks) & Tanques e veículos militares \\
\hline $\begin{array}{l}\text { Base Móvel: Juntas } \\
\text { e Articulações }\end{array}$ & $\begin{array}{l}\text { Bípedes } \\
4 \text { patas (quadrúpedes) } \\
6 \text { patas (hexápodes) } \\
\end{array}$ & $\begin{array}{l}\text { Robôs Humanóides } \\
\text { Robôs Sony Aibo }{ }^{7}, \mathrm{BigDog}^{8} \\
\text { Robôs Inseto }\end{array}$ \\
\hline $\begin{array}{l}\text { Base Móvel:Propulsão } \\
\text { Hélices ou Turbinas }\end{array}$ & $\begin{array}{l}\text { Veículos aéreos com hélices } \\
\text { Veículos aquáticos com hélices } \\
\text { Veículos subaquáticos }\end{array}$ & $\begin{array}{l}\text { Aviões, Helicópteros e Dirigíveis } \\
\text { Barcos autônomos } \\
\text { Submarinos autônomos }\end{array}$ \\
\hline Outros tipos & $\begin{array}{l}\text { Braços manipuladores com base móvel } \\
\text { Garras com ou sem feedback sensorial } \\
\text { Mecanismos de disparo }\end{array}$ & $\begin{array}{l}\text { Garras (Grippers) embarcadas } \\
\text { Mão robótica } \\
\text { Disparo do chute (futebol de robôs) }\end{array}$ \\
\hline
\end{tabular}

- Mapeamento: o ato de levantar os dados sobre o ambiente e a consequente construção de mapas (criação de uma representação do ambiente no qual está inserido o robô) é um problema de estimação que consiste em uma tarefa fundamental para o desenvolvimento de RMAs. Portanto, um mapa do ambiente é fundamental para que o caminho mais eficiente seja encontrado. Por meio do mapa, o robô verifica os possíveis caminhos que levam até à posição desejada e os obstáculos que devem ser evitados (Thrun et al., 2005); e

- Navegação: consiste em controlar o deslocamento do robô de uma posição inicial até uma posição de destino. A tarefa de navegação usualmente é implementada por meio do uso de uma arquitetura de controle, que representa a forma como o robô se comportará (Wolf et al., 2009).

\subsubsection{Arquiteturas de Controle}

Para realizar o controle do robô, sua arquitetura deve ser capaz de realizar tarefas, tais como fusão de sensores, desvio de obstáculos, auto-localização, mapeamento do ambiente,

\footnotetext{
${ }^{1}$ http://www.pumaair.com/

${ }^{2}$ http://www.k-team.com/

${ }^{3}$ http://www.mobilerobots.com/ResearchRobots/ResearchRobots.aspx

${ }^{4}$ http://www.acroname.com/robotics/info/PPRK/overview.html

${ }^{5}$ http://cs.stanford.edu/group/roadrunner//old/index.html

${ }^{6}$ http://www.darpa.mil/grandchallenge/index.asp

${ }^{7}$ http://support.sony-europe.com/aibo/

${ }^{8}$ http://www.bostondynamics.com/robot_bigdog.html
} 
planejamento de trajetórias, planejamento de ações, navegação robótica, interação e comunicação. Tais tarefas são realizadas com base na ideia básica do controle (Figura 2.1), na qual o robô percebe o ambiente e, com base nessa percepção, ele realiza uma ação sobre o ambiente. De acordo com Wolf et al. (2009), as principais arquiteturas de controle são:

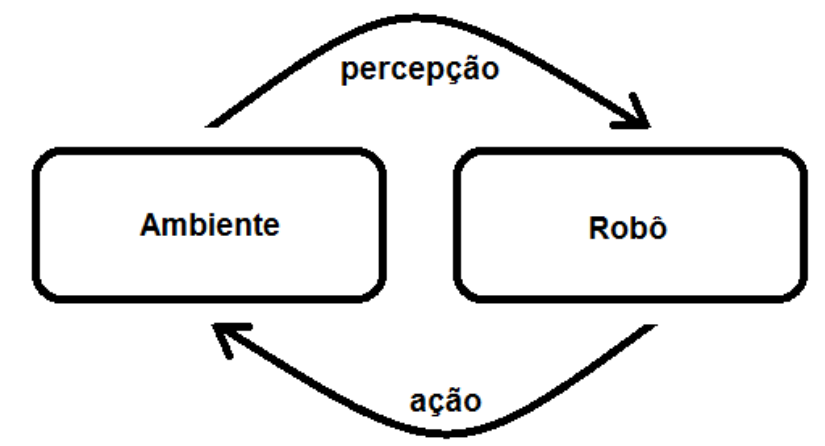

Figura 2.1: Percepção e Ação Realizados pelo Robô no Ambiente

Controle reativo: Sistema de reação sensorial-motora cujo controle normalmente é o mais simples de ser implementado. Tal simplicidade decorre da forma básica como tal arquitetura funciona. O robô faz a percepção do ambiente e reage a tal percepção, sem qualquer planejamento. Normalmente tal arquitetura é conhecida como "controle local", pois o robô conhece melhor sua posição local e atua nesse posicionamento;

Controle deliberativo: Consiste na aplicação de um mecanismo de planejamento das ações baseado nos conhecimentos que o sistema possui sobre o problema a ser resolvido e é usualmente mais complexo de ser implementado do que o controle reativo. Ao contrário do controle reativo, o deliberativo faz a percepção do ambiente, faz o planejamento e somente depois ele age sobre o ambiente. Normalmente tal arquitetura é conhecida como "controle global", pois o robô conhece melhor sua posição no ambiente e apresenta desempenho superior em tarefas que exijam tal conhecimento;

Controle hierárquico: Consiste da combinação de múltiplas camadas de controle, sendo que cada camada é reativa e/ou deliberativa (control layers) dispostas de modo que esses possam operar de modo hierárquico; e

Controle híbrido: É similar ao controle hierárquico; porém, combina os comportamentos obtidos de suas diferentes camadas (reativos e deliberativos), que podem inclusive ser executados em paralelo, a fim de obter um comportamento mais robusto e uma execução de tarefas mais complexas. 


\subsubsection{Sistemas Multirrobóticos}

A definição de sistemas multirrobóticos deriva da definição de sistemas multi-agentes, uma vez que o robô pode ser visto como um tipo de agente inteligente (Pfeifer et al., 2005). Um agente robótico possui quatro características principais (Pfeifer et al., 2005):

Autonomia: Operar com o mínimo possível de intervenção, supervisão e instrução humana;

Auto-suficiência: Operar por tempo prolongado, ou, pelo menos, suficiente para realizar a tarefa e buscar recarga de energia;

Localização: Adquirir informação sobre o ambiente de forma autônoma, por meio de sensores; e

Corpo: Ser desenvolvido como um sistema físico ou computacional, ou seja, ser um robô interagindo em um ambiente real ou um robô simulando interagindo com um ambiente virtual.

Sistemas multi-agentes são constituídos de múltiplos agentes que interagem ou trabalham em conjunto para realizar uma tarefa ou objetivo. Cada agente é visto como um solucionador de problemas, essencialmente autônomos, compondo uma rede de agentes que é capaz de solucionar problemas não que vão da capacidade individual (Agmon et al., 2008; Chevaleyre et al., 2004; Silveira, 2006). Nos trabalhos de Stone e Veloso (2000), Mondada et al. (2005) e Osagie (2006) sistemas multi-agentes são classificados de acordo com duas possíveis formas de controle:

Sistema centralizado: um único agente detém todo o poder de tomada de decisão para controle e definição de objetivos dos outros agentes do sistema, sendo comum a sobrecarga do agente principal. Apesar de ser mais suscetíveis a falhas localizadas, possui a vantagem de poder produzir planos de ação globais ótimos; e

Sistema distribuído: cada agente é responsável pela coordenação das próprias ações, culminando em que as busca de soluções decorre da soma das soluções obtidas por cada agente, podendo interação eles. É tipicamente utilizado em situações em que os agentes possuem independência total ou parcial, exigindo menos cooperação, uma vez que ela é custosa.

\subsubsection{Robôs de Serviço}

Dentre os robôs móveis, um tipo especial são os robôs de serviço. De acordo com Bekey e Junku (2008), um robô de serviço é um robô que opera de forma semiautônoma ou 
totalmente autônoma a fim de prestar serviços úteis aos seres humanos e aos outros equipamentos, excluindo robôs que atuam em processos de fabricação. Acrescentando-se a isso, Kwon et al. (2007) ainda afirma que tais robôs devem ser capazes de coexistir e de interagir com o ser humano e seu ambiente. Pode-se citar como exemplos de robôs de serviço: robôs para vigilância, robôs entregadores e robôs transportadores.

Estendendo-se o conceito apresentado por Bekey e Junku (2008) para multirrobôs, pode-se definir um sistema multirrobótico de serviço como um conjunto de robôs de serviço que têm como objetivo a realização de uma tarefa em comum. De acordo Zhang et al. (2007), os robôs de serviço podem ser classificados em dois grupos, de acordo com suas funções. Um grupo consiste em comunicar com humanos, a fim de obter ordens dos humanos através da interface homem-robô. Um outro grupo é constituído por robôs que irão realizar a tarefa de acordo com os comandos humanos. Esses robôs possuem várias funções específicas, tais como caminhar, segurando alguma coisa, movendo-se ao longo de uma trajetória.

\subsection{Frameworks para Desenvolvimento e Simulação de Sistemas Robóticos}

Diferentemente dos sistemas de software comuns, tais como aplicações web ou de banco de dados, o desenvolvimento de sistemas robóticos não leva em conta a codificação apenas da lógica da aplicação, mas também de fatores externos relevantes, como a leitura e interpretação de sensores ou passagem de comandos para os atuadores. Isso dificulta o desenvolvimento desse tipo de sistema, uma vez que, por exemplo, os sensores e atuadores utilizados pelo robô podem ser alterados durante o projeto, levando a necessidade de re-implementação de partes do software relacionados aos sensores e atuadores.

Dessa forma, uma maneira para se driblar esse problema é a utilização de frameworks que facilitem o tratamento desses fatores externos. Cada framework possui suas particularidades quanto à forma de tratamento do problema (interface, componentização, entre outros), funcionalidades e/ou meio mais adequado de aplicação. Além disso, há a necessidade de se realizar testes no sistema durante o desenvolvimento. O tempo e dificuldade em se realizar um teste em um robô real pode elevar excessivamente o custo e tempo de produção de um sistema. Para isso, existem simuladores tais como o Stage $^{1}$ e o Gazebo ${ }^{1}$, nos quais se pode realizar os testes primários antes da realização do teste de campo com 
um robô real. A seguir serão detalhados três frameworks bem aceitos pela comunidade científica: Player ${ }^{1}, \mathrm{ORCA}^{2}$ e $\mathrm{ROS}^{3}$.

\subsubsection{Player, Stage e Gazebo}

O Projeto Player é composto pelo servidor de dispositivos, chamado Player, e pelos simuladores Stage e Gazebo. O servidor de dispositivos combina um protocolo de mensagem com um modelo de dispositivo específico para dar acesso ao hardware do robô de forma transparente através da rede (Player, 2006). A comunicação pode acontecer internamente em uma única aplicação ou através da rede, que é o caso de uso mais comum do Player. Os dados são transmitidos através de conexões TCP (Transmission Control Protocol) entre vários servidores e clientes do Player. O modelo de dispositivo é baseado na filosofia Unix, na qual tudo é um arquivo. Isso significa que aparelhos como laseres ou câmeras são tratados de modo semelhante a um arquivo. Eles podem ser abertos para leitura e escrita, e os dados são lidos e escritos em forma de dados e streams de comando.

Existe um mecanismo de pedido/resposta que pode ser usado para configurar um dispositivo. Semelhante à programação de uma API (Application Programming Interface), as interfaces de programação especificam como os dados são trocados com um dispositivo. Além de dispositivos reais, o Player pode lidar com dispositivos abstratos. Esses são componentes de software que realizam cálculos arbitrários (provavelmente alimentados com dados adquiridos a partir dos sensores) e necessitam de informações sempre atualizadas, cumprindo tarefas tais como extrair a posição da bola a partir de uma imagem da câmera, e/ou a condução de atuadores. Um exemplo seria um driver de navegação simples, que poderia planejar um caminho e, em seguida, enviar comandos para a condução o atuador real.

Em um cenário típico do Player, executa-se uma instância no robô - o servidor. Incorporados como uma série de threads estão os drivers de hardware do robô, tais como os atuadores e sensores. Para resolver uma tarefa específica, uma outra parte do software atua como um cliente do Player. Ele lê as informações dos sensores através da rede, decide o que fazer e dá ordens aos atuadores apropriados, mais uma vez através da rede. Se vários robôs estão no mapa, informações podem ser trocadas entre eles por meio do Player. Por fim, o projeto Player também leva o desenvolvimento dos simuladores Stage e Gazebo. Enquanto Stage simula uma população de dispositivos do Player em um mundo 2D, Gazebo oferece uma completa simulação 3D com uma engine de física. A Figura 2.2

\footnotetext{
${ }^{1}$ http://playerstage.sourceforge.net/

${ }^{2}$ http://orca-robotics.sourceforge.net/

${ }^{3}$ http://www.ros.org//
} 
apresenta a interação entre servidores e clientes do Player, bem como a interação entre Palyer e Stage/Gazebo (a), e entre Player e Hardware (b).

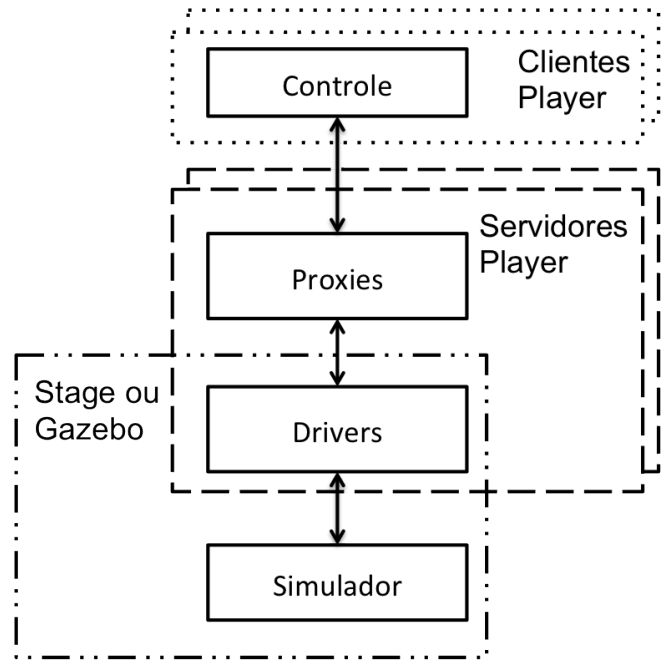

(a) Player + Stage ou Gazebo

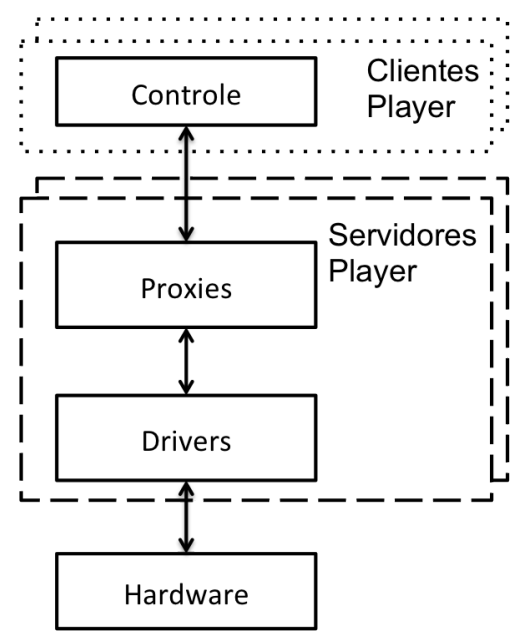

(b) Player + Robô real

Figura 2.2: Interação entre Servidores e Clientes do Player

\subsubsection{ORCA}

O ORCA (Open Robot Components API) é um framework voltado ao desenvolvimento de sistemas robóticos baseados em componentes (conforme pode-se observar na Figura 2.3). De um modo geral, ele provê meios para definir e desenvolver sistemas por meio de blocos (building-blocks) que podem ser unidos de forma a construir sistemas robóticos mais complexos, desde sistemas para veículos a redes de sensores distribuídos (Brooks et al., 2007). De acordo com os criadores do framework ORCA, a chave para o progresso contínuo das pesquisas e indústria da robótica está no reúso. Dessa forma, o objetivos do projeto são (ORCA Robotics, 2009):

- habilitar o reúso de software por meio da definição de interfaces comumente utilizadas;

- simplificar o reúso de software provendo bibliotecas com uma API de alto nível; e

- encorajar o reúso de software por meio da manutenção do repositório de componentes. 


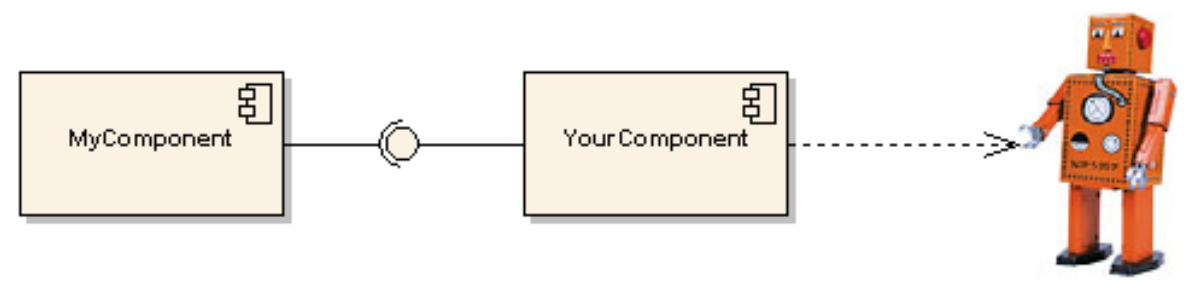

Figura 2.3: Ideia do Framework ORCA (ORCA Robotics, 2009)

Atualmente, todos os componentes disponíveis no repositório estão escritos em $\mathrm{C}++$; contudo, existem exemplos de componentes em Java, Python e PHP. Dessa forma, é importante ressaltar que as interfaces Slice (interface de definição dos arquivos - permite o uso de outras linguagens para construção dos componentes) podem ser compiladas para $\mathrm{C}++$, Java, Python, PHP, C\#, Visual Basic, Ruby e Objective C, permitindo o uso de qualquer uma dessas linguagens para construir os componentes.

O framework é um conjunto de quatro tecnologias (Mirisola, 2009): componentes ORCA; a Interface ICE (Internet Communications Engine); o Driver do Hydro; e o Driver de Dispositivo do GearBox. Em geral, o componente ORCA usa o Driver do Hydro, que usa as bibliotecas do GearBox (Figura 2.4). Porém, antes de explicar a relação entre eles, é importante ressaltar que tudo que é necessário para utilizar os componentes do ORCA é escrever ou ler tipos do Slice por meio da interface ICE.

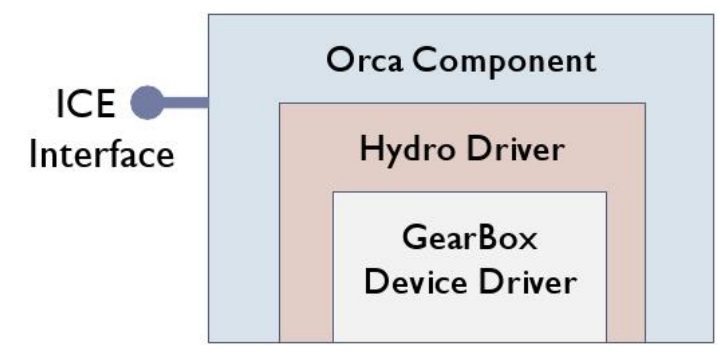

Figura 2.4: Relação entre Componentes do ORCA, Interface ICE, Driver do Hydro e Driver de Dispositivo Gearbox (Mirisola, 2009)

Um Driver de Dispositivo Gearbox não deve conter código específico para os frameworks Hydro ou ORCA. É apenas um driver de dispositivo básico que pode ser usado independentemente do Hydro e ORCA. Já um driver do Hydro usa um driver do Gearbox para acessar o dispositivo físico. Esse driver Hydro fornece uma interface padrão com tipos e semântica definidos para o componente ORCA, englobando toda a comunicação com os dispositivos reais. Alguns drivers da Hydro não acessam dispositivos físicos, mas sim implementam algoritmos.

O componente ORCA usa o driver do Hydro para acessar um dispositivo ou executar um algoritmo, além de fornecer uma interface ICE baseada em um tipo Slice, permitindo que outros componentes possam acessar seus dados. Os componentes ORCA também 
não necessariamente utilizam drivers do Hydro, uma vez que alguns componentes podem apenas obter dados de outros componentes através de suas interfaces ICE e colocar a saída em outras interfaces ICE. Usando esse tipo de driver, permite-se que a implementação seja alterada sem alterar a interface visível para os outros componentes (utilizar diferentes lasers sem alterar a forma de comunicação ou utilizar protocolos diversos para comunicação em uma aplicação multirrobôs). Dessa forma, se há vários drivers do Hydro disponíveis para o mesmo componente ORCA, o usuário pode escolher qual utilizar com uma opção de configuração, não exigindo recompilação.

\subsubsection{ROS}

O ROS (Robot Operating System) é um meta-sistema operacional e, por isso, ele possui características esperadas de um sistema operacional comum, tais como abstração de hardware, controle de dispositivos à baixo nível, implementação de funcionalidades básicas, passagem de mensagem entre processos e gerência de pacotes. Ele também disponibiliza ferramentas e bibliotecas para obter, criar, compilar e executar códigos em um ou mais computadores. Vale ressaltar ainda que o ROS é distribuído sob uma licença de software livre e possui código aberto.

Em alguns aspectos, o ROS é similar à alguns frameworks robóticos, como o Player e ORCA. Ele se utiliza de uma rede ponto-a-ponto para prover comunicação entre os processos, sendo esses fracamente acoplados. Por meio do ROS, essa comunicação pode ocorrer de diferentes formas, tais como RPC síncrono, transmissão assíncrona, repositório central de informações e passagem de mensagens. Do ponto de vista de sistema de arquivos, o ROS conta com quatro estruturas principais: Packages - Entidade de mais baixo nível na organização do software ROS, podendo conter bibliotecas, ferramentas e executáveis, dentre outros; Manifest - É a descrição de um package, tendo como principal função definir dependências entre pacotes; Stack - Coleção de packages, formando uma biblioteca de mais alto nível; e Stack Manifest - Igual ao manifest de um package, contudo, para descrever uma stack.

Por fim, a comunidade ROS organiza recursos desenvolvidos de acordo com dois conceitos principais: Distributions - Coleções de stacks em determinada versão, tornando mais fácil a instalação de um dado conjunto de softwares e manutenção de consistência através de versões; e Repositories - Rede compartilhada de repositórios de códigos fonte, nos quais instituições podem desenvolver e distribuir os próprios componentes. 


\subsection{Considerações Finais}

Com o crescimento da área de Robótica, têm surgido aplicações para robôs com diversas finalidades, tais como para agricultura ou armamento militar. Com isso, a evolução dos sistemas robóticos tem permitido construir sistemas cada vez mais complexos e que agregam diversas funcionalidades. Dessa forma, é muito importante agregar qualidade ao software que controla esses sistemas robóticos, ainda mais quando forem construídos sistemas muito complexos como, por exemplo, sistemas multirrobóticos, ou quando forem construídos para robôs de serviço que, por definição, irão interagir com o homem. Apesar de existirem ferramentas e frameworks que auxiliam nessa tarefa, ainda se faz necessário a utilização de outros meios como arquiteturas de software e arquiteturas de referência. O próximo capítulo apresenta de uma maneira mais detalhada os conceitos relacionados à arquitetura de software e à arquitetura de referência, bem como arquiteturas de referência que têm sido propostas para o domínio de robótica. 


\section{Arquitetura de Software e Arquitetura de Referência}

\subsection{Considerações Iniciais}

Seguindo as tendências e necessidades do mercado e da academia, os sistemas de software têm tomado proporções cada vez maiores e apresentado crescente complexidade. Seguindo essa demanda, são necessárias maneiras mais sistemáticas e eficientes para estruturar e desenvolver tais sistemas. De acordo com Bass et al. (2003) e Land (2002), convenções de nome, gerência de configuração, metodologias e processos de desenvolvimento e arquiteturas de software desempenham importante papel nesse sentido. Além disso, pode-se destacar que as arquiteturas de software são consideradas parte fundamental do projeto de sistemas (Clements et al., 2002; Land, 2002). Dentre os fatores determinantes da qualidade de um software, sua arquitetura é um dos principais, uma vez que elas proveem um conjunto de boas práticas de desenvolvimento, por meio do uso de modelos, arquiteturas de referência, padrões de projeto e padrões arquiteturais.

Nesse contexto, um tipo especial de arquitetura de software tem ganhado destaque a arquitetura de referência - podendo prover direções mais precisas para a especificação de arquiteturas de sistema de software. De acordo com Bass et al. (2003), arquiteturas de referência consistem de um conjunto de abstrações de informações de um domínio, estru- 
turadas de forma a auxiliar no desenvolvimento e evolução de um conjunto de sistemas de um dado domínio.

Na Seção 3.2 são discutidos conceitos, terminologias e representações relacionados à arquitetura de software. Na Seção 3.3, arquiteturas de referência são discutidas, bem como é apresentado um processo para o estabelecimento de arquiteturas de referência. As principais arquiteturas de referência na domínio de robótica são discutidos na Seção 3.4. Por fim, na Seção 3.5 são apresentadas as considerações finais deste capítulo.

\subsection{Arquitetura de Software}

De acordo com Wasserman (1996), Arquitetura de Software é considerada como o principal conceito na determinação de aspectos de qualidade e manutenibilidade do software. Além disso, o SEI ${ }^{1}$ considera que requisitos de qualidade de sistemas de software estão fortemente relacionados às suas arquiteturas. Dessa forma, pode-se inferir que arquiteturas de software são um fator determinante na qualidade dos sistemas construídos com base nelas. Devido à tal relevância, Nakagawa et al. (2009b) ainda afirma que arquiteturas de software podem influenciar diretamente no sistema a ser concebido, de modo a habilitar, facilitar, dificultar ou interferir no alcance das metas referentes aos requisitos funcionais e não-funcionais.

Segundo Bass et al. (2003) e Clements et al. (2011), arquiteturas de software são compostas por elementos de software, as propriedades externamente visíveis desses elementos e o relacionamento entre as partes que a compõe . Em geral, uma arquitetura é a abstração de um sistema e descreve o relacionamento entre os componentes do mesmo, descartando detalhes não relacionados à maneira pelo qual componentes usam, são utilizados, estão relacionados ou interagem com os demais (Bass et al., 2003).

Além da definição apresentada acima, diversos conceitos e terminologias vêm sendo definidos na área de Arquitetura de Software a fim de estabelecer um vocabulário comum entre os pesquisadores. Dentre tais conceitos, fazem-se importantes no contexto deste trabalho: instância arquitetural, estilo arquitetural (ou padrão arquitetural), arquitetura concreta, modelo de referência e arquitetura de referência. Os três primeiros serão apresentados a seguir, enquanto os dois últimos serão apresentados e discutidos na Seção 3.3.

A arquitetura concreta é um sinônimo para arquitetura de software e, complementando a definição já apresentada, ela ainda incorpora um conjunto de padrões e especificações, que guiam o desenvolvimento de cada parte pertencente ao sistema de software que será produzido (Software Engineering Institute, 2010). Quando for se referenciar à arquitetura

\footnotetext{
${ }^{1}$ http://www.sei.cmu.edu/
} 
concreta num contexto de aplicação ou problema específico (podendo ela ser proveniente de uma arquitetura de referência), utiliza-se o termo instância arquitetural (Nakagawa, 2006).

Já estilo arquitetural (ou padrão arquitetural) é um conceito mais abrangente, pois define um conjunto de restrições quanto à forma e à estrutura de uma família de arquiteturas concretas (Bass et al., 2003). Ele permite determinar características que serão comuns a todos os sistemas de software produzidos utilizando um mesmo estilo arquitetural (Bass et al., 2003; Mendes, 2002). Pode-se citar como exemplo de estilo arquitetural o Cliente-Servidor, o qual descreve que a comunicação entre esses dois elementos (cliente e servidor) deve ser feita por meio de um protocolo. Porém, não existe a preocupação de se identificar como cada um dos clientes deve ser construído ou como os protocolos de comunicação devem ser implementados (Bass et al., 2003). É possível ainda encontrar estilos arquiteturais provenientes de combinações de estilos pré-existentes.

Ainda se tratando de estilos arquiteturais, uma de suas características mais importantes é que esses possuem atributos de qualidade conhecidos, permitindo que seja mensurado e avaliado o uso de um estilo em detrimento a outros (Bass et al., 2003). Alguns estilos apresentam soluções a problemas de desempenho, outros podem ser utilizados em sistemas no qual a segurança é um importante atributo de qualidade, sendo que a decisão sobre qual estilo utilizar é frequentemente considerada como a maior decisão tomada durante a fase inicial de um projeto (Bass et al., 2003).

\subsubsection{Representação de Arquiteturas de Software}

Em virtude da importância da arquitetura de software no desenvolvimento de sistemas, esforços destinados à sua adequada representação podem ser encontrados. Embora o projeto da arquitetura seja fundamental para o sucesso do desenvolvimento, não existe um consenso acerca da maneira mais adequada para a sua representação. Na grande maioria dos casos, arquiteturas de software são representadas de maneira informal, como modelos contendo componentes e conectores, por exemplo box-and-lines. Componentes consistem de representações das grandes funcionalidades do sistema e dos dados nele armazenados. Os conectores, por sua vez, representam a comunicação entre os componentes, definindo as interações entre eles. Embora essa forma de representação arquitetural seja útil para prover uma visão geral do sistema a ser desenvolvido, é importante salientar que, se utilizada isoladamente, problemas relacionados à ambiguidade quanto ao seu entendimento podem acorrer (Land, 2002).

Face à necessidade de se prover representações formais para arquiteturas de software e que propusessem uma sintaxe e uma estrutura conceitual que permitissem caracterizar uma arquitetura de forma não ambígua, linguagens de descrição arquitetural (ADL) têm 
sido propostas (Medvidovic e Taylor, 2000). Essas linguagens fornecem abstrações adequadas à modelagem de grandes sistemas, garantindo detalhes suficientes para o estabelecimento das propriedades desejadas. Nesse contexto, cada ADL envolve uma abordagem particular de especificação e evolução de uma arquitetura, lidando com questões de avaliação específicas, relacionadas à modelagem, abordando aspectos do sistema de forma aprofundada. Contudo, em virtude da especificidade inerente às ADLs, a integração de modelos projetados por meio dessas linguagens a outros artefatos de desenvolvimento pode ser dificultada (Medvidovic et al., 2002).

Além do uso de linguagens de descrição arquitetural, a utilização de diferentes visões na representação de arquiteturas de software vem sendo largamente investigada (ANSI/IEEE, 2000; Buschmann et al., 1996; ISO/IEC, 2007; Kruchten, 1995; Medvidovic et al., 2002). Segundo Buschmann et al. (1996), cada visão arquitetural representa um aspecto em particular da arquitetura, que reflete em propriedades específicas do sistema de software. Em outras palavras, por meio de visões arquiteturais, é possível visualizar diferentes propriedades de um sistema, de acordo com o ponto de vista no qual a arquitetura é observada (Land, 2002). Apesar de não existir um consenso entre os pesquisadores sobre quais as visões arquiteturais e métodos de representação são mais adequados ao projeto de arquiteturas de software (ANSI/IEEE, 2000), as visões estrutural e comportamental têm sido as mais consideradas (ANSI/IEEE, 2000; Kruchten, 1995; Medvidovic et al., 2002). Merson (2005) propõe um conjunto mais amplo de visões para a representação de arquiteturas de software, que inclui: visão de módulos (module view), visão em tempo de execução (runtime view), visão de implantação (deployment view), visão de dados (data view) e visão de implementação (implementation view).

Recentemente, a UML ${ }^{1}$ (Unified Modeling Language) tem emergido como uma importante linguagem para representação de arquiteturas de software, sendo amplamente adotada tanto na acadêmica quanto na indústria (Medvidovic et al., 2002). A UML possui um grande conjunto de construções pré-definidas e é apoiada por um número considerável de ferramentas de modelagem. Também é considerada uma linguagem semi-formal e possui uma representação mais próxima da atividade de implementação, sendo facilmente compreendida pelos desenvolvedores do sistema. Além disso, têm surgido diversos perfis da UML especializado-a para determinados tipos de modelagem. Dentre ela, é importante destacar a SysML ${ }^{2}$ (Systems Modeling Language), que é um perfil para modelagem de requisitos, comportamentos, estruturas e parâmetros de sistema que são utilizados para integrar com outros modelos de análise da engenharia. Dessa forma, a SysML é uma linguagem semi-formal para a especificação, análise, projeto e verificação de sistemas

\footnotetext{
${ }^{1}$ http://www.uml.org/

${ }^{2}$ http://www.sysml.org/
} 
complexos que podem envolver hardware, software, informação, pessoas, procedimentos e instalações. Para isso, a SysML disponibiliza vários tipos de diagramas (compreendidos como tipos de modelo segundo o padrão ISO/IEC/IEEE 42010) para apoiar todo o ciclo de vida do software, sendo eles: Diagrama de Atividades, Diagrama de Sequência, Diagrama de Máquina de Estados, Diagrama de Casos de Uso, Diagrama de Definição de Blocos, Diagrama de Blocos Internos, Diagrama de Pacotes, Diagrama Paramétrico e Diagrama de Requisitos. A disponibilização de construtores de primeira ordem para interessados, interesses, visões e perspectivas também faz com que a SysML permita a criação de novas perspectivas em conformidade com o padrão ISO/IEC/IEEE 42010 (ISO/IEC, 2007).

\subsection{Arquitetura de Referência}

Segundo Angelov et al. (2008), arquitetura de referência vem ganhando importância como área de pesquisa em Arquitetura de Software, guiando-a para a especificação de arquiteturas concretas pertencentes a um dado domínio de aplicação. Como consequência, pode-se inferir que arquiteturas de referência influenciam diretamente na qualidade e no projeto de uma família de arquiteturas concretas e sistemas derivados dessa arquitetura de referência (Angelov et al., 2009).

Conforme dito na seção anterior, a fim de estabelecer um vocabulário comum entre pesquisadores, será apresentado o conceito de arquitetura de referência mais comumente utilizado pela comunidade. Para isso, será preciso entender antes o conceito de modelo de referência para, em seguida, apresentar o conceito de arquitetura de referência.

Segundo Bass et al. (2003), modelo de referência é a representação das funcionalidade divididas juntamente ao fluxo de dados pelo qual elas se relacionam. Esses modelos englobam o conhecimento de um domínio em partes que se comunicam para solucionar um dado problema. Por exemplo, o modelo de referência OASIS (2006) define a essência da arquitetura orientada a serviços, independente de conceitos tecnológicos. Além disso, modelo de referência pode ser também definida como sendo um conjunto minimal de conceitos unificados, axiomas e relacionamentos de um domínio particular, ilustrados de maneira independente de padrões específicos, tecnologias e demais conceitos concretos (OASIS, 2006).

Arquiteturas de referência são definidas como mapeamentos de modelos de referência em elementos de software que implementam funcionalidades que podem estar definidas em modelos de referência (Angelov et al., 2009; Bass et al., 2003). Segundo Bass et al. (2003), uma arquitetura de referência consiste de um repositório de conhecimento de domínio que promove o reúso arquitetural e apoia o desenvolvimento de sistemas. Embora os conceitos de modelo de referência e estilo arquitetural possuam similaridade com o 
conceito de arquitetura de referência, eles possuem definições distintas (Angelov et al., 2009; Bass et al., 2003). Enquanto arquiteturas de referência consistem de estruturas que provêem caracterizações de funcionalidades de sistemas de softwares em um dado domínio de aplicação, os estilos arquiteturais são soluções conhecidas que podem ser aplicadas de forma independente de domínio e os modelos de referência são divisões de funcionalidade para um domínio, sem aplicação específica (que gera a caracterização). Na Figura 3.1 é ilustrado o relacionamento entre modelos de referência e estilos arquiteturais, que podem ser utilizados no estabelecimento de arquiteturas de referência.

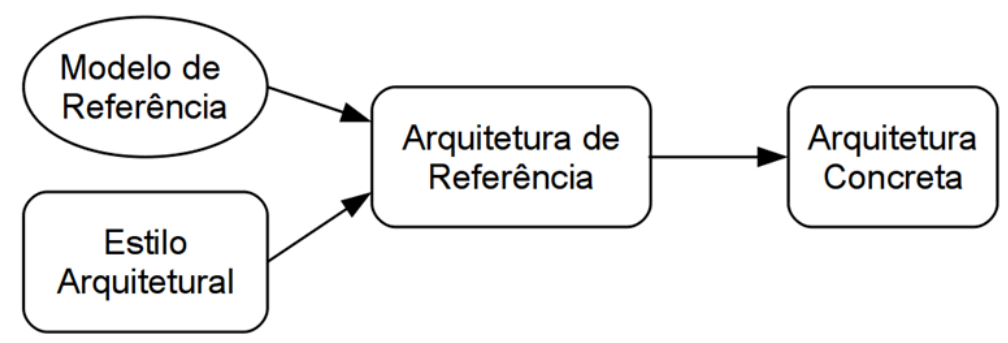

Figura 3.1: Relacionamento entre Modelo de Referência, Padrão Arquitetural, Arquitetura de Referência e Arquitetura Concreta (Bass et al., 2003)

De acordo com Muller (2008), arquiteturas de referência podem ser utilizadas como guia para projeto de arquiteturas concretas ou como ferramenta de padronização, provendo interoperabilidade entre sistemas ou componentes de sistemas. Dessa forma, uma arquitetura de referência pode ser utilizada em diversos contextos, resultando no desenvolvimento de instâncias arquiteturais distintas, dependentes dos stakeholders e metas pertencentes a cada instituição, conforme ilustrado na Figura 3.2. Diversas arquiteturas de referência para os mais diferentes domínios de aplicação podem ser encontradas. Os trabalhos de Arsanjani et al. (2007); AUTOSAR (2011); Bunzel (2011); Eickelmann e Richardson (1996); Nakagawa et al. (2011); UniversAAL Project (2012); Wolf et al. (2010) apresentam exemplos de arquiteturas de referência propostas.

\subsubsection{Classificações de Arquiteturas de Referência}

Como existem várias áreas de aplicação e existem diferentes interesses envolvidos em sua utilização, arquiteturas de referência podem ser classificadas quanto a diversos aspectos. Dessa forma, Angelov et al. (2009) propõem seis tipos, baseados na classificação do contexto, propósito e insumo da arquitetura de referência. A classificação quanto ao contexto refere-se ao número de organizações participantes, no caso: uma ou múltiplas; podendo visar a construção de um família de produtos ou padronização entre empresas. O propósito da arquitetura de referência está vinculado à: padronização ou facilitação. O insumo 


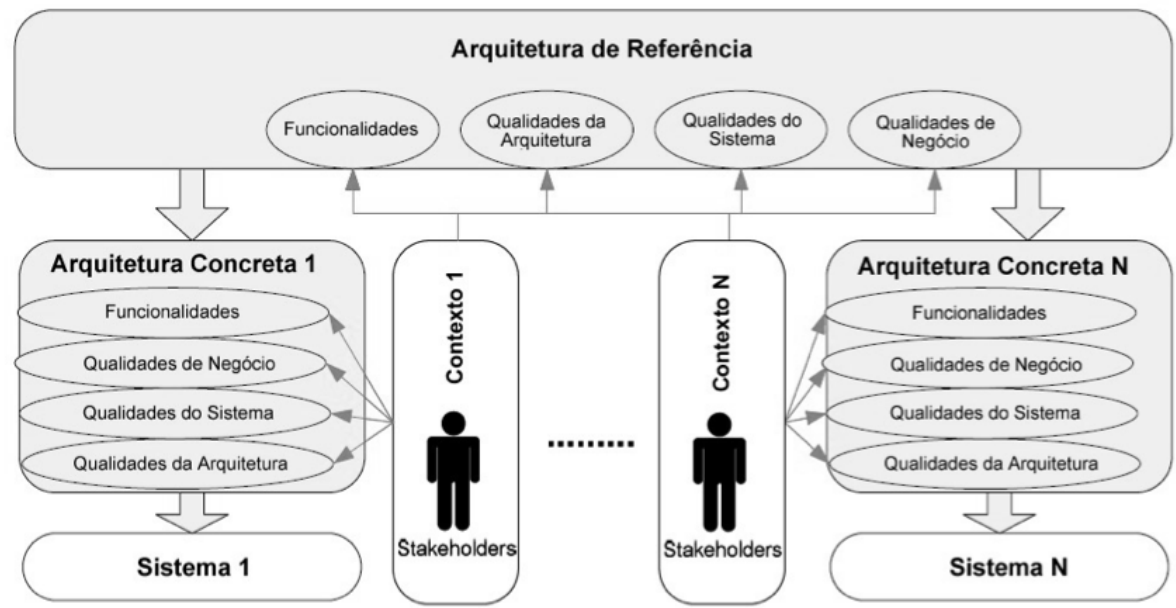

Figura 3.2: Interação de Stakeholders e Contextos entre Arquiteturas Concretas e de Referência (Angelov et al., 2008)

pode-se basear em: experiências anteriores ou decisões pouco antes da criação, caso do preliminar. Assim, os tipos de arquiteturas de referência são:

Tipo 1: Classificação para um contexto de múltiplas organizações, com o propósito de padronizar arquitetura de referência, num insumo clássico. Utilizadas na obtenção de consenso arquitetural entre organizações. Nesse tipo de arquitetura, o detalhamento dos componentes é desnecessário, pois cada organização pode escolher quais detalhes concretos são pertinentes;

Tipo 2: Para um contexto de uma única organização, com intuito de padronização de arquitetura de referência, adotando insumo clássico. Têm por objetivo auxiliar na construção de uma família de sistemas. Possuem características mais concretas, podendo especificar detalhes, tais como tecnologias, aplicações existentes e padrões;

Tipo3: Múltiplas organizações participantes, com o propósito de facilitar arquiteturas de referência futuras, num insumo baseado em experiências anteriores (clássico). Utilizadas para fins de construção de produtos de software tendo descrição mais concreta, provendo direções ao desenvolvimento.

Tipo 4: Uma única organização, facilitando a criação de arquiteturas de referência futuras, num insumo baseado em experiências anteriores (clássico). Similar ao Tipo 2; porém, projetadas para facilitar o desenvolvimento, sendo descritas de maneira mais informal;

Tipo 5: Classificação para um contexto de múltiplas organizações, com o propósito de facilitar a criação de arquiteturas de referência futuristas, num insumo preliminar. Definem componentes requeridos à sua implementação, podendo indicar algoritmos e protocolos que facilitem a interação entre esses componentes; e 
Tipo 6: Uma única organização, facilitando a criação de arquiteturas de referência futuristas, num insumo preliminar. Criação restrita às organizações líderes de mercado, pois requer considerável esforço.

É possível notar que não existem os tipos referentes à utilização de insumos preliminares com o intuito de padronização. Isso decorre do fato de que não existe uma motivação forte em criar uma arquitetura de referência para padronização, uma vez que a necessidade não foi demonstrada, fato comumente observado pela existência prévia de trabalhos naquele contexto (o que levaria ao uso de insumos clássicos).

Como cada tipo de arquitetura de referência possui suas particularidades, diferentes tipos de instituições costumam concentrar esforços na construção dessas arquiteturas. Em especial, arquiteturas preliminares desenvolvidas por centros de pesquisa, com o objetivo de facilitar o desenvolvimento de sistemas ainda não existentes, são consideradas um tipo particular de arquitetura, pois concentram-se em elementos de inovação da arquitetura, sendo consideradas contribuições para projetos futuros (Angelov et al., 2009).

\subsubsection{Processo para o Estabelecimento de Arquiteturas de Referên- cia}

Segundo Nakagawa et al. (2009b), a sistematização do processo para o estabelecimento de arquiteturas de referência constitui uma atividade de grande importância. Por isso, o ProSA-RA foi proposto por Nakagawa et al. (2009b), tendo objetivo de sistematizar um conjunto de passos para a construção de arquiteturas de referência orientadas a aspecto. O ProSA-RA sistematiza o desenvolvimento, projeto e avaliação das arquiteturas de referência, sendo resultado de experiência na criação de arquiteturas de referência orientadas a aspecto para o domínio de engenharia de software (Nakagawa, 2006; Nakagawa et al., 2007; Nakagawa e Maldonado, 2008).

Em suma, como pode-se observar na Figura 3.3, para estabelecer arquiteturas de referência usando o ProSA-RA, fontes de informação são primeiramente selecionadas e investigadas (Passo RA-1 da Figura 3.3) e os requisitos arquiteturais ${ }^{1}$ são identificados (Passo RA-2). Depois disso, uma descrição da arquitetura referência é criada (Passo RA-3) e a avaliação dessa arquitetura é realizada (Passo RA-4). Vale ainda destacar que quando há a possibilidade de identificar ontologias para o domínio para o qual a arquitetura está sendo criada, pode-se aplicar o conhecimento contido nas ontologias nos quatro passos do ProSA-RA, como discutido em mais detalhes em (Nakagawa et al., 2009a).

\footnotetext{
${ }^{1} \mathrm{Um}$ requisito arquitetural refere-se ao requerimento de uma arquitetura de referência de um determinado domínio e descreve funcionalidades e configurações em comum apresentados em sistemas desse domínio.
} 


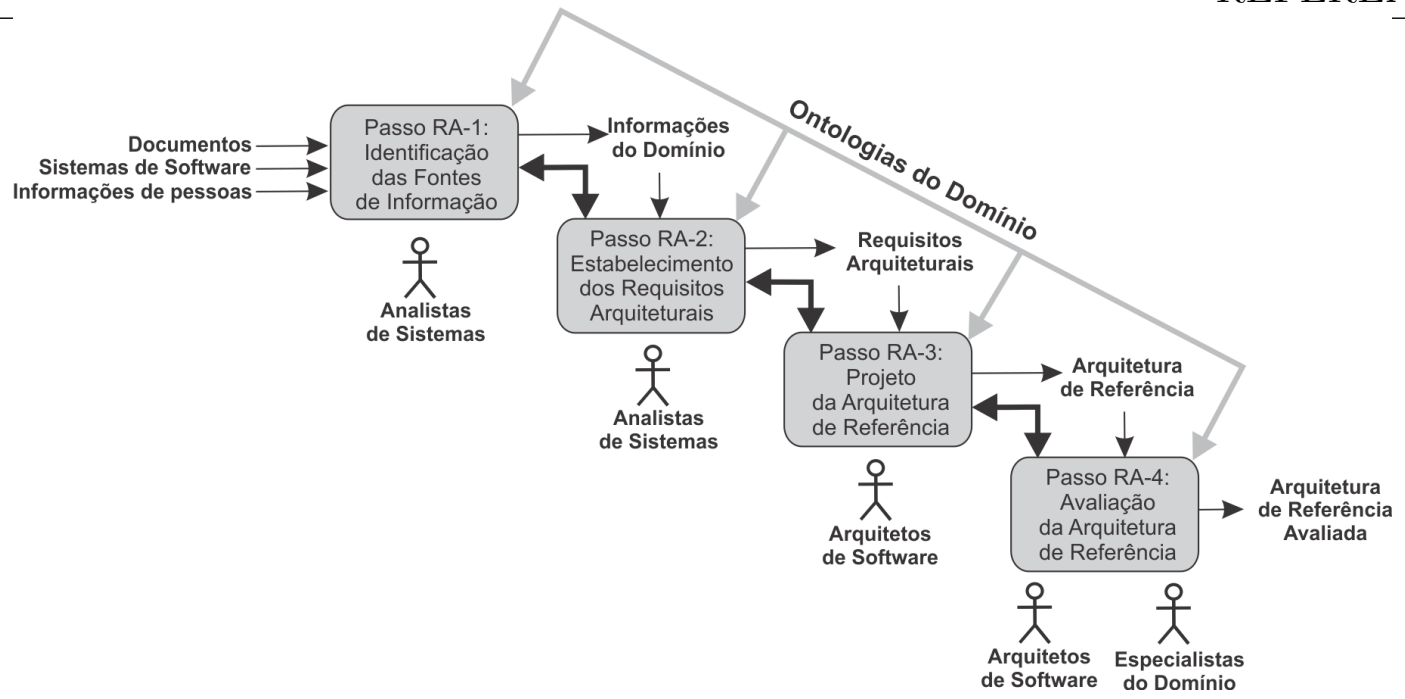

Figura 3.3: Passos do ProSA-RA (Nakagawa et al., 2009b)

\subsection{Arquiteturas de Referência para Sistemas Robóticos}

Com a carência de padronização e de direções ao desenvolvimento de sistemas robóticos, arquiteturas de referência vêm sendo propostos como soluções arquiteturais em diversas subáreas da Robótica (Álvarez et al., 2001; Peters et al., 2000; Weyns e Holvoet, 2006). Desse modo, uma revisão sistemática foi conduzida pelo autor com o objetivo da investigar de maneira formal trabalhos relacionados às arquiteturas de referência para o domínio de Robótica. Por meio dessa revisão sistemática ${ }^{1}$ foram identificados os domínios de aplicação nos quais as arquiteturas de referência têm sido utilizadas, bem como as características que vêm sendo consideradas nesse nível de abstração.

Revisões sistemáticas têm como objetivo apresentar uma avaliação justa a respeito de um tópico de pesquisa, fazendo uso de uma metodologia de revisão que seja confiável, rigorosa e que permita auditagem (Kitchenham, 2004). A revisão sistemática é uma abordagem sistêmica de revisão da literatura, assim, para a condução desse tipo de pesquisa, é utilizado um conjunto de passos bem definidos e planejados de acordo com um protocolo previamente estabelecido (Biolchini et al., 2007). O processo utilizado pelo ??, foi proposto por Kitchenham (2004) e é ilustrado pela Figura 3.4, sendo composto das seguintes fases: (i) Fase 1 - Planejamento: Nesta fase, os objetivos da pesquisa e do protocolo de revisão são definidos. O protocolo constitui um plano pré-determinado, que descreve as questões de pesquisa e como a revisão sistemática será realizado; (ii) Fase 2 - Condução: Durante esta fase, os estudos primários são identificados, selecionados e avaliados de acordo com critérios de inclusão e exclusão estabelecidos anteriormente. Para cada estudo

\footnotetext{
${ }^{1}$ No ano de 2012 foram considerados trabalhos anteriores ao mês de setembro.
} 
selecionado, os dados são extraídos e sintetizadas, e (iii) Fase 3 - Relato: Nesta fase, um relatório final será formatado e apresentado.

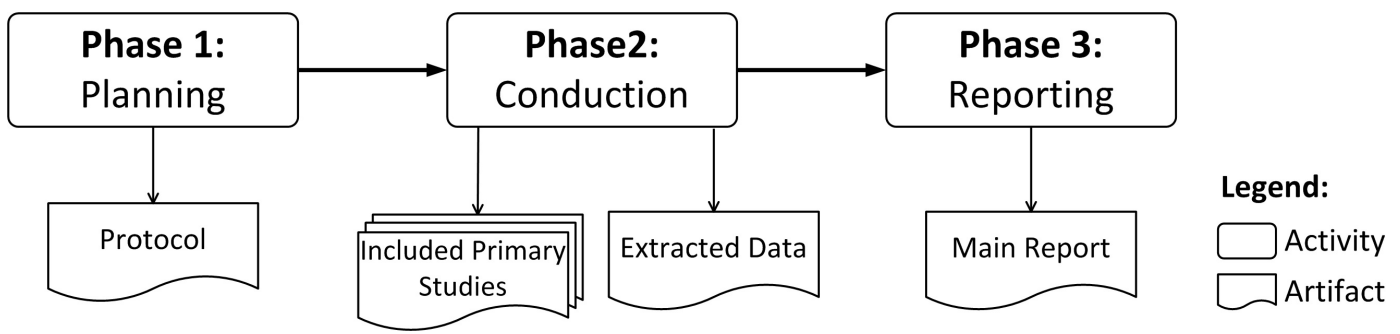

Figura 3.4: Passos da Revisão Sistemática (Adaptado de Kitchenham (2004))

\subsubsection{Planejamento e Condução}

Resumindo a condução da revisão sistemática, foi estabelecida a questão de pesquisa: "Which existing reference architectures could be applied to develop robotic systems to mobile robots?". A partir da questão, foram estabelecidas as palavras-chave — "reference architecture", "robot", e "unmanned ground vehicle" — que originaram a string de busca (utilizado também possíveis sinônimos para essas palavras): ("reference architecture" OR "reference model") AND ("robot" OR "robotic" OR "unmanned ground vehicle" OR "UGV" OR "intelligent vehicle"). Foi adicionado "reference model" à string de busca, uma vez que percebeu-se que era também utilizado no sentido de arquitetura de referência. Também foi incluído "intelligent vehicle" como sinônimo para "mobile robots". Finalmente, para buscar os trabalhos (também chamados, no contexto de revisão sistemática, de estudos primários), foram utilizadas as seguintes bases de dados de publicações: ACM Digital Library ${ }^{1}$, IEEEXplore ${ }^{2}$, ISI Web of Knowledge ${ }^{3}$, e Scopus 4. Como resultado da busca nessas bases usando a string apresentada, um total de 409 estudos primários foram descobertos. Removendo os estudos repetidos, obtiveram-se 371 estudos únicos. O título e resumo de cada estudo foram lidos e um total de 14 estudos foram selecionados para leitura posterior. Em seguida, esses estudos foram lidos na totalidade e, finalmente, sete arquiteturas de referência, que são aplicáveis a robôs móveis, foram identificadas (Tabela 3.1). Para a seleção dessas arquiteturas, considerou-se que elas deveriam possuir três requisitos principais: (i) a arquitetura apresenta um conjunto de funcionalidades pré-definidas que podem estar contidos em sistemas robóticos, (ii) a arquitetura explica a interação entre essas funcionalidades, e (iii) a arquitetura permite a derivação de arquiteturas de software e os seus respectivos sistemas.

\footnotetext{
${ }^{1}$ http://portal.acm.org

${ }^{2}$ http://ieeexplore.ieee.org

${ }^{3}$ http://apps.isiknowledge.com

${ }^{4}$ http://www.scopus.com
} 
CAPÍTULO 3. ARQUITETURA DE SOFTWARE E ARQUITETURA DE

Tabela 3.1: Arquiteturas de Referència para Robòs Móveis

\begin{tabular}{ll}
\hline Nome & Tipo \\
\hline \hline 4D/RCS (Albus, 2002) & Veículos terrestres não tripulados \\
\hline JAUS (Clark, 2005) & Sistemas não tripulados \\
\hline ACROSET (Ortiz et al., 2005) & Robôs de serviço teleoperados \\
\hline Servicebots (Peters et al., 2000) & Robôs de serviço indoor \\
\hline SMAS (Weyns e Holvoet, 2006) & Sistemas multi-agentes situados \\
\hline Robot Teleoperation (Álvarez et al., 2001) & Robôs com vários controladores \\
\hline AIS (Hayes-Roth et al., 1995) & Sistemas inteligentes adaptativos \\
\hline
\end{tabular}

A arquitetura de referência 4D/RCS (4D Real-time Control System) fornece uma base teórica para a concepção, engenharia, integração e testes de sistemas de software para sistemas inteligentes de veículos não tripulados (Albus, 2002). É constituída por uma hierarquia multi-camadas e multi-resolutional de nodos computacionais, cada um contendo os elementos de processamento sensorial (SP), de modelagem de mundo (WM), julgamento de valor (VJ) e geração de comportamento (BG). A partir dos níveis superiores para os níveis inferiores, a arquitetura de referência contém funcionalidades que permitem a definição de objetivo, indo para a cognição, percepção e raciocínio, envolvendo sensores e atuadores. Segundo o autor, esta arquitetura permite respostas precisas e rápidas em níveis mais baixos ao mesmo tempo que formula planos e abstrai conceitos em níveis superiores.

A arquitetura de referência JAUS (Joint Architecture for Unmanned Systems) (JAUS, 2012) usa um protocolo de envio de mensagens para fornecer interoperabilidade entre subsistemas e componentes que compõem os sistemas resultantes desta arquitetura (Clark, 2005). JAUS se utiliza da SOA para permitir comandos distribuídos e controle destes sistemas. A arquitetura de referência fornece informações sobre como permitir a interoperabilidade online de sistemas não tripulados e seus componentes. Para isso, JAUS define um conjunto de serviços básicos que são necessários para a maioria dos componentes de nível superior, e eles são definidos no JAUS Core Service Set (JSS Core).

A ACROSET (Arquitectura de Control para Robots de Servicio Teleoperados) é uma arquitetura de referência orientada a componentes para robôs de serviço teleoperados (Ortiz et al., 2005). Sua principal característica é a reutilização de componentes de diferentes sistemas. A arquitetura de referência é composta pelos subsistemas: Coordination, Control and Abstraction Subsystem (CCAS); Intelligence Subsystem (IS); User Interaction Subsystem (UIS); e Safety, Management and Configuration Subsystem (SMCS). O CCAS abstrai e encapsula a funcionalidade dos dispositivos físicos dos robôs. Este subsistema é composto por componentes virtuais que podem ser implementados em software ou hardware. Além disso, a fim de lidar com sistemas semi-autônomas, o IS foi inserido nesta arquitetura. Esse subsistema permite ter diferentes tipos de usuário (e até mesmo um sub- 
sistema autônomo). A UIS é responsável por interpretar, combinar e arbitrar entre ordens que podem vir de diferentes usuários simultaneamente. Finalmente, a SMCS apresenta duas funcionalidades principais: (i) monitorar as funcionalidades de outros subsistemas; e (ii) gestão e configuração da inicialização da aplicação.

A arquitetura de referência Servicebots foi projetada para robôs de serviços que operam em ambientes indoor (Peters et al., 2000). Nesse contexto, robôs de serviço são aqueles que realizam tarefas como a entrega de cartas e guiar turistas, em edifícios de características variadas (Peters et al., 2000). A arquitetura de referência é composto por três subsistemas que utilizam o backbone de TI (Tecnologia da Informação) para se comunicar e completar a tarefa, sendo os subsistemas: servicebots, fixbots, e softbots. Servicebots é um tipo de robô capaz de guiar-se de forma autônoma, apenas com informações sensoriais em um ambiente de média complexidade (por exemplo, corredores). Fixbots apresentam sensores e atuadores distribuídos por todo o ambiente, tendo sua própria inteligência e canal de comunicação. Softbots referem-se aos agentes de software que executam várias tarefas para o usuário solicitante, fixbot ou servicebot. Assim, a arquitetura de referência é preocupada com a gerência de desempenho, configuração, problema, humano-interface e segurança.

A arquitetura de referência SMAS (Situated Multiagent Systems Architecture) fornece um modelo para o projeto de arquitetura de aplicações multi-agentes (Weyns e Holvoet, 2006). É composto por dois subsistemas: agent e application environment. O primeiro é composto por três módulos: (i) percepção através de obtenção de informações a partir do ambiente; (ii) tomada de decisão, a seleção da ação do agente; e (iii) comunicação, responsável por interações com outros agentes. O segundo subsistema compreende sete módulos: (i) gerador de representação, percebendo o ambiente; (ii) interação, lidando com influências dos agentes no ambiente; (iii) serviços de comunicação, fazendo coleta de mensagens e entregando-as para os agentes apropriados; (iv) observação, analisando o contexto de implantação; (v) sincronização, controlando partes específicos de domínio do contexto de implantação, e mantendo atualizada a representação correspondente no estado do ambiente de aplicação; (vi) dinâmica, controlando processos, no ambiente de aplicação, que são independentes de agentes ou o contexto de implantação; e (vii) tradução de influências e mensagens para as primitivas de interação de baixo nível com o contexto de implantação, e tradução de mensagens formatadas de baixo nível em mensagens para os agentes.

A arquitetura de referência Robot Teleoperation foca em robôs com diferentes controladores (Álvarez et al., 2001). Para alcançar tal objetivo, ela foi proposta de acordo com a definição de Bass et al. (2003). Assim, a análise do domínio foi feita para identificar um conjunto de componentes, seguida pelo projeto de domínio a fim de criar um projeto 
genérico, em que padrões e modelos comuns podem ser utilizados. Os principais componentes identificados foram: graphical representation, collisions detection, user interface, communications e, o mais importante, controller. Para especificar como os diferentes componentes vão interagir, dois estilos arquiteturais foram selecionados: (i) cliente-servidor, utilizado nas interações entre graphical representation (cliente) e collisions detection (cliente) com controller (servidor); e (ii) processos de comunicação, utilizado nas interações entre user interface e communications com controller, porque todos eles podem tomar a iniciativa de enviar dados.

Por fim, a arquitetura de referência AIS (Adaptive Intelligent Systems) é uma mistura heterogênea de estilos arquiteturais comuns (Hayes-Roth et al., 1995), permitindo a criação de vários sistemas adaptativos inteligentes. É dividido hierarquicamente em camadas de diferentes conjuntos de tarefas computacionais. Propriedades estilo arquitetural pipe and filter são fornecidos pelas camadas e as relações entre elas. Assim, a arquitetura de referência tem duas camadas (ou níveis): o nível físico, responsável pela ação e percepção em ambiente, e o nível cognitivo, responsável por atividades mais abstratas (por exemplo, planejamento e resolução de problemas). Os componentes que compõem cada camada são organizados com base no estilo blackboard, permitindo uma série de comportamentos potencialmente complexas, uma vez que as funcionalidades básicas oferecidas em cada nível podem trabalhar em conjunto para realizar funcionalidades mais complexas.

\subsubsection{Relato dos Resultados}

Em relação à análise das arquiteturas de referência, também utilizou-se orientações propostas pela revisão sistemática. Para isso, foram definidos três perspectivas utilizadas na compararação entre as arquiteturas de referência: contexto de aplicação, maturidade e funcionalidades. Para a primeira perspectiva, analisou-se cada arquitetura de referência a fim de determinar se foram desenvolvidas em "contexto acadêmico" ou "contexto industrial". O resultado dessa análise é apresentados na Tabela 3.2. Observou-se que tanto a indústria quanto academia estão interessados em propor arquiteturas de referência. Considerando outros domínios nos quais o sucesso de uma arquitetura de referência depende da participação da indústria, podemos observar que as arquiteturas de referência para robôs móveis apresentam uma boa perspectiva de sucesso, já que mais de metade das arquiteturas apresentam esforços da indústria.

Com o objetivo de determinar o nível de maturidade das arquiteturas (ou seja, o quanto elas foram avaliados), estabeleceram-se três níveis: (i) Instanciação de arquitetura: a arquitetura de referência só foi instanciado, ou seja, a concepção de sistemas robóticos foi desenvolvido, mas nenhuma implementação é apresentado; (ii) Implementação: pelo menos um sistema robótico foi implementado com base na arquitetura de referência, através, 
CAPÍTULO 3. ARQUITETURA DE SOFTWARE E ARQUITETURA DE REFERENNCIA

Tabela 3.2: Contexto de Desenvolvimento das Arquiteturas de Referencia

\begin{tabular}{ll}
\hline Arquitetura de Referência & Contexto de Desenvolvimento \\
\hline \hline 4D/RCS & Industrial \\
\hline JAUS & Industrial \\
\hline ACROSET & Industrial \\
\hline Servicebots & Acadêmico \\
\hline SMAS & Acadêmico \\
\hline Robot Teleoperation & Industrial \\
\hline AIS & Acadêmico \\
\hline
\end{tabular}

por exemplo, de um estudo de caso; e (iii) Utilização em situação real: a arquitetura de referência foi de fato utilizada em situações reais, em particular, na indústria. A Tabela 3.3 apresenta o resultado da investigação, na qual observou-se que as arquiteturas de referência para robôs móveis são, em geral maduras, já que três arquiteturas apresentaram implementação de sistemas robóticos baseado na arquitetura; além de que, a maior parte delas (ou seja, quatro arquiteturas) já foram utilizadas na indústria .

Tabela 3.3: Nível de Maturidade das Arquiteturas de Referência

\begin{tabular}{ll}
\hline Arquitetura de Referência & Nível de Maturidade \\
\hline \hline 4D/RCS & Uso em situação real \\
\hline JAUS & Uso em situação real \\
\hline ACROSET & Uso em situação real \\
\hline Servicebots & Implementação \\
\hline SMAS & Implementação \\
\hline Robot Teleoperation & Uso em situação real \\
\hline AIS & Implementação \\
\hline
\end{tabular}

A análise da última perspectiva é a mais complexa de ser realizada, uma vez que é necessário determinar um conjunto de funcionalidades que englobe todas as arquiteturas de referência e, frequentemente, foram encontradas funcionalidades internas a outras já apresentadas. Assim, foram definidos 11 funcionalidades (com base em especialistas do domínio e nos próprios estudos) e indicou-se, para cada arquitetura de referência, quais funcionalidades estavam presentes. O resultado dessa investigação é apresentado na Tabela 3.4, na qual um "X" indica uma funcionalidade completamente presente, um "X*" refere-se a uma funcionalidade parcialmente presente, e um espaço em branco indica funcionalidade não presente. Em geral, a ACROSET parece ser a arquitetura mais completa. Além disso, esse conjunto de funcionalidades pode também apoiar a proposta de novas arquiteturas de referência, uma vez que pode ser considerada como um conjunto inicial de funcionalidades a serem consideradas.

É importante ressaltar que esses resultados não indicam se uma arquitetura de referência é melhor do que outra. Além disso, existe também funcionalidades ou aspectos das 
arquiteturas de referência que não foram abordados, pois não diziam respeito ao domínio da robótica móvel.

Tabela 3.4: Funcionalidades Contidas nas Arquiteturas de Referência

\begin{tabular}{|c|c|c|c|c|c|c|c|}
\hline \multirow{2}{*}{ Funcionalidade } & \multicolumn{7}{|c|}{ Arquitetura de Referência } \\
\hline & $4 \mathrm{D} / \mathrm{RCS}$ & JAUS & ACROSET & Servicebots & SMAS & $\begin{array}{l}\text { Robot Te- } \\
\text { leoperation }\end{array}$ & AIS \\
\hline $\begin{array}{l}\begin{array}{l}\text { Processamento } \\
\text { sensorial }\end{array} \\
\end{array}$ & $\mathrm{X}$ & $\mathrm{X}$ & $\mathrm{X}$ & $\mathrm{X}$ & $\mathrm{X}^{*}$ & $\mathrm{X}^{*}$ & $\mathrm{X}$ \\
\hline Controle & $\mathrm{X}$ & $\mathrm{X}$ & $\mathrm{X}$ & $\mathrm{X}$ & $\mathrm{X}$ & $\mathrm{X}$ & $\mathrm{X}$ \\
\hline $\begin{array}{l}\text { Detecção de coli- } \\
\text { são }\end{array}$ & $\mathrm{X}$ & $\mathrm{X}^{*}$ & $\mathrm{X}^{*}$ & $\mathrm{X}^{*}$ & & $\mathrm{X}$ & $\mathrm{X}^{*}$ \\
\hline Mapeamento & $\mathrm{X}^{*}$ & & & $\mathrm{X}^{*}$ & & & $\mathrm{X}$ \\
\hline Localização & $\mathrm{X}^{*}$ & $\mathrm{X}^{*}$ & & $\mathrm{X}$ & $\mathrm{X}$ & $\mathrm{X}^{*}$ & $\mathrm{X}$ \\
\hline Planejamento & $\mathrm{X}$ & $\mathrm{X}^{*}$ & $\mathrm{X}^{*}$ & $\mathrm{X}^{*}$ & $\mathrm{X}$ & & $\mathrm{X}$ \\
\hline $\begin{array}{ll}\text { Interface } & \text { com } \\
\text { usuário } & \\
\end{array}$ & & $\mathrm{X}$ & $\mathrm{X}$ & $\mathrm{X}$ & $\mathrm{X}^{*}$ & $\mathrm{X}$ & \\
\hline Comunicação & $\mathrm{X}$ & $\mathrm{X}$ & & $\mathrm{X}$ & $\mathrm{X}$ & $\mathrm{X}$ & $\mathrm{X}^{*}$ \\
\hline Segurança & & $\mathrm{X}$ & $\mathrm{X}$ & $\mathrm{X}$ & & & \\
\hline $\begin{array}{l}\text { Julgamento de } \\
\text { decisões }\end{array}$ & & & $\mathrm{X}$ & & & $\mathrm{X}^{*}$ & $\mathrm{X}^{*}$ \\
\hline $\begin{array}{ll}\text { Interação } & \text { entre } \\
\text { robôs } & \end{array}$ & $\mathrm{X}^{*}$ & $\mathrm{X}^{*}$ & & $\mathrm{X}$ & X & & $\mathrm{X}^{*}$ \\
\hline
\end{tabular}

\subsection{Considerações Finais}

Neste capítulo foram apresentados conceitos relacionados á área de Arquitetura de Software que são importantes no contexto deste trabalho. Dentre tais conceitos foram discutidos, em particular, classificações e exemplos de arquiteturas de referência e orientação a aspectos. Além disso, foram apresentados trabalhos relacionados á arquitetura de referência para o domínio de robótica, bem como uma comparação entre eles.

Nessa perspectiva, a investigação apresentada pode apoiar o estabelecimento de novas arquiteturas de referência contribuindo com qualidade das mesmas no desenvolvimento de sistemas de robóticos móveis. Em geral, o domínio de robótica apresenta boas perspectivas sobre arquiteturas de referência, principalmente porque é notória a participação da indústria no estabelecimento de tais arquiteturas. No que diz respeito a sua documentação, essas arquiteturas são bem documentados, no entanto, algumas delas, por exemplo a ACROSET e a Robot Teleoperation, poderiam apresentar uma representação co mais detalhes, que se destine a uma adequada disseminação de suas arquiteturas. Nessa perspectiva, essas arquiteturas teriam mais chances para oferecer uma contribuição efetiva para a área de robótica. Além disso, percebe-se que algumas arquiteturas, em particular 
CAPÍTULO 3. ARQUITETURA DE SOFTWARE E ARQUITETURA DE REFERÊNCIA a Servicebots, poderia ter seus componentes e funcionalidades apresentados de maneira mais detalhada. 


\subsection{Considerações Iniciais}

Neste capítulo é apresentada a arquitetura de referência para sistemas multirobóticos

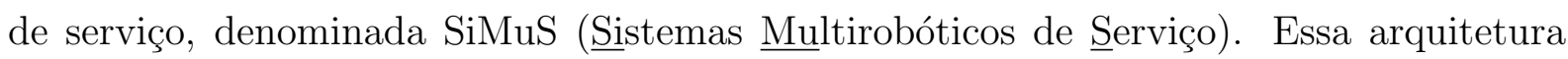
tem por objetivo apoiar a fase de projeto arquitetural no desenvolvimento de sistemas computacionais para robôs de serviços que necessitem realizar tarefas de forma conjunta.

Para o estabelecimento da SiMuS, foi utilizado o ProSA-RA, um processo que provê um conjunto de quatro passos que guiam o desenvolvimento de arquiteturas de referência, desde a investigação das fontes de informação do domínio, utilizadas na definição dos requisitos arquiteturais, até a fase de avaliação arquitetural. A fim de melhor descrever a arquitetura sendo proposta, as visões serão apresentadas de acordo com quatro categorias de pontos de vista, sendo essas: transversal; estrutural; em tempo de execução; e implantação. Além disso, também serão destacados os principais objetivos, stakeholders e interesses considerados durante o desenvolvimento da SiMuS.

Este capítulo está organizado de acordo com os passos definidos pelo ProSA-RA. Na Seção 4.2 são descritas as fontes de informações utilizadas na identificação dos requisitos arquiteturais da SiMuS. O conjunto de requisitos arquiteturais identificados por meio da análise das fontes de informação é apresentado na Seção 4.3. Na Seção 4.4 o projeto da SiMuS, descrito pela representação geral e as três visões arquiteturais, é apresentado. Na 
Seção 4.5 são discutidas informações referentes à avaliação da arquitetura proposta. Por fim, na Seção 4.6 são apresentadas as considerações finais deste capítulo.

\subsection{Passo RA-1: Investigação das Fontes de Informação}

Durante o primeiro passo do ProSA-RA, denominado "Investigação das Fontes de Informação", foram identificadas diferentes fontes para obtenção de informações sobre o domínio sistemas multirrobóticos e também sobre o domínio de robôs de serviço. Para essa atividade, foram considerados os seguintes grupos de fontes de informação: (i) padronizações aplicáveis à produção de software para robôs móveis; e (ii) arquiteturas de referência para o domínio de robótica móvel, disponíveis na literatura, e aplicações provenientes delas. A seguir, são discutidos os detalhes a respeito das fontes de informação utilizadas no estabelecimento da arquitetura de referência proposta.

\subsubsection{Grupo 1: Padronizações Aplicáveis à Produção de Software para Robôs Móveis}

Com o objetivo de nortear o desenvolvimento de sistemas multirrobóticos de serviço, buscou-se por padronizações internacionais que fossem aplicáveis a esse tipo de software. A ANSI/UL 1740 (ANSI/UL, 2007) é uma padronização para robôs e equipamentos robóticos, criada para fornecer padrões de segurança que sejam aplicáveis em sistemas indoor e outdoor. Contudo, essa padronização possui foco em robôs industriais (como braços robóticos utilizados em linhas de produção) e em especificar os requisitos para o hardware. Ainda assim, a ANSI/UL 1740 é relevante, pois vários dentre os requisitos apresentados impactam na arquitetura e na forma de implementação do software que será desenvolvido. Os principais tópicos presentes e que influenciam diretamente o software são: Gerência interna (voltagem, temperatura, baterias); Controle do robô (atuadores e sensores); Proteção dos usuários e pessoas ao redor; Funcionamento sob condições anormais; e Avaliação do estado do robô.

Além da ANSI/UL 1740, o comitê técnico ISO/TC 184 (ISO/TC 184, 1983) é responsável por elaborar padronizações que também são aplicáveis ao desenvolvimento de robôs móveis. Assim como a ANSI/UL 1740, as padronizações propostas por esse comitê possuem foco em robôs industriais e em especificar os requisitos para o hardware; contudo, de forma mais detalhada e não limitando somente aos critérios de segurança. Dessa forma, a contribuição de tais padronizações vêm no sentido de confirmar os tópicos que impactam o desenvolvimento do software, e que foram listados anteriormente. 
Portanto, apesar de não tratarem diretamente dos aspectos do software, é importante considerar as padronizações uma vez que elas guiam o desenvolvimento do hardware e impactam na criação da arquitetura do software.

\subsubsection{Grupo 2: Arquiteturas de Referência para o Domínio de Ro- bótica Móvel e Aplicações}

A fim de compilar os principais aspectos no desenvolvimento de sistemas multirrobóticos de serviço, buscou-se por arquiteturas de referência para o domínio de Robótica Móvel. Para isso, foi conduzida uma revisão sistemática para esse domínio. O processo de condução, descrição das arquiteturas e análise dos resultados foi apresentado em detalhes na Seção 3.4.

Em suma, foram identificadas sete arquiteturas de referência: 4D/RCS (Albus, 2002), JAUS (Clark, 2005), ACROSET (Ortiz et al., 2005), Servicebots (Peters et al., 2000), SMAS (Weyns e Holvoet, 2006), Robot Teleoperation (Álvarez et al., 2001) e AIS (Hayes-Roth et al., 1995). Elas englobam diversas subáreas da Robótica Móvel entre, veículos não tripulados, sistemas multi-agentes, sistemas adaptativos e robôs de serviço. Vale ainda destacar que dentre os principais resultados obtidos durante essa investigação, tem-se a lista de importantes funcionalidades a serem consideradas durante a elaboração de uma arquitetura de referência para o domínio da Robótica Móvel, sendo elas: Processamento sensorial, Controle, Deteç̧ão de colisão, Mapeamento, Localização, Planejamento, Interface com usuário, Comunicação, Segurança, Julgamento de decisões e Interação entre robôs. Além disso, uma capacidade que foi abordada em algumas arquiteturas e que se faz importante neste trabalho é a evolução do sistema desenvolvido, uma vez que tal capacidade promove o reúso de artefatos de diferentes fases do processo de desenvolvimento. Isso acontece pois exige uma adaptabilidade do sistema, guiando para uma preocupação com o "semi-desconhecido" (apesar de não se conhecer os futuros elementos, é determinado um padrão para utilização dos mesmos) .

Levando-se em consideração que a SiMuS trata-se de uma arquitetura de referência para sistemas multirrobóticos de serviço, é importante compará-la com a Servibots, que também considera a interação de vários robôs de serviço, a fim de realizar tarefas para humanos. Com isso, deve-se destacar que a Servicebots possui duas principais limitações: (i) ambiente de atuação - é considerado que os robôs estarão em um ambiente que possui um backbone de TI, ou seja, grande parte da comunicação é perdida caso o backbone não exista ou ocorra um problema com ele; e (ii) escopo dos robôs - devido principalmente à limitação do ambiente, o conjunto de funcionalidades também é limitada. Enquanto o primeiro fator limita o escopo de aplicação da Servicebots, o segunda limita a reusabili- 
dade de elementos fora da arquitetura, possivelmente exigindo maior tempo para integrar soluções já construídas. Contudo, observa-se que esses mesmos fatores são também um ponto forte para Servicebots, pois dentro do seu escopo de atuação, suas caraterísticas promovem o desenvolvimento mais ágil de soluções, e um nível considerável de reúso das soluções já desenvolvidas para outros sistemas com base nela.

\subsection{Passo RA-2: Estabelecimento dos Requisitos Arqui- teturais}

Durante o segundo passo do ProSA-RA, chamado "Estabelecimento de Requisitos Arquiteturais", as informações e conceitos do domínio obtidos como resultado da investigação das fontes de informação foram utilizados na elicitação dos requisitos da arquitetura de referência sendo proposta. Além das principais fontes de informação, apresentadas na seção anterior, também levou-se em conta a literatura do domínio, especialistas do domínio e sistemas desenvolvidos para o domínio. Os requisitos arquiteturais da SiMuS foram divididos em três conjuntos: requisitos arquiteturais para robôs móveis em geral, requisitos arquiteturais para sistemas multirrobótiso e requisitos arquiteturais para robôs de serviço.

\subsubsection{Requisitos Arquiteturais para Robôs Móveis}

A seguir são apresentados os 11 requisitos arquiteturais identificados para o desenvolvimento de sistemas para robôs móveis.

1. A arquitetura de referência deve viabilizar a manipulação e teste de sensores próprios ou distribuídos no ambiente;

2. A arquitetura de referência deve viabilizar a manipulação e teste de atuadores;

3. A arquitetura de referência deve viabilizar a manipulação e teste de recursos, tais como bateria e memória;

4. A arquitetura de referência deve viabilizar a realização de tarefas reativas;

5. A arquitetura de referência deve viabilizar o planejamento de tarefas e decomposição das mesmas em tarefas mais simples;

6. A arquitetura de referência deve viabilizar desenvolvimento de sistemas tolerantes à falha;

7. A arquitetura de referência deve viabilizar a persistência de informações referentes ao cumprimento das tarefas designadas para o robô; 
8. A arquitetura de referência deve viabilizar evolução do sistema por meio da incorporação de novas funcionalidades;

9. A arquitetura de referência deve viabilizar a navegação de robôs controlados por sistemas desenvolvidos com base nela;

10. A arquitetura de referência deve viabilizar a localização de robôs controlados por sistemas desenvolvidos com base nela; e

11. A arquitetura de referência deve viabilizar o mapeamento de ambientes.

\subsubsection{Requisitos Arquiteturais para Sistemas Multirrobóticos}

A seguir, são apresentados os quatro requisitos arquiteturais identificados para o desenvolvimento de sistemas multirrobóticos.

1. A arquitetura de referência deve viabilizar o desenvolvimento de sistemas robóticos que envolvam a manipulação de vários robôs;

2. A arquitetura de referência deve viabilizar a utilização de uma máquina central ou robô que concentre parte ou a totalidade das decisões a serem tomadas pelo sistema desenvolvido com base na arquitetura;

3. A arquitetura de referência deve viabilizar a comunicação entre os robôs e entre robô e máquina central; e

4. A arquitetura de referência deve viabilizar a interações entre robôs mesmo sem cooperação, ou seja, quando um robô não é informado ou não se importa com existência dos demais.

\subsubsection{Requisitos Arquiteturais para Robôs de Serviço}

A seguir, são apresentados os seis requisitos arquiteturais identificados para o desenvolvimento de robôs de serviço.

1. A arquitetura de referência deve viabilizar que robôs controlados por sistemas desenvolvidos com base nela prestem serviços para humanos;

2. A arquitetura de referência deve viabilizar a interação do robô com humanos;

3. A arquitetura de referência deve viabilizar que um humano interfira nas decisões do robô; 
4. A arquitetura de referência deve viabilizar que os sistemas desenvolvidos com base nela priorizem a segurança do humano sobre as tarefas do robô;

5. A arquitetura de referência deve viabilizar que os sistemas desenvolvidos com base nela avaliem o próprio desempenho; e

6. A arquitetura de referência deve viabilizar que os sistemas desenvolvidos com base nela modifiquem o planejamento com base no seu desempenho e na segurança dos humanos com os quais o robô interage.

\subsection{Passo RA-3: Projeto Arquitetural}

No terceiro passo do ProSA-RA, os requisitos arquiteturais elicitados são utilizados como base para realizar o projeto da arquitetura de referência. Como forma de melhor documentar a arquitetura sendo proposta, são apresentados os objetivos, stakeholders e interesses (Seção 4.4.1), além de cinco visões arquiteturais: duas para o ponto vista transversal (Seção 4.4.2), uma para o ponto de vista de implantação (Seção 4.4.3), uma para o ponto de vista estrutural (Seção 4.4.4) e uma para o ponto de vista em tempo de execução (Seção 4.4.5). Para cada visão será apresentado: descrição; interesses capturados (dentre os listados na Seção 4.4.1); e representação primária e secundárias (se houver). Levando-se em conta o domínio de aplicação da SiMuS, utilizou-se a SysML para representar a maioria das visões criadas, uma vez que essa linguagem é um perfil da UML que se preocupa com sistema complexos que podem envolver hardware, software, informação, pessoas, procedimentos e instalações. É importante destacar que os conceitos representados nas visões arquiteturais são independentes da abordagem de desenvolvimento, podendo ser implementados em diferentes linguagens de programação e tecnologias.

\subsubsection{Objetivos, Stakeholders e Interesses}

Os principais objetivos estabelecidos para SiMuS são:

- Auxiliar o desenvolvimento de sistemas multirrobóticos de serviço;

- Contribuir para melhor modularização, estruturação e manutenção dos sistemas desenvolvidos com base na SiMuS;

- Contribuir para o reúso de elementos de software, desenvolvidos ou não, no contexto da SiMuS; e

- Dar suporte à evolução dos sistemas desenvolvidos com base na SiMuS; 
Com base nos requisitos arquiteturais e objetivos da arquitetura, foram definidos os stakeholders da SiMusS. Contudo, é importante ressaltar que uma arquitetura de referência não considera todos os stakeholders possíveis, uma vez que não se pode prevê-los. Dessa forma, foram considerados os principais stakeholders que podem ser considerados nas instanciações arquiteturais. São eles:

Arquiteto: Responsável pela identificação das necessidades dos sistemas e posterior instanciação da arquitetura de referência;

Especialista de domínio: Responsável por fornecer informações específicas de domínio e verificar se os requisitos referentes ao domínio foram atendidos;

Analista: Responsável por validar o conjunto de informações da instanciação arquitetural;

Gerente de QA (Quality Assurance): Responsável por garantir que os requisitos de qualidade sejam atendidos;

Desenvolvedor: Responsável pela implementação da arquitetura instanciada;

Mantenedor: Responsável por efetuar eventuais manutenções e atualizações no sistema desenvolvido; e

Usuário: Utiliza o sistema desenvolvido.

Da mesma maneira que os stakeholders, não é possível identificar os interesses de todas instâncias arquiteturais. Sendo assim, a seguir, estão os principais interesses identificados com base nos stakeholders apresentados:

I1. Reúso: Espera-se que SiMuS possibilite o reúso de informações em diferentes níveis, entre documentações, módulos e padrões;

I2. Conformidade entre arquiteturas de referência e instanciada: Espera-se que toda documentação presente neste documento possibilite manter a conformidade entre as arquiteturas de referência e a instanciada, através da instanciação de forma mais simplificada, passo-a-passo;

I3. Rastreabilidade: Espera-se que a organização utilizada na SiMuS facilite o rastreio dos problemas arquiteturais e de implementação;

I4. Integrar desenvolvimento dos módulos: Mesmo que os módulos tenham papéis distintos, espera-se que eles sejam desenvolvidos e incorporados de maneira mais integrada, facilitando a identificação de problemas em fases iniciais do projeto; 
I5. Requisitos de segurança e desempenho: Por se tratarem de robôs de serviço, é importante priorizar a interação física com humanos e, dessa forma, os requisitos de segurança e desempenho devem ser facilmente identificados dentro da instância arquitetural; e

I6. Evolução estática e dinâmica: Além da instanciação, espera-se também facilitar a evolução dos sistemas, tanto estaticamente, por meio da modificação da estrutura do sistema, quanto dinamicamente, por meio da incorporação de novas capacidades em tempo de execução.

\subsubsection{Ponto de Vista Transversal}

Os elementos, e relações, apresentadas nessas visões estarão presentes nas demais visões, e serão importantes para o entendimentos das mesmas. A seguir são descritas a Visão Conceitual e a Visão Global. O histórico de alterações desse ponto de vista é apresentado na Tabela 4.1 .

\section{VISÃO CONCEITUAL}

Essa visão apresenta um glossário de todos os conceitos que serão utilizados nas demais visões. A Figura 4.1 apresenta as relações diretas entre os conceitos, por meio do Diagrama de Definição de Blocos da SysML. Uma vez que todas as representações da SiMuS foram elaboradas em inglês, o glossário foi inteiramente escrito no mesmo idioma.

Interesses Capturados: I2 e I3.

\section{Representação}

- Actuator: Robot hardware that actuates in the environment. For example, engine, robotic arm and robotic claw.

- Actuators Interface: Part of the Devices Manager, responsible to provide the high level interfaces to access the robot actuators.

- Central Machine: Computer that runs part or entire software that controls the $\operatorname{robot}(\mathrm{s})$.

- Communication Manager: Part of the system responsible for exchanging messages among robots, and between robot and central machine. 
- Controller: Part of the system that controls the $\operatorname{robot}(\mathrm{s})$. It is responsible to interpret the environment information and take the needed actions the complete the received tasks.

- Devices Manager: Part of the system that manages robot's sensors, actuators, and resources.

- Efficiency Manager: Part of the Controller, responsible for monitoring the system and warn it about any performance problem.

- Environment: Place where the robot works on, sensing and actuating on it.

- Environment System: System, not from the robot, that it must work with.

- Evolution Manager: Part of the system that manages the acquisition, storage and discarding of modules and interfaces of the robot.

- Executor: Part of the Controller, responsible to act reactively. It loops among simple actions of reading sensors information, interpreting them and programing the actuators.

- Information Manager: Part of the system that persists the data of the robot, like maps, modules and interfaces.

- Interfaces Manager: Part of the Evolution Manager, responsible for dealing with interfaces of the robot.

- Modules Manager: Part of the Evolution Manager, responsible for dealing with modules of the robot.

- Planner: Part of the Controller, responsible to act deliberatively. It plans and manage the necessary tasks to accomplish the robot's objective.

- Resource: Components that are not sensors or actuators, like battery, CPU and RAM memory.

- Resources Interface: Part of the Devices Manager, responsible to provide the high level interfaces to access the robot resources.

- Safety Manager: Part of the Controller, responsible for monitoring the system and warning it about any safety problem.

- Self-test: Part of the Devices Manager, responsible for providing, at real-time, the status of all devices known and controlled by the robot. 
- Sensor: Robot hardware capable of obtaining and providing a specific information from the environment. For example, sonar, laser and camera.

- Sensors Interface: Part of the Devices Manager, responsible to provide the high level interfaces to access the robot sensors.

- Service Robot: A type of robot, capable of providing one or more services to people, and interacting with them, without representing any danger.
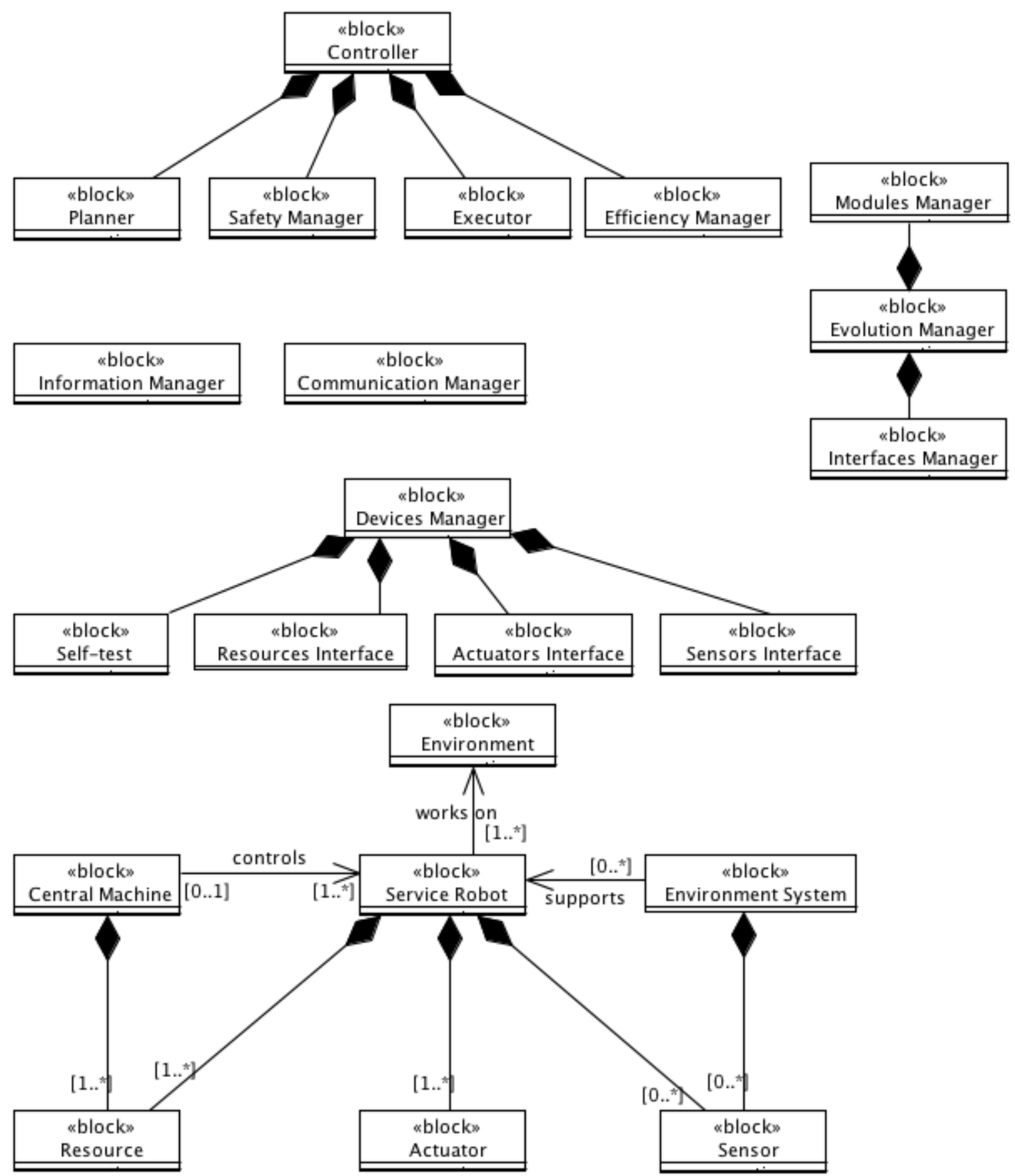

Figura 4.1: Visão Conceitual da SiMuS 


\section{VISÃO GLOBAL}

Essa visão apresenta os principais elementos que compõem a SiMuS e a dependência entre eles e com o hardware. Conforme pode-se observar na Figura 4.2, a SiMuS é composta por cinco elementos principais, sendo eles Devices Manager, Information Manager, Communication Manager, Controller e Evolution Manager. Esses elementos estão organizados em camadas, nas quais as camadas inferiores dão suporte para as camadas superiores, exceto pelo Evolution Manager que atua de forma transversal, modificando o Controller e o Devices Manager, a fim de inserir ou remover funcionalidades. As camadas inferiores abstraem soluções de mais baixo nível para apoiar as soluções das camadas superiores, até a camada Controller, na qual são implementadas as soluções para controlar os robôs de serviço. Dessa forma, espera-se que a organização em camadas, juntamente com as abstrações entre elas, favoreçam o reúso, rastreabilidade e evolução das instâncias arquiteturais originadas com base na SiMuS.

Interesses Capturados: I1, I2, I3, I4 e I6.

\section{Representação}

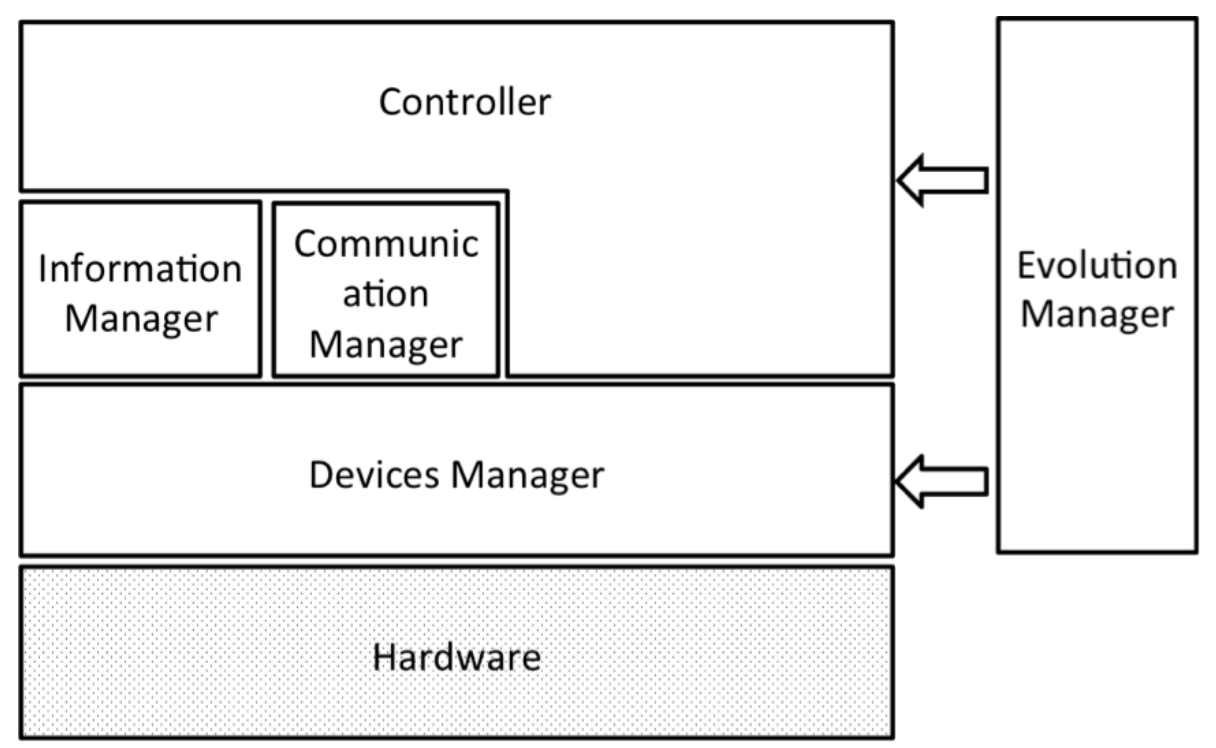

Figura 4.2: Visão Global da SiMuS 


\section{HISTÓRICO DE ALTERAÇÕES}

Tabela 4.1: Histórico de Alterações do Ponto de Vista Transversal

\begin{tabular}{ll}
\hline Data & Descrição \\
\hline \hline Out. 2012 & Criação \\
\hline Dez. 2012 & Atualização com base em avaliação \\
\hline
\end{tabular}

\subsubsection{Ponto de Vista de Implantação}

Visa apresentar a forma de implantação de sistemas desenvolvidos a partir de uma instância arquitetural da SiMuS. A seguir é descrita a Visão de Implantação. O histórico de alterações desse ponto de vista é apresentado na Tabela 4.2.

\section{VISÃO DE IMPLANTAÇÃO}

Essa visão apresenta o hardware e software presentes no ambiente de implantação, bem como a relação entre eles. Os elementos em questão são mostrados na Figura 4.3. Para representar essa visão, utilizou-se o Diagrama de Pacotes da SysML. Sendo assim, existem um ou mais robôs que podem comunicar-se entre eles (Service Robots) e/ou com uma máquina central (Central Machine). Levando em conta o hardware presente em cada robô, esses devem possuir, ao menos, um atuador (Actuators) e recursos (Resources) básicos (como bateria, CPU e memória RAM), podendo contar também com mais atuadores e recursos, além de sensores (Sensors) próprios. Ainda é possível existirem sensores distribuídos pelo ambiente (Environment), por exemplo câmeras, que sejam acessíveis aos robôs e máquina central.

Acerca do software, ele pode estar presente total ou parcialmente nos robôs e máquina central, isso dependerá do contexto do sistema sendo desenvolvido, determinado assim, a forma de orquestração do sistema. Por exemplo, em um sistema multirrobótico descentralizado e sem comunicação, no qual existam apenas robôs com seus sensores próprios, o ambiente contará apenas com robôs de serviço e esses não necessitam de comunicação (Communication Manager). Em um outro cenário, em que todos os robôs sejam gerenciados pela máquina central, essa poderia assumir o controle deliberativo (Controller), sendo também responsável pela persistência de dados (Information Manager) e evolução do sistema (Evolution Manager), enquanto os robôs possuiriam o controle reativo (Controller). A partir da Figura 4.4 pode-se observar as quatro diferentes formas de orquestração possibilitadas pela SiMuS, sendo elas classificadas de acordo com dois critérios: presença da máquina central e homogeneidade dos robôs de serviço. Além disso, tal classificação influência nas duas principais características de um sistema multirrobótico: se existe comunicação e se o sistema é centralizado (por meio da presença de coreógrafo). 
Quando o sistema conta com a presença de máquina central, é possível notar que possuindo diferentes tipos de robôs de serviço (com diferentes funções — sistema heterogêneo) ou não, isso implica em um sistema centralizado, no qual a máquina central assume o papel do coreógrafo, e com comunicação, uma vez que a máquina central precisa coreografar os robôs de serviço. Isso também implica que a arquitetura do sistema será implementada parcialmente em cada elemento (máquina central e tipos de robôs), compondo a solução para o problema proposto. No cenário sem máquina central e heterogêno, percebe-se que a arquitetura será também parcialmente implementada em cada elementos, porém o sistema pode ser centralizado (no qual um tipo de robô assume o papel de coreógrafo) ou não, e com comunicação ou não, no qual os robôs cumprem diferentes papeis sem trocar informações, mas compõem a solução do problema. No último cenário, sem máquina central e homogêneo, a arquitetura é integralmente implementada em casa robô, o sistema é descentralizado, e pode haver ou não comunicação entre os robôs idênticos.

Interesses Capturados: I2, I3, I4 e I5.

\section{Representação}

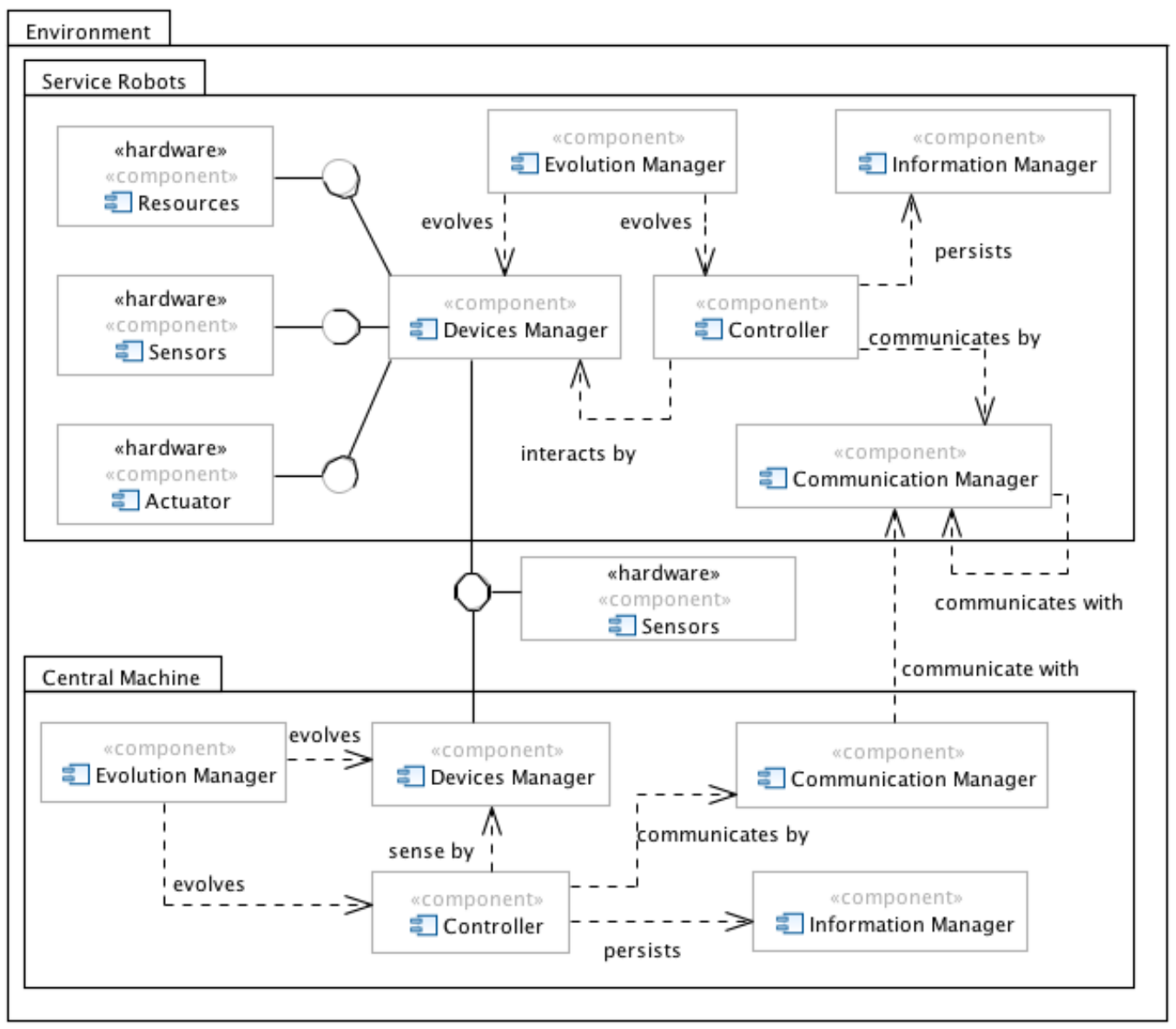

Figura 4.3: Visão de Implantação da SiMuS 


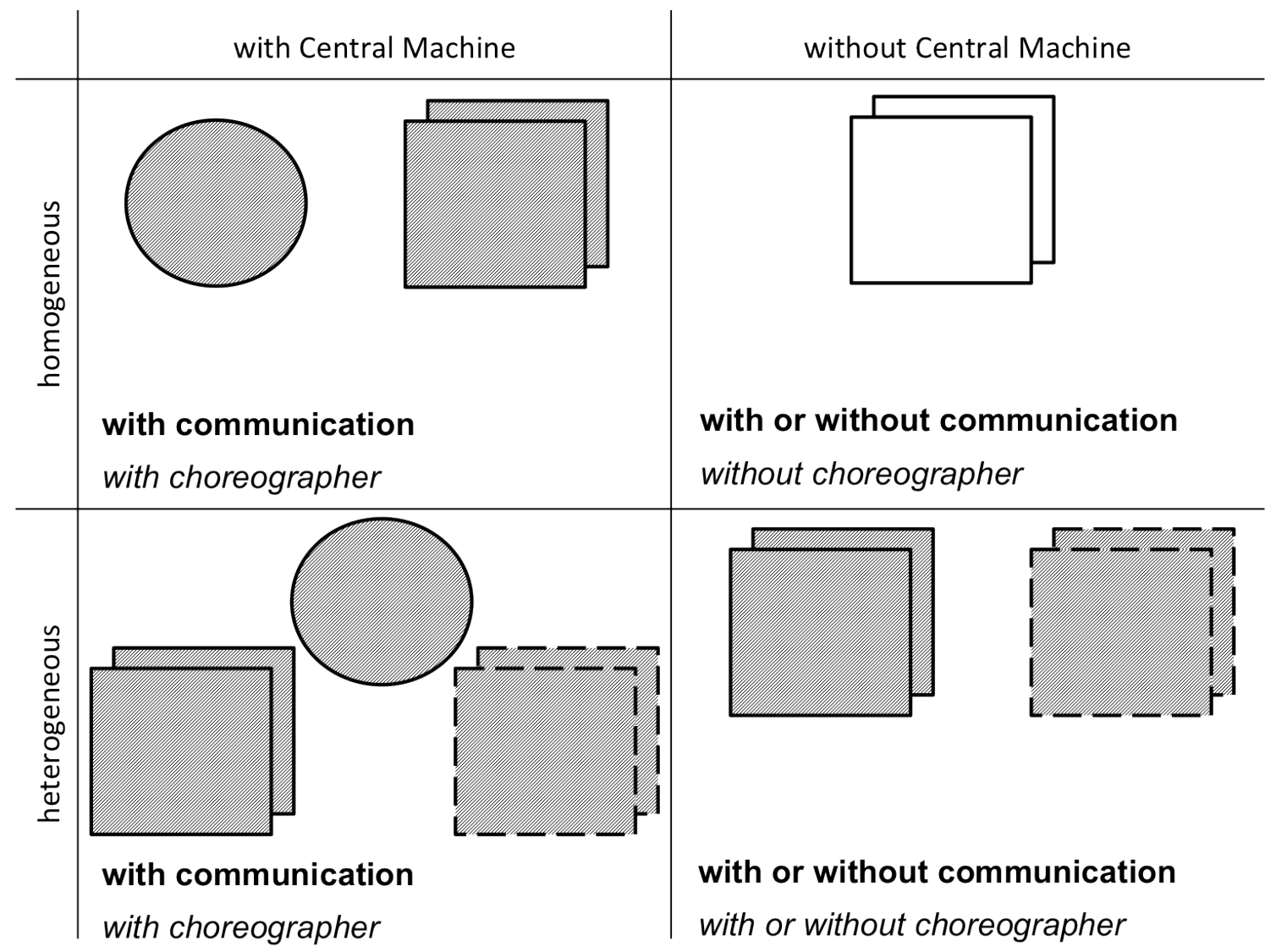

Figura 4.4: Formas de Orquestração da SiMuS

\section{HISTÓRICO DE ALTERAÇÕES}

Tabela 4.2: Histórico de Alterações do Ponto de Vista de Implantação

\begin{tabular}{ll}
\hline Data & Descrição \\
\hline \hline Out. 2012 & Criação \\
\hline Dez. 2012 & Atualização com base em avaliação \\
\hline
\end{tabular}

\subsubsection{Ponto de Vista Estrutural}

Visa apresentar a estrutura dos sistemas desenvolvidos a partir de uma instância arquitetural da SiMuS. A seguir é descrita a Visão Estrutural. O histórico de alterações desse ponto de vista é apresentado na Tabela 4.3.

\section{VISÃO ESTRUTURAL}


A partir dessa visão, é possível delimitar o contexto da arquitetura de referência, bem como de seus elementos internos. Essa visão foi representada por meio de Diagramas de Blocos Internos da SysML. Dessa forma, a Figura 4.5 apresenta a estrutura geral da SiMuS, na qual observam-se cinco módulos, referentes ao elementos principais apresentados nas visões anteriores, Controller, Devices Manager, Evolution Manager, Information Manager e Communication Manager. Esses módulos englobam as principais funcionalidades esperadas de um sistema multirrobótico de serviço, e serão detalhados a seguir.

O Communication Manager é o módulo responsável pela comunicação entre robôs ou entre robô e máquina central. Possui como principais funcionalidades o recebimento e envio de informações, ressaltando que tais informações compreendem não somente dados de sistema (como localização, mapas e avisos), mas também módulos e interfaces que estão sendo enviado ou incorporados pelo robô/máquina central. Esse módulo é responsável por atender, dentre outros possíveis requisitos, os de segurança para tráfego de informação como, por exemplo, criptografia.

O Information Manager é o módulo responsável pela persistência de quaisquer dados que sejam necessárias para o sistema como, por exemplo, mapas, protocolos, interfaces e módulos. Ou seja, as mesmas informações que podem trafegar pelo Communication Manager podem ser também manipuladas pelo Information Manager; contudo, visando a persistência dessa informação. Dessa forma, esse módulo, também atende aos requisitos de segurança da informação.

O Devices Manager é responsável pela gerência dos sensores, atuadores e recursos manipulados pelo robô. Conforme pode-se observar detalhado na Figura 4.6, ele fornece as interfaces de acesso para esses elementos, além de fornecer dados de teste sobre o funcionamento desses. Assim, o Sensors Manager possui as interfaces de acesso para os sensores, o Actuators Manager possui as interfaces de acesso para os atuadores, e o Resources Manager possui as interfaces de para os recursos. Esses três submódulos devem fornecer funcionalidades de alto nível para o Controller, além de serem capazes de responder se uma desejada interface está disponível ou não. O Self-test deve ser capaz de requisitar as informações necessárias para realizar os testes, e fornecer funcionalidades de alto nível para o Controller consultá-las.

Ainda observando-se a Figura 4.5, o Evolution Manager é responsável por gerenciar a evolução do sistema, ou seja, a aquisição, fornecimento e invalidação de módulos e interfaces. Por exemplo, ele permite que o robô possa executar uma nova tarefa ou uma mesma tarefa de outro modo, desde que o Evolution Manager seja capaz de descobrir o(s) módulo(s) necessário(s) e de que o Controller possua os requisitos para utilizá-lo(s). Dentre os requisitos para se utilizar um novo módulo, pode ser que o robô necessite de uma interface para um tipo sensor, atuador ou recurso desconhecido, ou mesmo existindo 
a necessidade de uma substituição de algum desses elementos. Conforme detalhado na Figura 4.7, cabe ao Modules Manager a gerência dos módulos, ao Interfaces Manager a gerência das interfaces e ao Evolution Manager coordenar esses dois submódulos, além de fornecer funcionalidades de alto nível para que o Controller possa consultar e adquirir outras funcionalidades.

O Controller é responsável por realizar o "controle" do robô, ou seja, ele deve ser capaz de tomar as medidas necessárias para alcançar o objetivo imposto ao sistema. Para isso, ele realiza todo o planejamento e execução das tarefas necessárias, orquestrando os outros quatro módulos principais (Communication Manager, Information Manager, Devices Manager e Evolution Manager). Assim, esse é o módulo mais complexo por dois motivos: interação com demais módulos e complexidade das funcionalidades internas. Apesar da interação com todos os demais, as funcionalidades de alto nível fornecidas por eles privam o Controller de diversas decisões que não deveriam caber a ele. Dessa forma, o número de mensagens trocadas com os demais módulos é proporcionalmente menor, não sobrecarregando-o.

Internamente, o Controller possui quatro submódulos, Efficiency Manager, Safety Manager, Planner e Executor, conforme pode-se observar na Figura 4.8. O primeiro deles é responsável por atender aos requisitos de desempenho do sistema, e para isso, obtém informações do Self-test e dos recursos. O Safety Manager é responsável por atender aos requisitos que dizem respeito à segurança das pessoas que irão interagir com o robô e, para isso, são providos de informações de desempenho e das leituras dos sensores, além de poder ser alertado manualmente por uma pessoa (por exemplo, por meio de um botão ou comunicação pela central). Caso algum problema de segurança seja detectado, ele é responsável por avisar os submódulos Planner e Executor, responsáveis respectivamente por planejar as ações e programar os atuadores. A fim de definir as ações a serem tomadas pelo robô, o Planner é responsável também por interagir com os demais módulos principais e humanos, buscando informações e enviando decisões tomadas, além de atribuir ao submódulo Executor, as tarefas que devem ser executadas a fim de programar os atuadores do robô, movimentando-os.

Interesses Capturados: I1, I2, I3, I4, I5 e I6. 


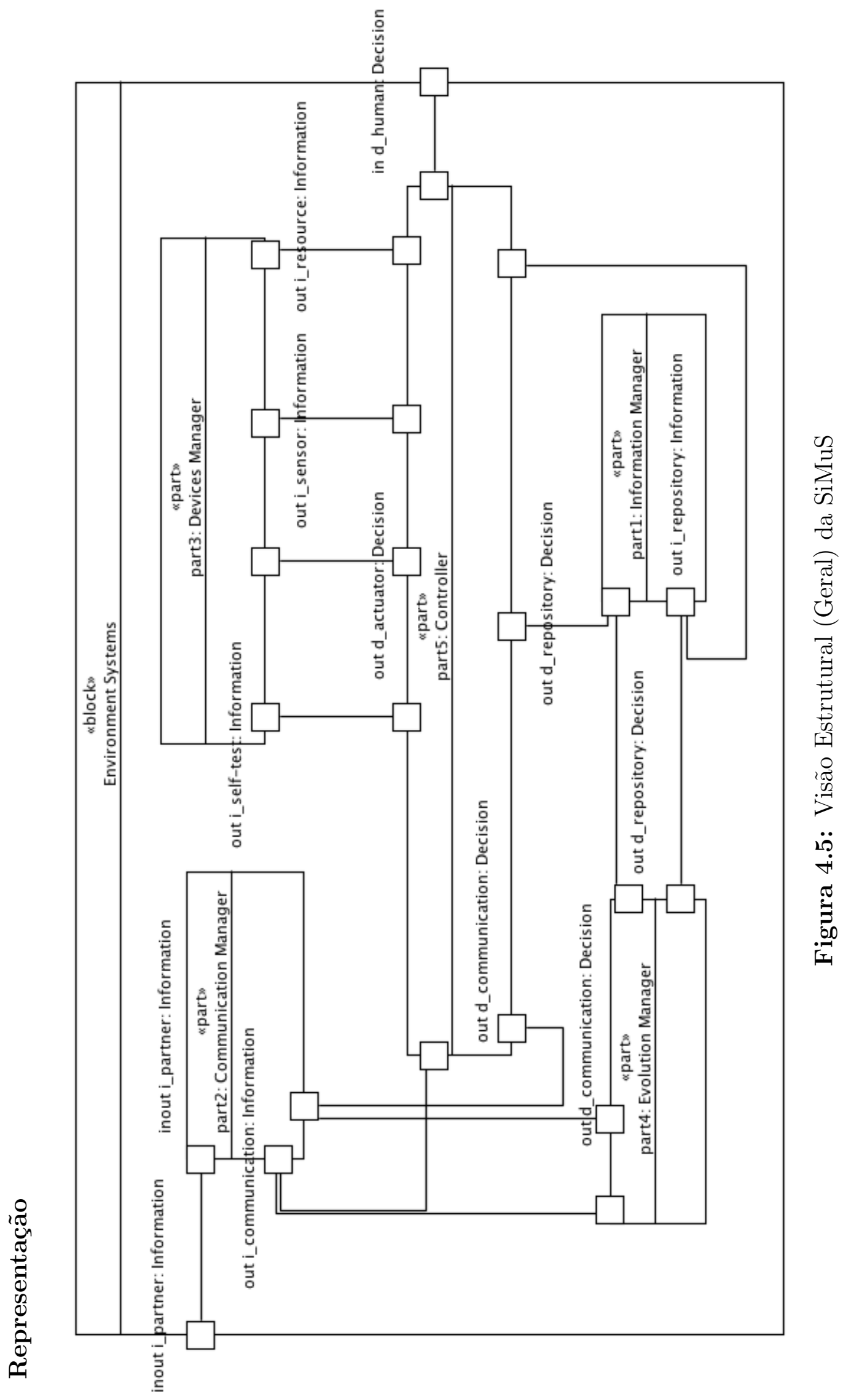




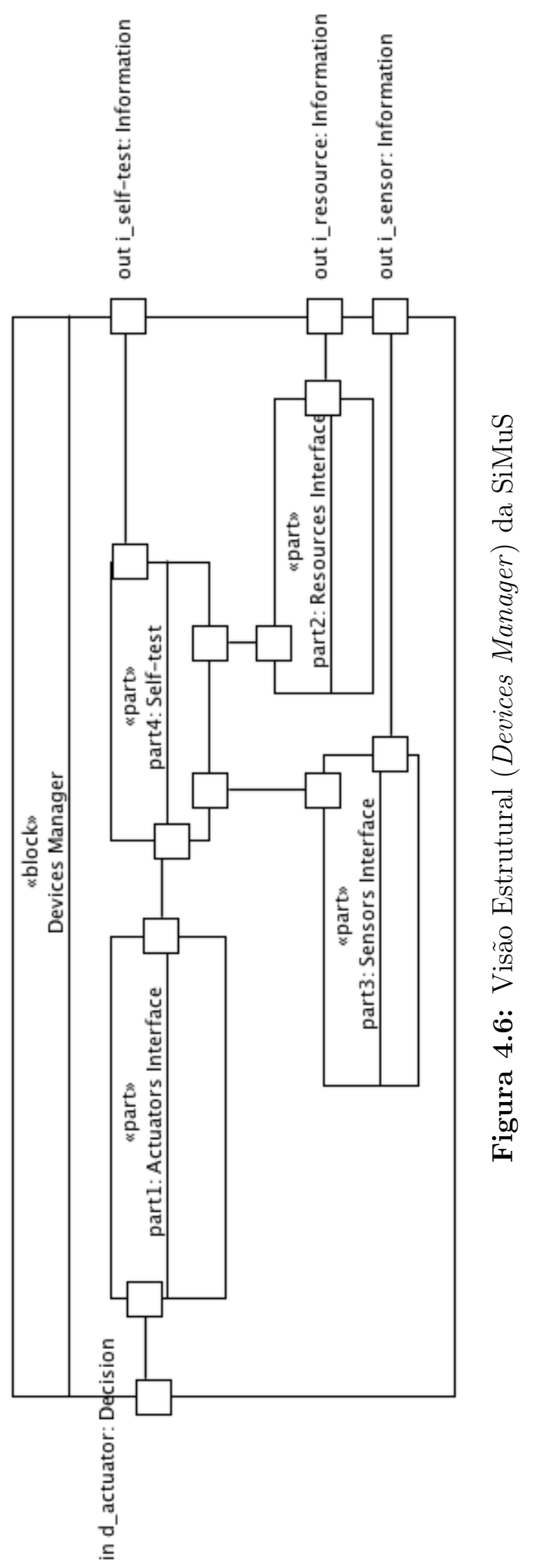




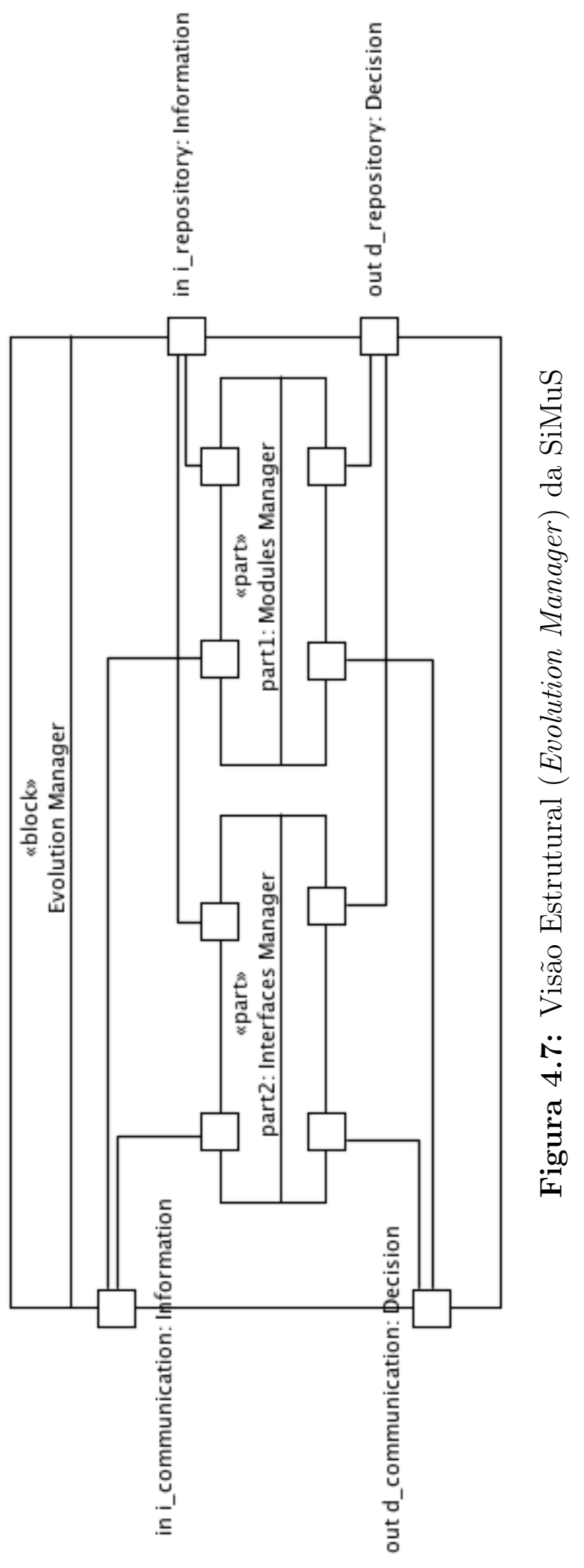




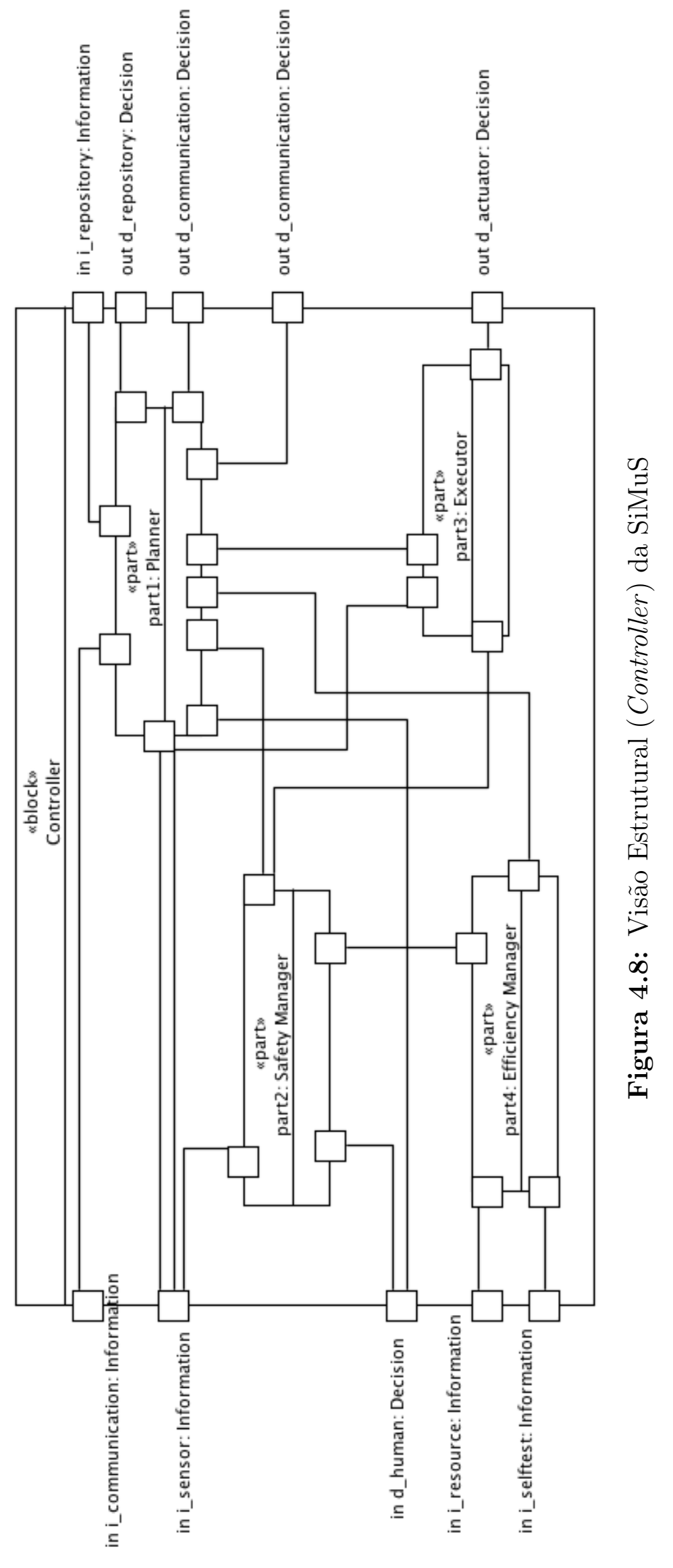




\section{HISTÓRICO DE ALTERAÇÕES}

Tabela 4.3: Histórico de Alterações do Ponto de Vista Estrutural

\begin{tabular}{ll}
\hline Data & Descrição \\
\hline \hline Out. 2012 & Criação \\
\hline Dez. 2012 & Atualização com base em avaliação \\
\hline
\end{tabular}

\subsubsection{Ponto de Vista em Tempo de Execução}

Visa apresentar o comportamento esperado pelos sistemas desenvolvidos a partir de uma instância arquitetural da SiMuS. A seguir é descrita a Visão de Processos. O histórico de alterações desse ponto de vista é apresentado na Tabela 4.4.

\section{VISÃO DE PROCESSOS}

Essa visão, representada por meio do Diagrama de Atividades da SysML, apresenta as principais linhas de execução de um sistema desenvolvido a partir de uma instância arquitetural da SiMuS, indicando responsabilidades e colaborações. A Figura 4.9 apresenta as cinco principais linhas de execução, sendo quarto delas inerentes ao Controller (Executor, Planner, Safety Manager e Efficiency Manager) e uma acerca do Evolution Manager. Os demais elementos principais (Devices Manager, Information Manager e Communication Manager) não são representados pelo fato de suas funções estarem bem estabelecidas e que seus comportamentos dependem fortemente dos requisitos da aplicação que está sendo desenvolvida.

Existem três processos iniciais, responsáveis pelos módulos Efficiency Manafer, Safety Manager e Planner. Os dois primeiros são caracterizados por ciclos curtos e executados em tempo real. Dessa forma, a SiMuS permite a verificação da segurança e desempenho do robô com o intervalo desejado entre os ciclos. De forma semelhante, esses dois módulos fornecem informação para o controle; contudo, um aviso de segurança possui maior prioridade para ser atendida do que uma informação de desempenho. Um aviso de segurança é atendido pelo Planner e pelo Executor, que devem tomar as devidas providências a fim de responder apropriadamente ao aviso.

O Planner é responsável pela parte deliberativa do controle, na qual é realizado o planejamento e gerência das tarefas que cumprirão o objetivo do robô. Ele é caracterizado por um ou mais níveis de ciclos, mais longos que os demais. O número de níveis depende do sistema que está sendo desenvolvido. Contudo, esses níveis se caracterizam de tal forma que os que possuem ciclos mais curtos realizam planejamento a mais curto prazo 


\section{CAPÍTULO 4. ESTABELECIMENTO DA SIMUS}

para atender ao planejamento de mais longo prazo do nível superior. Dessa forma, é possível obter, por exemplo, um planejamento com ciclo mais longo de 24 horas e mínimo de 1 segundo. Parte do planejamento inclui a criação e finalização de execuções, que são tarefas reativas realizadas pelo Executor. Apesar de possuir a permissão de finalizar uma execução, ele também pode aguardar que ela termine por si só. Isso permite maior versatilidade para os diversas sistemas que podem surgir a partir da SiMuS.

Por fim, o Evolution Manager não possui ciclo e tem a finalidade de atender a requisições do Planner, que é responsável por verificar a necessidade de módulos/interfaces. O tempo para o atendimento de uma requisição é bastante variado, levando em conta o funcionamento interno dos módulos.

Interesses Capturados: I2, I3, I4, I5 e I6. 
Representação

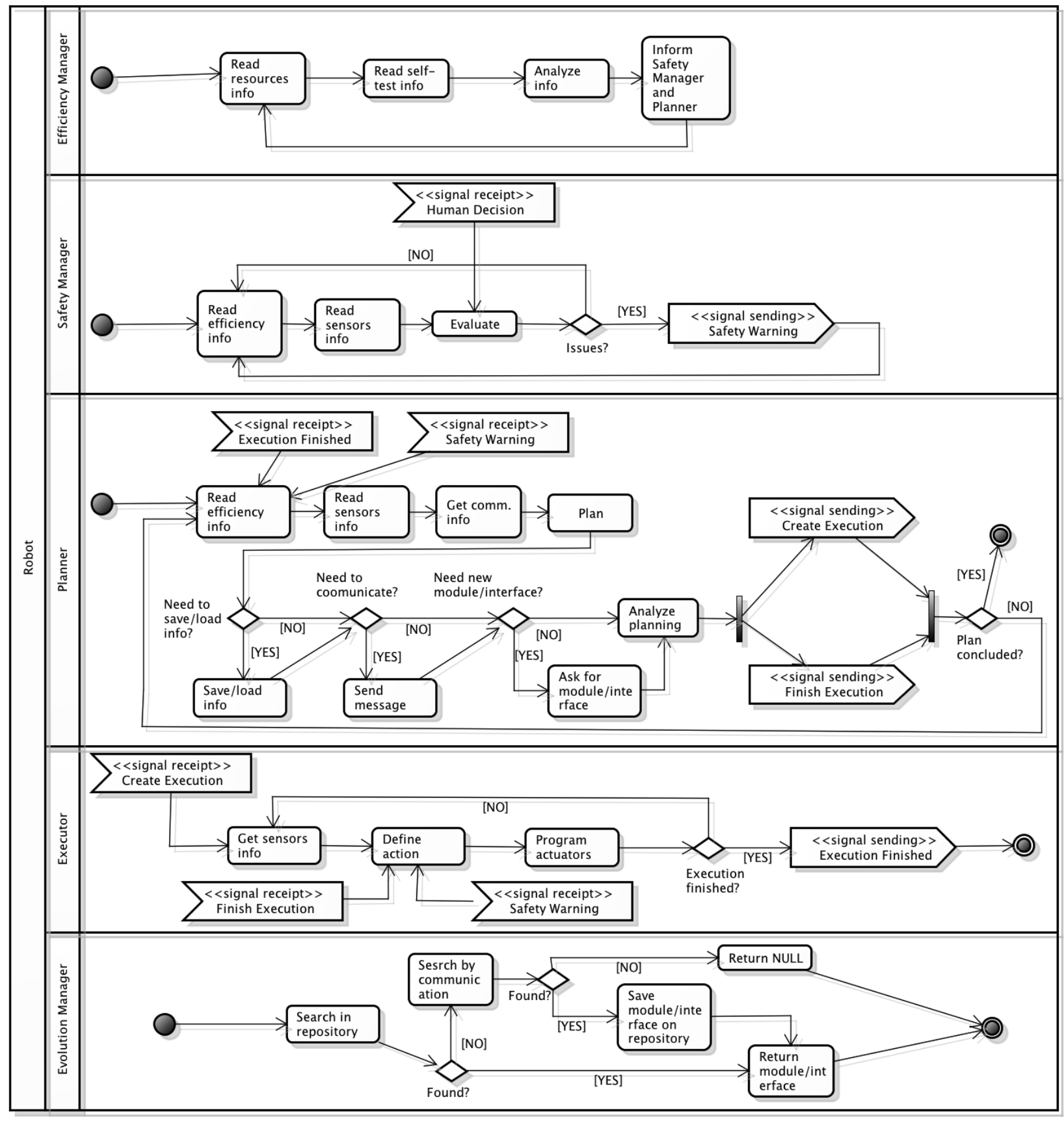

Figura 4.9: Visão de Processos da SiMuS 


\section{HISTÓRICO DE ALTERAÇÕES}

Tabela 4.4: Histórico de Alterações do Ponto de Vista em Tempo de Execução

\begin{tabular}{ll}
\hline Data & Descrição \\
\hline \hline Nov. 2012 & Criação \\
\hline Dez. 2012 & Atualização com base em avaliação \\
\hline
\end{tabular}

\subsection{Passo RA-4: Avaliação da Arquitetura de Referência}

No quarto passo do ProSA-RA, denominado "Avaliação da Arquitetura de Referência", são realizadas avaliações com o objetivo de evidenciar a qualidade da arquitetura de referência proposta. Para isso, podem ser aplicados métodos de avaliação arquitetural, como os propostos por Kazman et al. (1998) e Software Engineering Institute (2010), e inspeções por meio de checklists. No contexto deste trabalho, além das avaliações informais realizadas a partir de entrevistas com especialistas da área de robótica, foi realizada uma inspeção por checklist e um estudo de caso, a fim de identificar defeitos relacionados à omissão, ambiguidade, inconsistência e de informações incorretas. No Capítulo 5.1 são apresentados os detalhes da instanciação de uma arquitetura de software para um sistema de vigilância em um ambiente indoor, com o propósito de prover evidências da aplicabilidade da SiMuS, bem como observar os benefícios relacionados ao reúso e à facilidade de integração.

A inspeção realizada na SiMuS, utilizou um checklist para avaliação de arquiteturas de referência voltadas a sistemas embarcados, elaborado pelo grupo de pesquisa no qual este trabalho foi desenvolvido. Ele possui um total de 93 questões distribuídas entre 9 diferentes stakeholders, sendo eles: analista, arquiteto, projetista, desenvolvedor, especialista de domínio, integrador, gerente de garantia de qualidade, gerente de software e testador. A avaliação foi realizada em três passos, nos quais, partes das questões eram respondidas a cada passo. O três passos são: (i) verificar a completude das informações gerais, da construção e conteúdo (25 questões); (ii) verificar adequação para liberação de uso (65 questões); e (iii) verificar possibilidades de mudança e viabilidade (3 questões). É importante ressaltar que parte das questões possuem sub-itens, logo as estatísticas das respostas serão apresentadas por meio de uma porcentagem aproximada.

A inspeção foi realizada por três pessoas diferentes do autor, e os grupos de questões (por stakeholder) foram distribuídos entre elas de acordo com as qualificações de cada uma, sendo um especialista da área de sistemas embarcados e 2 especialistas da área de arquitetura de software. Como resultados do primeiro passo, pôde-se observar que aproximadamente $70 \%$ das questões foram atendidos na totalidade, $23 \%$ parcialmente e $7 \%$ não 
foram atendidos. Após a análise conclui-se que a documentação está satisfatória, contendo todas as informações mais importantes e atende aos principais requisitos elencados pelo checklist. Percebeu-se apenas a falta de algumas informações, tais como limitações de cada visão, indicação da utilização de padrões internacionais e relação entre stakeholders e cada visão.

O segundo passo contou com 7 questões respondidas por todos os stakeholders e 58 questões distribuídas entre os eles. Aproximadamente $65 \%$ das questões foram atendidos na totalidade, $26 \%$ parcialmente e $9 \%$ não foram atendidos. Ao desse passo, notou-se que a SiMuS possui um bom nível de adequação; contudo algumas alterações são necessárias antes da liberação, tais como descrição mais detalhada dos pontos que são fixos e variáveis dentro da arquitetura e de como os pontos de variabilidade afetam os pontos fixos.

O terceiro contava apenas com questões que foram respondidas por todos os stakeholders. Dessa forma, a análise das respostas indicou possibilidades de mudança, acerca dos problemas relatados anteriormente, e a viabilidade de utilização desde que esses pontos sejam revistos dentro da arquitetura de referência. Dessa forma, concluiu-se que a SiMuS possui um nível adequado para publicação; contudo, ainda são necessárias revisões antes da liberação para uso, dentre elas, um maior detalhamento sobre os pontos fixos e variáveis da arquitetura e sobre a relação entre visões e stakeholders.

\subsection{Considerações Finais}

Frente à complexidade e importância que sistemas robóticos vêm adquirindo, especialmente aqueles para robôs de serviço, neste capítulo foi apresentada a SiMuS, uma arquitetura de referência que visa prover direções ao desenvolvimento sistemas multirrobóticos para robôs de serviço. Por meio da SiMuS, objetiva-se contribuir para a criação de sistemas multirrobóticos de serviço que possam ser mais facilmente mantidos, aprimorando também a capacidade de reúso e a qualidade. Além disso, vale a pena ressaltar que as fontes de informação identificadas durante o primeiro passo do ProSA-RA podem ser utilizadas por projetos de outras arquiteturas do domínio.

O estabelecimento de uma arquitetura de referência não é uma tarefa trivial. Por isso, deve-se destacar a importância da adoção de um processo que guie o estabelecimento da arquitetura de referência desde a identificação das fontes de informação, até a atividade de avaliação arquitetural. Nesse contexto, a utilização do ProSA-RA foi de grande valia para o estabelecimento da SiMuS.

É importante lembrar que a arquitetura de referência estabelecida neste trabalho possui características de uma arquitetura de referência dirigida à pesquisa, na qual os detalhes de desenvolvimento de alguns módulos ainda necessitam ser futuramente investigados, 


\section{CAPÍTULO 4. ESTABELECIMENTO DA SIMUS}

conforme foi identificado pela aplicação do checklist. A fim de complementar a avaliação realizada durante o quarto passo do ProSA-RA, no próximo capítulo, é apresentado um estudo de caso no qual é possível compreender mais detalhes sobre a instanciação da SiMuS e sobre suas características. 


흔

\section{Estudo de Caso: Utilização da SiMuS}

\subsection{Considerações Iniciais}

Neste capítulo é apresentado um estudo de caso de utilização da SiMuS na instanciação de um sistema multirrobótico de serviço. Esse estudo de caso foi elaborado com base em um sistema que foi implementado pelo autor no contexto do grupo no qual este trabalho foi desenvolvido. Assim, acredita-se que seja suficiente para evidenciar a viabilidade de utilização da SiMuS.

Para instanciação do sistema proposto, os requisitos arquiteturais do sistema a ser desenvolvido foram elicitados, seguindo-se pela identificação dos stakesholders e interesses. Partindo-se dessas informações, cada visão da SiMuS foi instanciada com objetivo de atender aos requisitos arquiteturais e interesses. Foram também construídos modelos de projeto visando refinar a representação do sistema.

Na Seção 5.2 é apresentada uma descrição completa do sistema a ser desenvolvido. Na Seção 5.3 é apresentada a instanciação arquitetural realizada com base na SiMuS. As perspectivas para implementação do sistema são apresentadas na Seção 5.4. Questões como variabilidade dos módulos da SiMuS e evolução do sistema projetado no estudo de caso são discutidos na Seção 5.5. Por fim, na Seção 5.6 são apresentadas as considerações finais deste capítulo. 


\subsection{Descrição do Sistema}

A seguir será apresentada a descrição do sistema considerado nesse estudo de caso. Ele constitui-se de um sistema de vigilância para ambientes indoor, sendo composto por quatro robôs Pioneer 3-DX (Figura 5.1) autônomos que se movimentam livremente em um cenário simulado que representa um conjunto de corredores conectados. Os robôs têm posições iniciais diferentes no mapa, e seu objetivo é o de navegar aleatoriamente por esse cenário a fim de detectar e neutralizar um possível intruso. A Figura 5.2 apresenta um exemplo de utilização desse sistema, na qual é possível observar os robôs monitorando diferentes locais do ambiente.

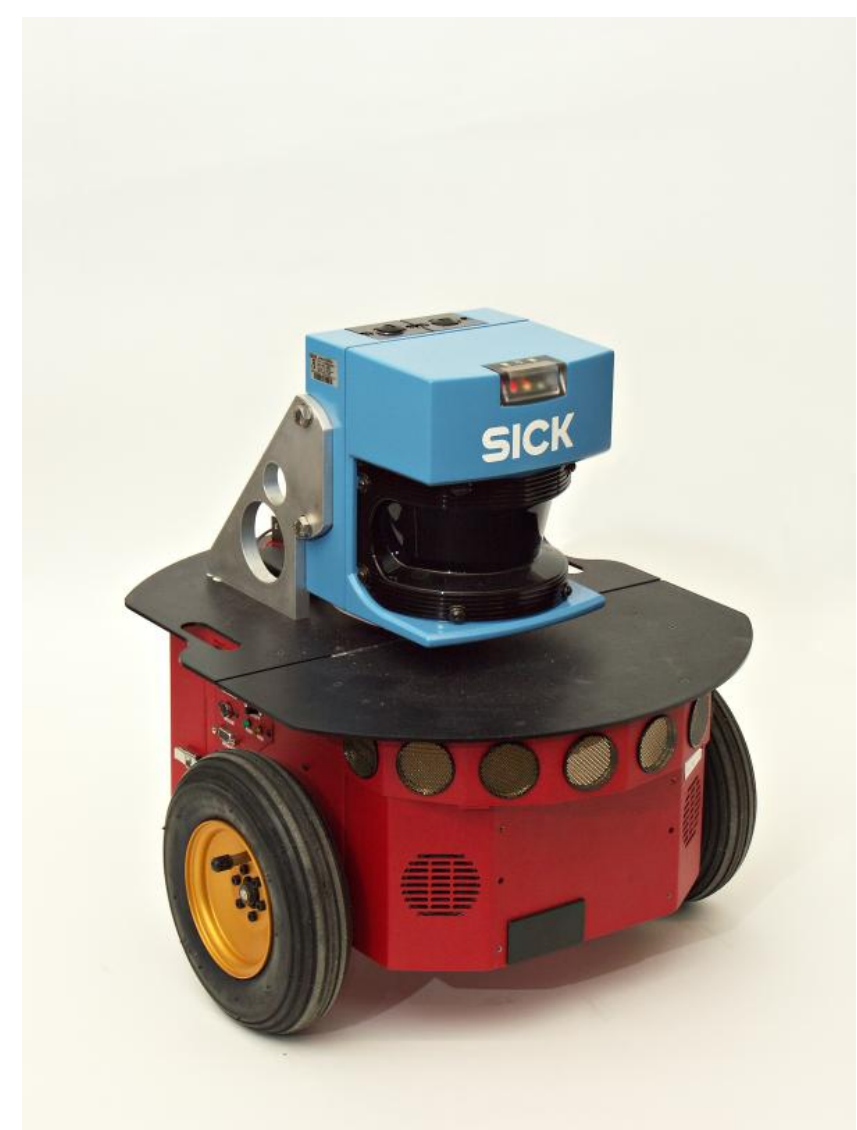

Figura 5.1: Robô Pioneer-3DX Equipado com Laser Sick LMS-200 (Fonte: http://www.ti.uni-bielefeld.de/html/research/equipment.html)

O sistema de navegação adotado é a topológica (que se baseia numa descrição mais qualitativa da posição do robô e dos vários objetivos a atingir), que possibilita não só a navegação dos robôs como também a localização dos mesmos. Esse sistema é composto por uma RNA (Redes Neurais Artificiais) treinada para classificar as situações de uma máquina de estados que representa os cinco possíveis estados desse cenário: reta, curvas para direita e esquerda, cruzamentos e intruso à frente. As entradas dessa RNA são 
obtidas a partir do sensor utilizado, nesse caso um Sick LMS-200 (Figura 5.1), com 180 graus e alcance de oito metros. Devem ser usados 180 pontos, cada um correspondente a um feixe do laser com distância de um grau. A saída da RNA é a codificação binária em três bits do estado corrente detectado. Sendo assim, a RNA utilizada nesse sistema é uma MLP (Multi-Layer Perceptron) (Haykin, 2001) composta de uma camada de entrada com 180 neurônios, uma camada oculta com 90 neurônios, e uma camada de saída com três neurônios.

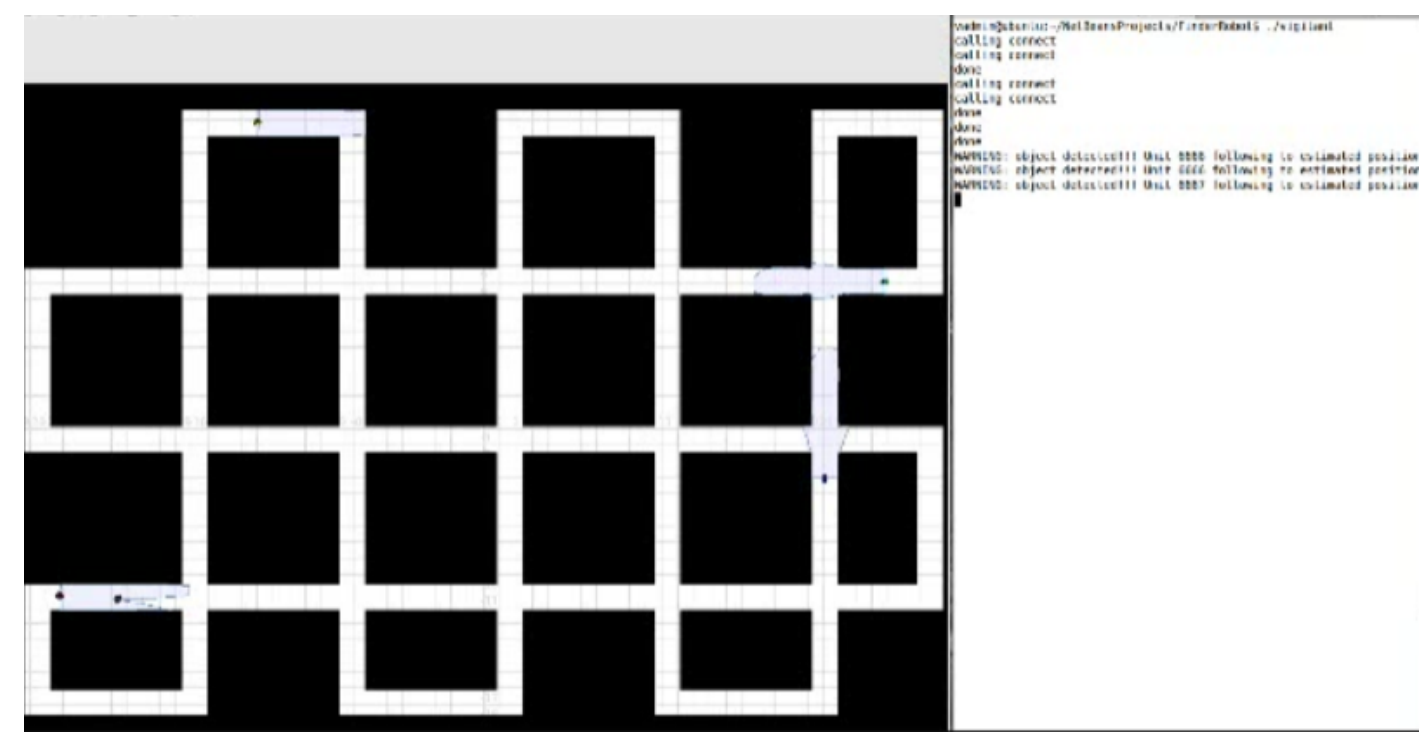

Figura 5.2: Exemplo de Utilização do Sistema de Vigilância

O mapa do cenário é conhecido e representado como um grid no formato de matriz, no qual a posição inicial de cada robô é conhecida. Inicia-se então o controle autônomo dos robôs, que consiste em uma navegação topológica com decisões aleatórias até que seja detectado um intruso. Enquanto navega autonomamente, o robô coleta e classifica os dados do laser, de forma a conhecer em qual estado se encontra, sabendo então sua posição aproximada (em qual corredor, curva ou cruzamento ele está). Se durante essa navegação o robô detectar um objeto à sua frente, ele envia uma mensagem em broadcast, pedindo a localização atual de todos os outros robôs. Se nenhum dos companheiros responde com uma posição igual a do objeto detectado, confirma-se então a suspeita de intruso, e uma nova mensagem em broadcast é enviada, solicitando a aproximação dos outros vigilantes.

Cada robô calcula o menor caminho até esse intruso, com base na conversão da posição estimada do robô no cenário em posições do grid. O caminho gerado por esse algoritmo é então convertido para uma lista de estados e ações associadas que deverão ser seguidas com o sistema de navegação topológica. Inicia-se então a fase final de execução, na qual os robôs seguem o caminho planejado tomando decisões definidas na etapa anterior até alcançar o alvo. Além disso, cada robô deve dirigir-se ao centro de recarga se a bateria estiver abaixo de 10\%, e evitar colisão com qualquer objeto a menos de 10 centímetros. 


\subsection{Instanciação da SiMuS}

A fim de melhor documentar a arquitetura sendo instanciada, são apresentados os requisitos arquiteturais identificados, stakeholders e interesses (Seção 5.3.1), os quais foram obtidos com base na descrição do sistema. Utilizando essas informações, seis visões arquiteturais foram criadas a partir da instanciação da SiMuS: duas para o ponto vista transversal (Seção 5.3.2), uma para o ponto de vista de implantação (Seção 5.3.3), duas para o ponto de vista estrutural (Seção 5.3.4) e uma para o ponto de vista em tempo de execução (Seção 5.3.5). Para cada visão, serão apresentados: descrição da instanciação; interesses capturados (dentre os listados na Seção 5.3.1); e representação.

\subsubsection{Requisitos Arquiteturais, Stakeholders e Interesses}

É importante ressaltar que o sistema a ser construído não prevê a modificação dinâmica de módulos ou interfaces de dispositivos. Assim, além dos refinamentos motivadas pelos requisitos arquiteturais, stakeholders e interesses, os elementos relativos ao módulo Evolution Manager serão desconsiderados. Com base na descrição do sistema e no conhecimento de um especialista do domínio, os requisitos arquiteturais identificados foram:

- A arquitetura deve viabilizar a manipulação e teste de um sensor laser;

- A arquitetura deve viabilizar a manipulação e teste do motor do robô;

- A arquitetura deve viabilizar a manipulação e teste de recursos, tais como bateria e memória;

- A arquitetura deve viabilizar a persistência de mapas e atualizações nos mesmos;

- A arquitetura deve viabilizar a classificação do cenário em que o robô está, em um dado momento;

- A arquitetura deve viabilizar a localização do robô por meio de conhecimento previamente estabelecido;

- A arquitetura deve viabilizar o planejamento de trajetórias com informações do mapa, da localização, do desempenho e de segurança;

- A arquitetura deve viabilizar a navegação topológica, com base em mapa conhecido;

- A arquitetura deve viabilizar o planejamento de ações com base nos objetivos e estado atual do cenário;

- A arquitetura deve viabilizar o planejamento de ação em caso de falha; 
- A arquitetura deve viabilizar a comunicação entre os robôs vigilantes;

- A arquitetura deve viabilizar a cooperação entre os robôs; e

- A arquitetura deve viabilizar que o sistema priorize a segurança do ser humano sobre as tarefas do robô.

Com base nos requisitos arquiteturais e descrição, foram identificados os stakeholders do sistema em questão. Contudo, é importante ressaltar que, pelo projeto estar na fase de construção da arquitetura, o conjunto identificado ainda pode sofrer alterações. Os stakeholders são:

Arquiteto: Responsável pela identificação das necessidades do sistema e instanciação da arquitetura;

Especialista de domínio: Responsável por fornecer informações específicas de domínio e verificar se os requisitos referentes ao domínio foram atendidos;

Analista: Responsável por validar o conjunto de informações da instanciação arquitetural;

Gerente de QA: Responsável por garantir que os requisitos de qualidade sejam atendidos;

Desenvolvedor: Responsável por definir as tecnologias, implementação do sistema e realizar manutenções; e

Usuário: Utiliza o sistema desenvolvido.

Da mesma maneira que os stakeholders, o conjunto de interesses identificado ainda pode sofrer alterações. Sendo assim, a seguir, estão os interesses identificados para stakeholders apresentados:

I1. Localização e aviso de intrusos: O principal interesse é o cumprimento do objetivo estabelecido para o sistema, de localizar e comunicar a presença de intrusos no ambiente monitorado;

I2. Reúso de código do sistema anteriormente desenvolvido: Espera-se que o máximo de código desenvolvido na implementação da primeira versão do sistema, possa ser reutilizado durante a nova implementação;

I3. Conformidade entre arquiteturas de referência e instanciada: Espera-se que toda documentação do sistema possibilite manter a conformidade entre a arquitetura de referência e a arquitetura instanciada; 
I4. Rastreabilidade: Espera-se que a organização do sistema facilite o rastreio dos problemas arquiteturais e de implementação;

I5. Integrar desenvolvimento dos módulos: Mesmo que os módulos tenham papéis distintos, espera-se que eles sejam desenvolvidos e incorporados de maneira mais integrada, facilitando a identificação de problemas em fases iniciais do projeto; e

I6. Requisitos de segurança e desempenho: Por se tratarem de robôs de serviço, é importante que a interação física com humanos seja priorizada e, dessa forma, os requisitos de segurança e desempenho sejam facilmente identificados dentro do sistema.

\subsubsection{Ponto de Vista Transversal}

Os elementos e relações apresentadas nessas visões estarão presentes nas demais visões, e serão importantes para o entendimentos das mesmas. Durante a instanciação não se fez necessário a criação de visões adicionais. Dessa forma, a seguir são apresentadas as visões do ponto de vista transversal.

\section{VISÃO CONCEITUAL}

O glossário de conceitos utilizados para representar essa visão é apresentado a seguir. A Figura 5.3 apresenta as relações diretas entre os conceitos. Uma vez que todas as representações do projeto do sistema de vigilância foram elaboradas em inglês, o glossário foi inteiramente escrito no mesmo idioma.

Interesses Capturados: I2, I3 e I4.

\section{Representação}

- Communication Manager: Part of the system responsible for exchanging messages, containing position or intruder warning, among robots.

- Controller: Part of the system that controls the robot. It is responsible for interpreting all the informations and patroling the environment, warning about any intruder.

- Devices Manager: Part of the system that manages the robot laser, engine and resources. 
- Efficiency Manager: Part of the Controller, responsible to monitoring the battery and warning about low charge.

- Environment: Place where the robots work on, sensing and actuating on it.

- Executor: Part of the Controller, responsible to read laser information, classify the data based on an ANN, define an action and program the robot engine.

- Information Manager: Part of the system that persists the data of maps.

- Planner: Part of the Controller, responsible for interpreting the information, planing the actions and distributing tasks to the other modules.

- Player: Part of the Devices Manager, responsible for providing the high level interfaces to access the robot's laser and engine. This part thakes advantage of Player ${ }^{1}$ technology.

- Resource: Components that are not sensors or actuators, like battery, CPU and RAM memory.

- Robot Engine: Robot hardware that moves the robot through the environment.

- Robot Laser: Robot hardware capable of obtain and provide distance data.

- Robot System: System that resulted by the implementation of the this architecture.

- Safety Manager: Part of the Controller, responsible for monitoring the range between robot and any obstacle, warning the system at low distance.

- Self-test: Part of the Devices Manager, responsible for providing, at real-time, the status of all kown devices that are controlled by the robot.

- Service Robot: A type of robot, capable of provide one or more services to people, and interact with them, without representing any danger.

\footnotetext{
${ }^{1}$ http://playerstage.sourceforge.net/
} 


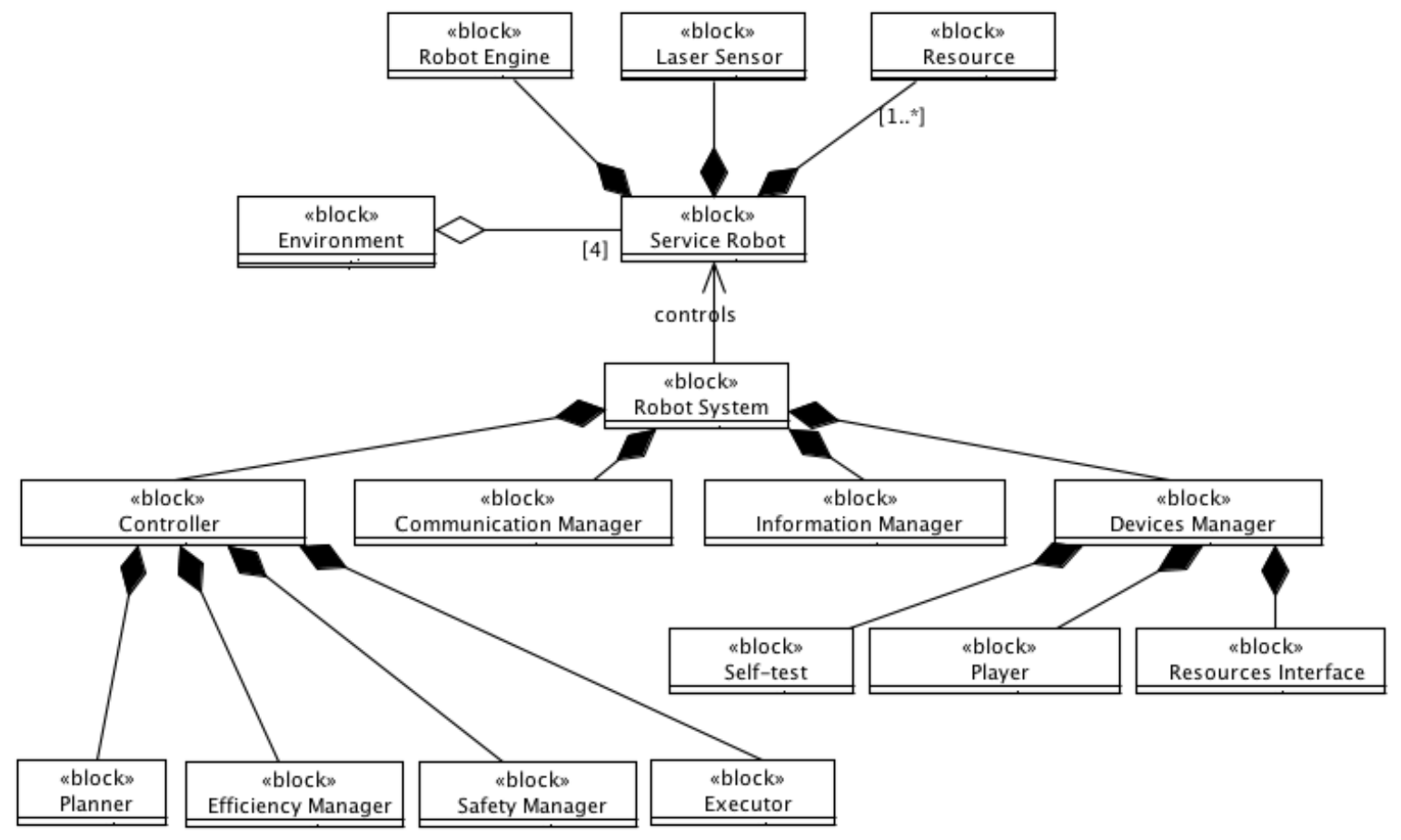

Figura 5.3: Relação entre Conceitos do Sistema de Vigilância

\section{VISÃO GLOBAL}

Essa visão apresenta a organização dos principais módulos que compõem o sistema de vigilância e com o hardware. Conforme pode-se observar a partir da Figura 5.4, o sistema de vigilância é composta por quatro módulos, sendo eles Devices Manager, Information Manager, Communication Manager e Controller. Esses elementos estão organizados em camadas, nas quais as camadas inferiores dão suporte para as camadas superiores. As camadas inferiores abstraem soluções de mais baixo nível para apoiar as soluções das camadas superiores, até a camada Controller, na qual são implementadas as soluções para controlar os robôs de vigilância.

Interesses Capturados: I3 e I5. 


\section{Representação}

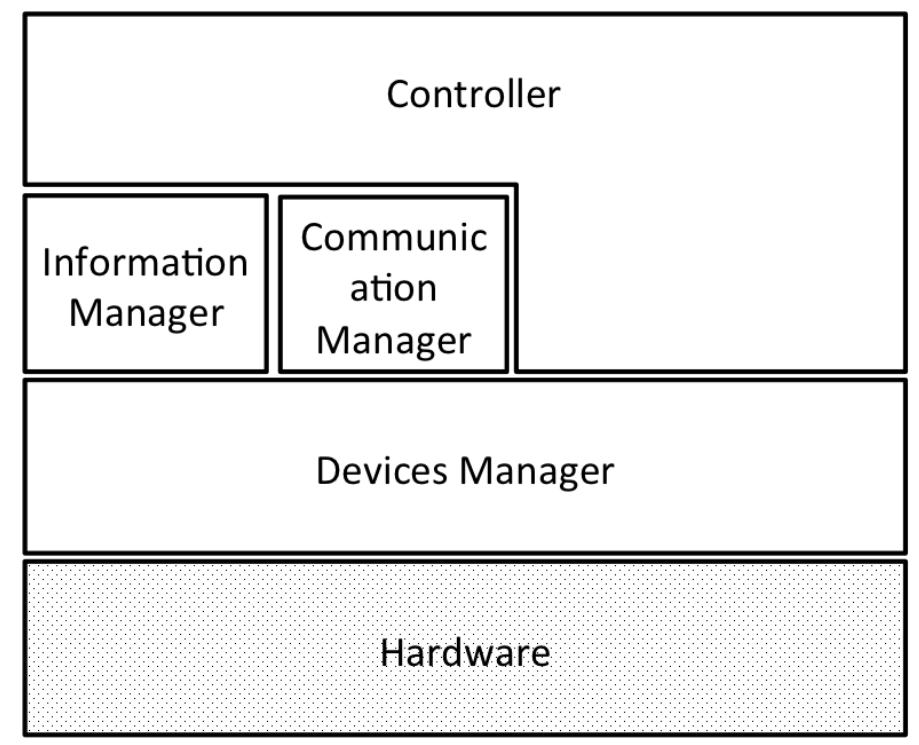

Figura 5.4: Visão Global do Sistema de Vigilância

\subsubsection{Ponto de Vista de Implantação}

Visa apresentar a forma de implantação do sistema de vigilância. Durante a instanciação não se fez necessário a criação de visões adicionais. Dessa forma, a seguir é descrita a Visão de Implantação.

\section{VISÃO DE IMPLANTAÇÃO}

Apresenta o hardware e software presentes no ambiente de implantação, bem como a relação entre eles. Os elementos em questão podem ser visualizados a partir da Figura 5.5. Sendo assim, existem robôs de serviço (Service Robots) que podem comunicar-se entre eles (pelo módulo Communication). Levando em conta o hardware presente em cada robô, esses devem possuir um motor (Robot Engine), um laser (Laser Sensor) e recursos (Resources) básicos (como bateria, CPU e memória RAM).

Acerca do software, esse sistema é classificado como homogêneo e sem máquina central logo, a arquitetura é integralmente implementada em todos os robôs, sendo descentralizado, ou seja, cada robô é responsável planejar e realizar suas próprias tarefas (pelo módulo Controller) a fim de cumprir o objetivo de monitorar os locais por onde passa. A necessidade de interação entre robôs surge em duas situações: quando é necessário saber a localização dos demais, ou quando um intruso é identificado e os demais devem ser notificados. Por fim, a necessidade de armazenar informações (pelo módulo Information Manager) vem da utilização dos mapas do ambiente (Environment). 
Interesses Capturados: I1 e I3.

\section{Representação}

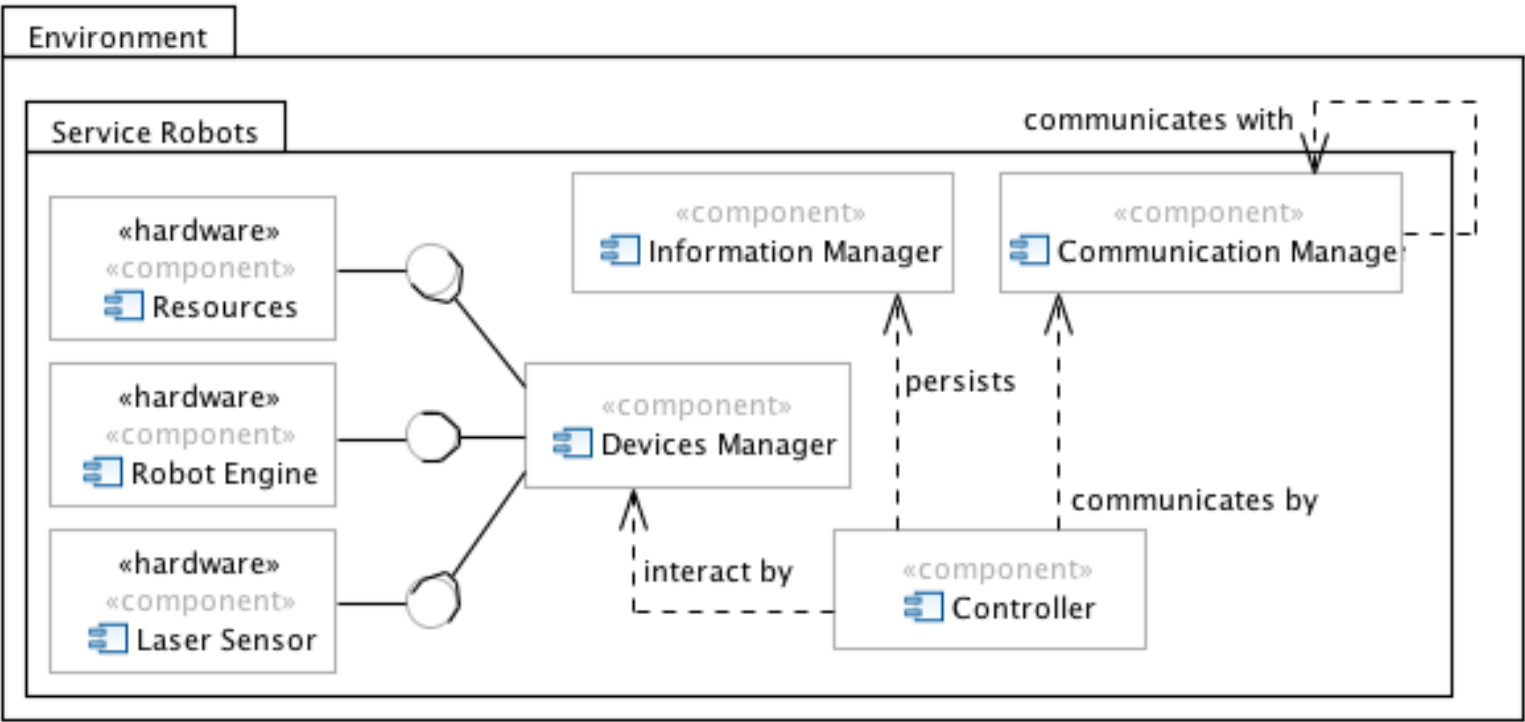

Figura 5.5: Visão de Implantação do Sistema de Vigilância

\subsubsection{Ponto de Vista Estrutural}

Visa apresentar a estrutura do sistema de vigilância por meio de seus módulos e respectivos submódulos, bem como pelas funcionalidades apresentadas por eles. Durante a instanciação fez-se necessário a criação de uma visão adicional, a fim de representar as funcionalidades definidas para o sistema de vigilância. Dessa forma, a seguir são apresentadas a Visão Estrutural e a Visão de Funcionalidades.

\section{VISÃO ESTRUTURAL}

A partir dessa visão, é possível delimitar o contexto de aplicação do sistema de vigilância, bem como de seus elementos internos. A Figura 5.6 apresenta a estrutura desse sistema, na qual se observam quatro módulos referentes aos elementos principais apresentados nas visões anteriores, Controller, Devices Manager, Information Manager e Communication Manager. Esses módulos englobam todas as funcionalidades identificadas para o sistema de vigilância.

O Communication Manager é o módulo responsável pela comunicação entre os robôs. É responsável pelo envio e recebimento de mensagens contendo informações de posição ou avisos. O Information Manager é o módulo responsável pela persistência dos mapas 
que forem necessários para vigilância do ambiente. O Devices Manager é responsável pela gerência do laser, motor e recursos do robô. Conforme pode-se observar na Figura 5.7, ele fornece, por meio do Player, as interfaces de acesso para o laser e motor, além de fornecer, por meio do Self-test, informações referentes ao estado dos dispositivos.

O Controller é responsável por orquestrar os demais módulos a fim de realizar a vigilância do ambiente. Para isso, ele realiza todo o planejamento e execução das tarefas previstas na descrição do sistema. Internamente, o Controller possui quatro submódulos, Efficiency Manager, Safety Manager, Planner e Executor, conforme pode-se observar na Figura 5.8. O primeiro deles é responsável por atender aos requisitos de desempenho do sistema, ou seja, por monitorar o nível de bateria do robô e informar o Planner caso o nível mínimo seja ultrapassado. O Safety Manager é responsável por atender aos requisitos que dizem respeito à segurança das pessoas que irão interagir com o robô, ou seja, o monitoramento da distância entre o robô e qualquer objeto em suas proximidades. Caso a distância mínima entre objetos seja ultrapassada, um aviso é enviado para o Planner e Executor. Esses por sua vez são responsáveis respectivamente por planejar as ações de vigilância e programar o motor, com base no estado do cenário e planejamento.

Interesses Capturados: I1, I3, I4 e I6. 


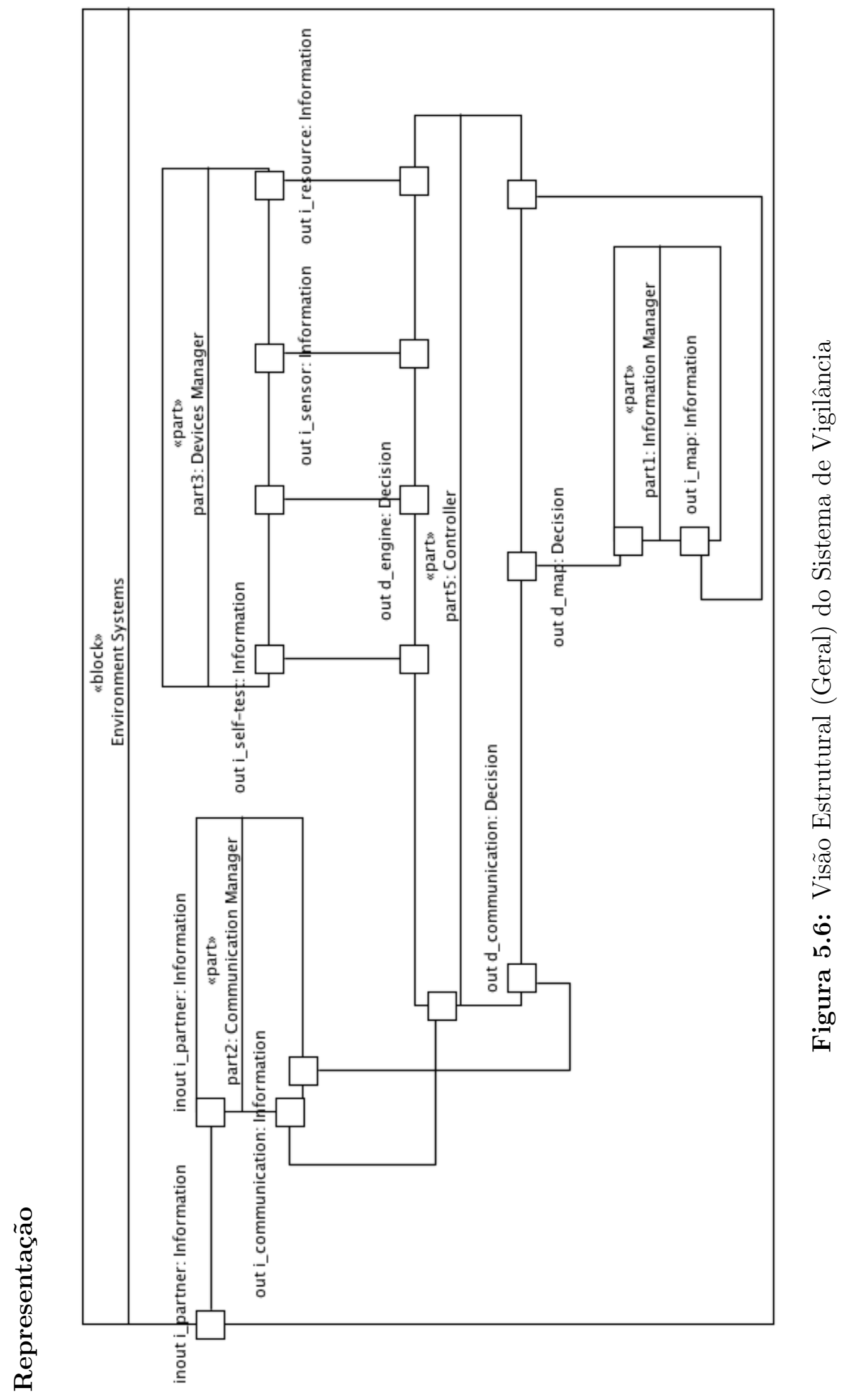




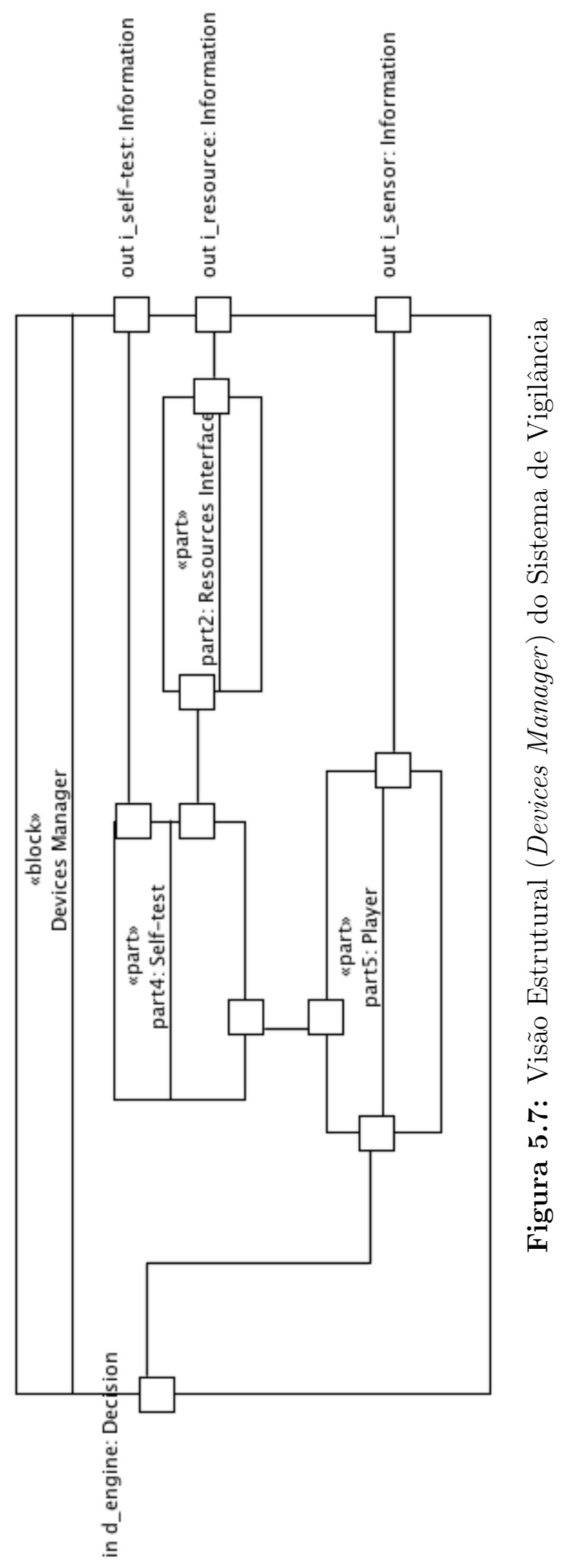




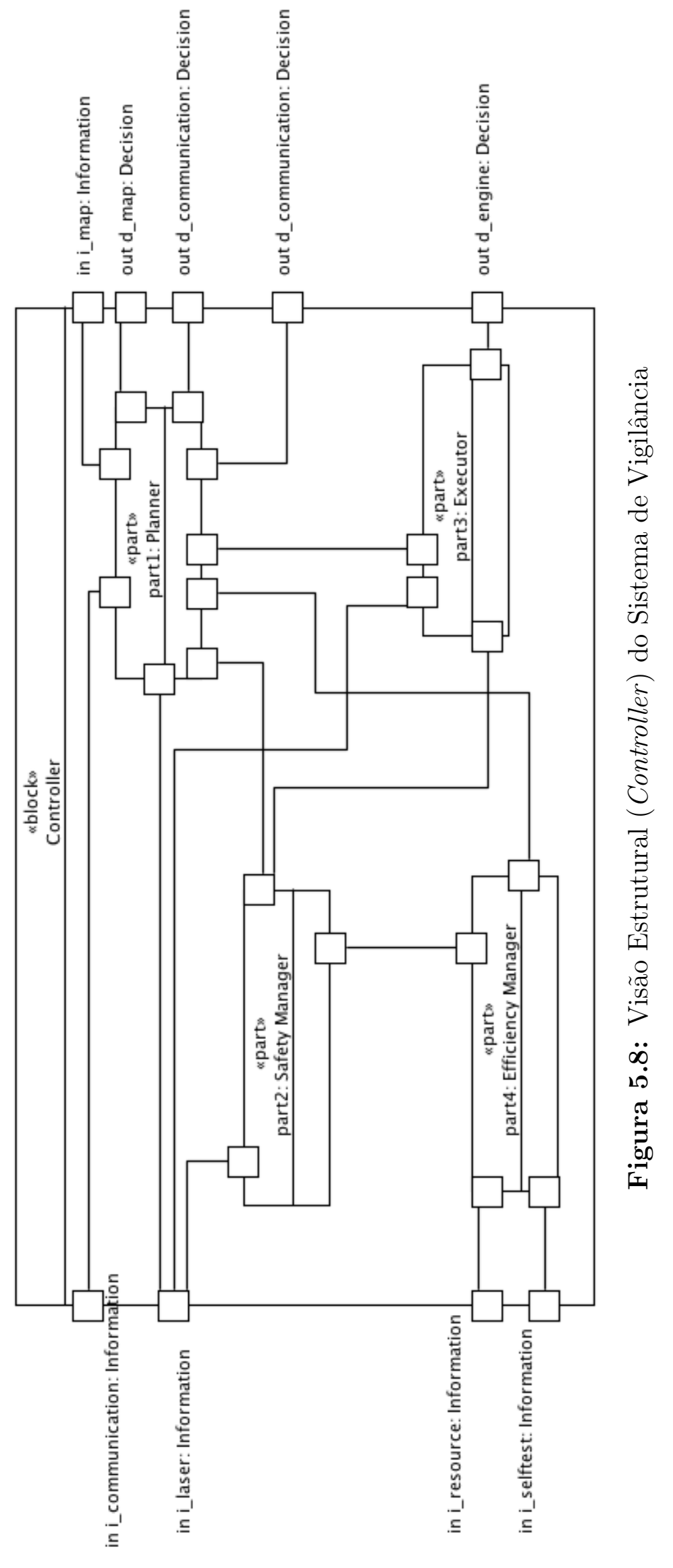




\section{VISÃO DE FUNCIONALIDADES}

A partir das necessidades identificadas em cada parte do sistema de vigilância, foram elencadas as funcionalidades e restrições. A Figura 5.9 apresenta a distribuição dessas funcionalidades e restrições, dentre os módulos e submódulos do sistema de vigilância, com base nos escopos explicitados na visão estrutural. Assim, é possível identificar a distribuição de responsabilidades entre os módulos principais, e desses para seus submódulos. Pro exemplo, o Controller deve ser capaz de ir para uma posição no mapa, e essa responsabilidade é repassada para o Executor, que é o especializado para tal. Também pode-se observar as restrições sendo mapeadas em responsabilidades para submódulos, como no caso da restrição de bateria imposta ao Controller, que é mapeada como uma responsabilidade do Safety Manager.

Interesses Capturados: I2, I4, I5 e I6.

\section{Representação}

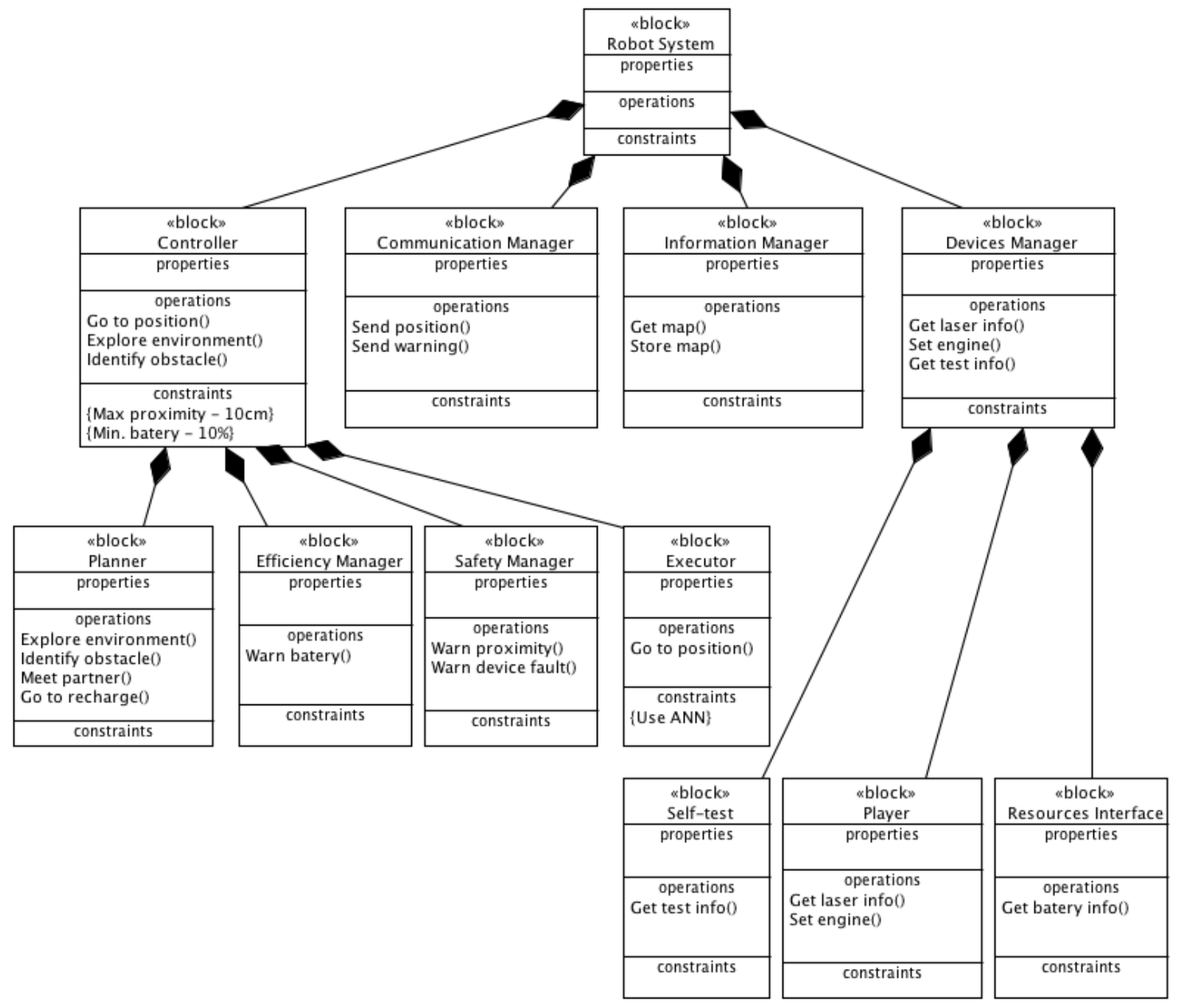

Figura 5.9: Visão de Funcionalidades do Sistema de Vigilância 


\subsubsection{Ponto de Vista em Tempo de Execução}

Visa apresentar o comportamento esperado para sistema de vigilância. Durante a instanciação não se fez necessário a criação de visões adicionais. Dessa forma, a seguir é apresentada a Visão de Processos.

\section{VISÃO DE PROCESSOS}

Essa visão apresenta as principais linhas de execução do sistema de vigilância, indicando responsabilidades e colaborações. A Figura 5.10 apresenta as quatro principais linhas de execução, todas elas inerentes ao Controller (Planner, Executor, Safety Manager e Efficiency Manager). Os demais elementos principais (Devices Manager, Information Manager e Communication Manager) não são representados pelo fato de suas funções estarem bem estabelecidas por meio das visões anteriores.

Existem três processos iniciais, responsáveis pelos módulos Efficiency Manafer, Safety Manager e Planner. Os dois primeiros permitem a verificação da segurança (distância de objetos) e desempenho (nível da bateria) do robô. De forma semelhante, esses dois módulos fornecem informação para o controle; contudo, um aviso de segurança possui maior prioridade para ser atendida do que uma informação de desempenho. Uma vez que um aviso de segurança é emitido, o Executor deve parar o motor e finalizar sua execução, avisando o Planner. Esse, por sua vez, deve verificar se o objeto é conhecido (uma parede ou outro robô) a fim de enviar um aviso de intruso ou se afastar e continuar a vigilância.

O Planner também é responsável pelo planejamento e monitoramento das ações do robô (vigilância do ambiente, identificação de obstáculo, ir ao encontro de outro robô e ir para recarga) e de efeitos dessas ações, como o aviso de intruso. Além disso, ele deve manter o mapa atualizado em relação à sua navegação, e interpretar mensagens que venham dos outros robôs. Por fim, ele deve enviar comandos ao Executor, a fim de que o robô se movimente pelos corredores do ambiente.

Interesses Capturados: I2, I4, I5 e I6. 


\section{Representação}

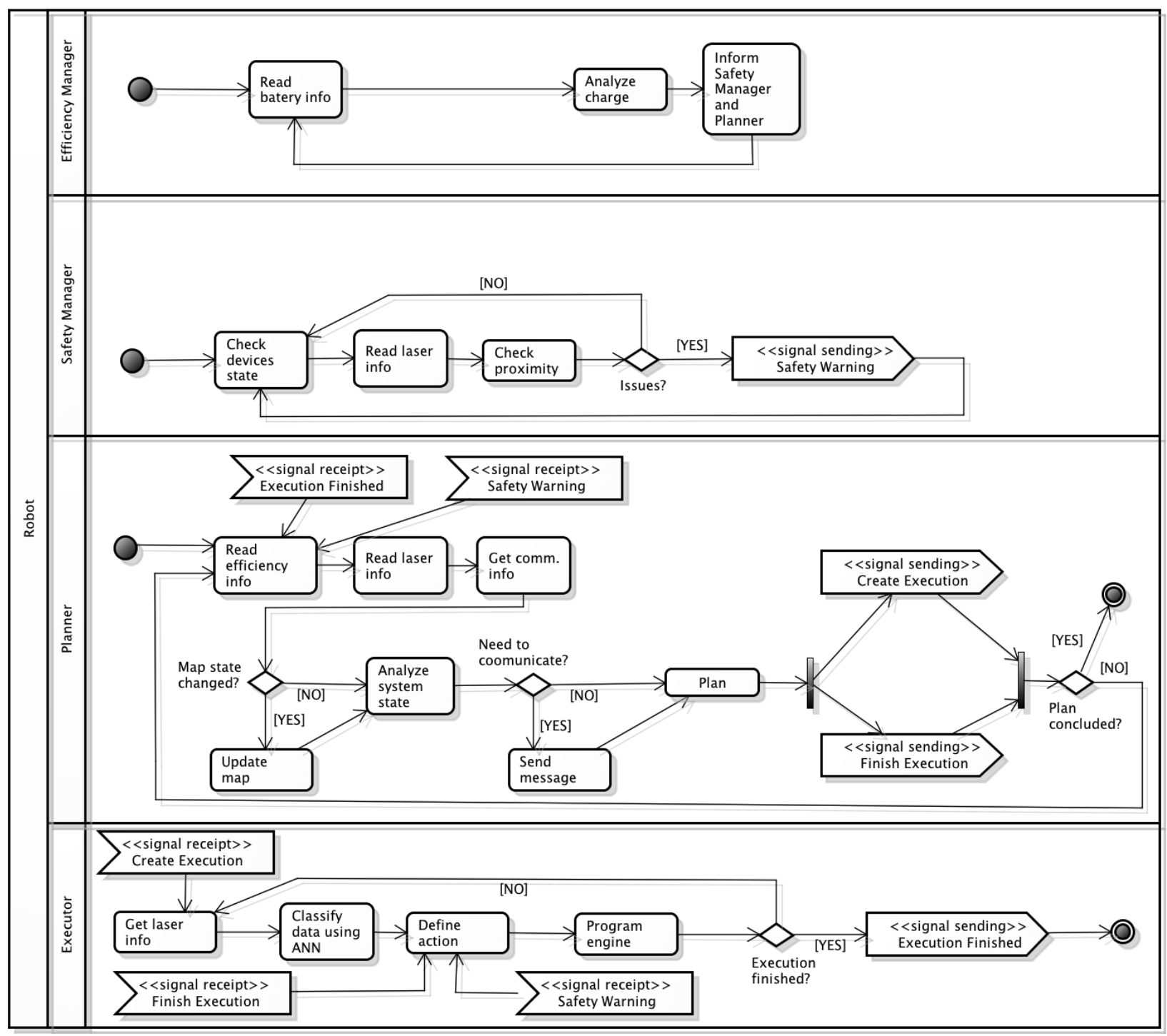

Figura 5.10: Visão de Processos do Sistema de Vigilância

\subsection{Perspectivas para a Implementação do Sistema}

A fim implementar a sistema de vigilância, com base na arquitetura projetada, seria necessário definir os seguintes aspectos, não especificados na arquitetura: paradigma de programação, meio de comunicação e meio de persistência dos mapas. Destaca-se que as decisões tomadas em relação a esses aspectos devem levar em consideração a utilização do Player, já imposta pela arquitetura do sistema. O paradigma de programação está fortemente ligado à utilização do Player, uma vez que a linguagem escolhida deve possuir uma biblioteca para ele. Assim, os principais paradigmas que podem ser considerados são o estruturado e o orientado à objetos. Como o Player está escrito nativamente na 
linguagem C, esta seria a opção recomendada. Contudo, caso se desejasse utilizar uma linguagem orientada a objetos, a linguagem Java poderia ser escolhida.

Como os robôs são independentes, é necessário que os mesmos se comuniquem por meio de uma tecnologia de sem-fio, tais como $W i-f i$ e bluetooth. As opções para meio de persistência são mais diversas, podendo-se utilizar desde arquivos até banco de dados. Dessa forma, a implementação para esses meios dependerão da opção escolhida, bem como da linguagem utilizada.

\subsection{Discussões}

Importantes pontos de discussão surgiram durante a instanciação da SiMuS para o sistema de vigilância em ambiente indoor. O primeiro ponto refere-se ao processo de instanciação da arquitetura de referência com base nos artefatos existentes, tais como descrição e requisitos do sistema. Exceto para nova visão criado (visão de funcionalidades), é possível comparar as representações das arquiteturas de referência e a instanciada. No geral, os elementos relativos ao módulo Evolution Manager foram desconsiderados, e os demais elementos foram "filtrados" a fim de refinar o escopo para o domínio do sistema projetado. Como o sistema de vigilância possui um escopo bastante reduzido e bem definido, não foi necessária a criação ou modificação de diversos submódulos, ocorrendo apenas adaptação para utilização do Player e a posterior distribuição das funcionalidades dentre os módulos previamente apresentados na SiMuS, conectando o escopo da funcionalidade com o escopo dos módulos e submódulos da arquitetura de referência (explicitado pela visão de funcionalidades).

Contudo, caso houvesse necessidade, outros módulos poderiam ser criados, dada algumas restrições. Espera-se que os módulos principais (Devices Manager, Information Manager, Communication Manager, Controller e Evolution Manager) e suas relação sejam mantidas, sem adicionar novos módulos que interajam diretamente com eles, pois pode resultar em sobrecarga de algum deles. Se tais restrições forem atendidas, é possível acrescentar submódulos em qualquer nível inferior, desde que o escopo deles corresponda ao que é esperado pelo módulo principal no qual ele está inserido.

Outro importante ponto a se discutir é evolução dos sistemas desenvolvidos com base na SiMuS. Isso pode ocorrer de forma estática ou dinâmica. Uma evolução é estática quando a arquitetura concreta é alterada, causando uma modificação no sistema final. Levando em consideração a instanciação realizada no estudo de caso, pode-se citar como exemplos de evolução estática: (i) alterar a forma de identificar os estados do cenários, substituindo a RNA por outra forma de identificação de padrões; e (ii) alterar a tecnologia de acesso aos dispositivos, por exemplo, utilização o ORCA ao invés do Player (visando 
o aproveitamento da arquitetura de componentes utilizada no ORCA). Em ambos os casos, não seria custoso identificar e alterar os pontos a serem evoluídos na instância arquitetural. Mesmo em um caso mais complexo, como a utilização do ROS (que envolve maiores modificações), o custo seria consideravelmente mitigado pelo uso da SiMuS. Dessa forma, é possível evidenciar capacidade de evolução que a SiMuS proporciona aos sistemas desenvolvidos com base nela, possibilitando que mais qualidade seja agregada ao software construído.

A evolução dinâmica é quando determinados padrões de alteração são previamente estabelecidos, permitindo que o sistema seja alterado em tempo de execução. Para isso, a SiMuS possui o módulo Evolution Manager, que apoia a evolução dinâmica de módulos

e interfaces. Supondo que esse módulo estivesse presente na arquitetura instanciada no estudo de caso, alterações como a forma de identificação dos estados do cenários poderiam ser transparentes para o Controller, uma vez que ele conhece o protocolo (fornecer dados do laser e receber uma resposta contendo um dos cinco estados conhecidos). Até mesmo o sensor utilizado poderia ser transparente para o Controller, precisando apenas saber se ele possui informações de um sensor de mesma interface exigida pelo módulo de identificação do estado do cenário. Dessa forma, é possível evidenciar, além da capacidade de evolução, também a capacidade de reúso proporcionada pela SiMuS.

Essa discussão acerca da evolução leva ao último ponto: o reúso de hardware entre sistemas. A aquisição de robôs de serviço pode representar um custo financeiro considerável, levando o possível usuário a optar por outra solução. Contudo, a possibilidade de se possuir sistemas que evoluem dinamicamente representa uma valiosa motivação para aquisição de tais bens. Por meio da evolução dinâmica, é possível alcançar níveis como o desenvolvimento de uma linha de produtos de software que utilizem um mesmo hardware já adquirido anteriormente pelo usuário, e que funcione de forma relativamente simples, levando-se em conta que ele estaria adquirindo apenas novos módulos que o próprio sistema presente no robô já é capaz de interpretar e utilizar. Assim, o gasto para aquisição de novas funcionalidades estaria restrita a software e, possivelmente, novos sensores ou atuadores exigidos pelo novo software. Dessa forma, a SiMuS pode contribuir não só para o reúso a nível de software, mas também para o reúso a nível de hardware, possibilitando a construção de softwares melhor estruturados e com mais qualidade.

\subsection{Considerações Finais}

A utilização da SiMuS no projeto de sistemas multorrobóticos de serviço pode contribuir para a capacidade de evolução e reúso, aumentando a produtividade durante a fase de desenvolvimento. Neste capítulo foram discutidos os detalhes relacionados à instanciação 
da arquitetura para um sistema de vigilância em ambiente indoor. A elaboração dessa arquitetura concreta apresentou evidências da aplicabilidade da arquitetura de referência proposta e, em uma análise preliminar, indicou que sua utilização pode trazer benefícios quanto ao aumento da capacidade de reúso e evolução. É importante destacar que os resultados obtidos por meio do estudo de caso são válidos não somente para sistemas semelhantes projetado, mas também para qualquer sistema multirribótico de serviço, tais como sistema de entrega de correspondências, sistema para controle de robôs guias, e sistema de prestadores de serviço, no qual os robôs ficariam vagando pelo ambiente à espera de ordens para serem cumpridas. Dentre as limitações do estudo de caso, está a falta da posterior implementação do sistema, com base na arquitetura concreta elaborada, fato que poderia apoiar a descoberta de lacunas de informação necessárias para o projeto de implementação e que deveriam estar presentes na arquitetura do sistema. 


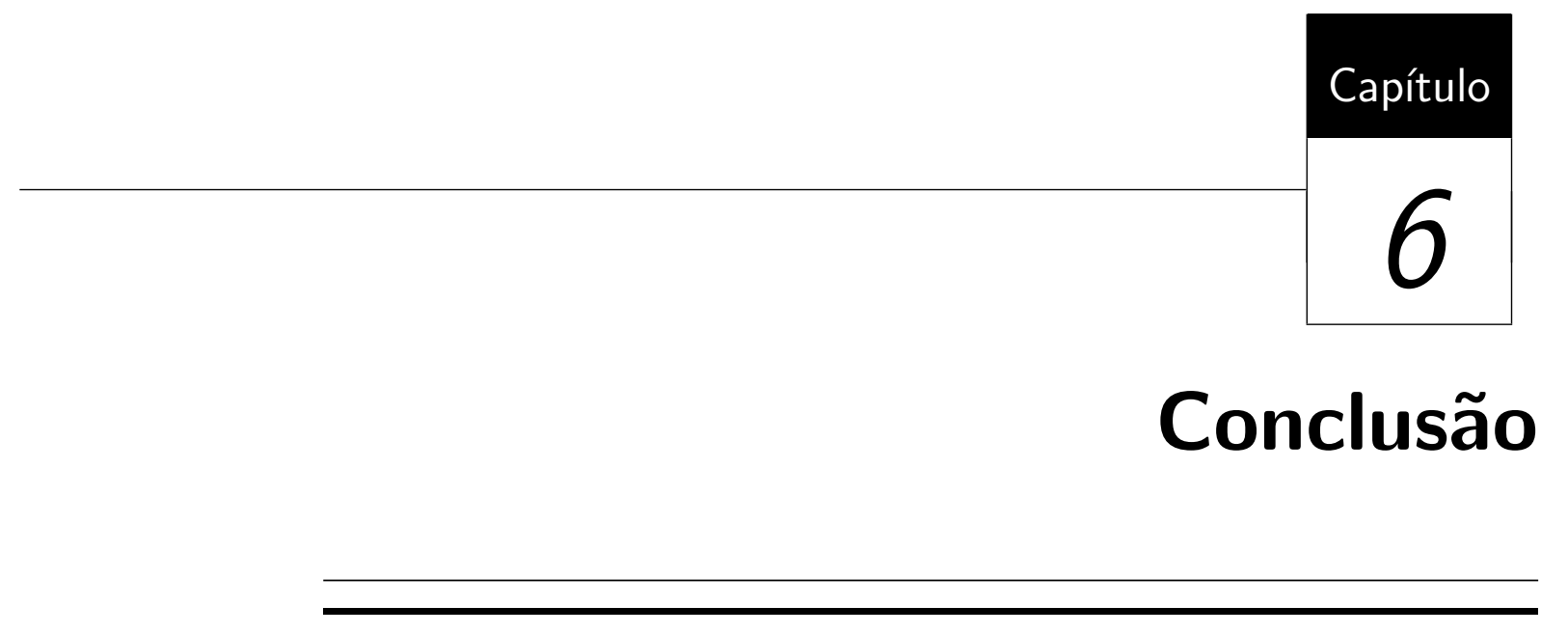

Neste capítulo são retomados brevemente o contexto no qual este trabalho se insere e suas principais contribuições. São apresentadas também, as dificuldades encontradas, limitações referentes a esta pesquisa e perspectivas de trabalhos futuros.

\subsection{Caracterização da Pesquisa Realizada}

O campo de Robótica tem apresentado um crescimento cada vez maior nos últimos anos, afetando vários setores da sociedade e abrindo novas áreas de aplicação importantes. Diferentes tipos de robôs têm sido desenvolvidos e usados e, em particular, os robôs de serviço têm atualmente destacado pela sua relevância e gama de aplicações. Bons exemplos de robôs de serviço são aspiradores de pó e robôs vigilantes. Nos próximos anos, o mercado para esses robôs está previsto para crescer exponencialmente. Nessa perspectiva, a complexidade desses robôs tende a aumentar, criando um desafio considerável para o seu desenvolvimento. Dessa forma, esforços no sentido de estabelecer arquiteturas de software adequadas para esse domínio possuem grande importância e podem auxiliar no desenvolvimento de sistemas mais facilmente reusáveis e escaláveis.

Considerando-se arquiteturas de software, um tipo especial, a arquitetura de referência, tem se destacado pela capacidade de capturar a essência das arquiteturas de sistemas de um determinado domínio, ou seja, ela engloba o conhecimento sobre como projetar, padronizar e desenvolver as arquiteturas de sistemas de um domínio específico. Vale desta- 
car que essas arquiteturas têm sido, por vezes, desenvolvidas por consórcios que envolvem academia e grandes empresas (tais como fabricantes e fornecedores). Assim, arquiteturas de referência têm sido consideradas como um elemento muito importante para melhorar a produtividade e qualidade dos sistemas de software. Dessa forma, uma arquitetura de referência que auxilie no desenvolvimento sistemas multirrobóticos de serviço constitui também um importante ponto de partida em direção ao aumento da capacidade de integração, reúso e qualidade desses sistemas.

\subsection{Contribuições}

Como principal contribuição deste trabalho, destaca-se o estabelecimento de uma arquitetura de referência que objetiva apoiar o desenvolvimento de sistemas multirrobóticos de serviço. É importante destacar que, apesar da existência de outra arquitetura de referência que apoia o desenvolvimento de sistemas multirrobóticos utilizando robôs de serviço, a SiMuS possui escopo mais abrangente e fornece suporte para o desenvolvimento de sistemas capazes de evoluir estática ou dinamicamente. Dessa forma, espera-se um crescimento no índice de reúso e melhor estruturação do sistemas desenvolvidos, possibilitando uma melhora melhora de qualidade dos produtos.

Além da contribuição principal, pode ser também considerada como contribuição deste trabalho o conjunto de requisitos arquiteturais, stakeholders e interesses identificados durante a condução deste projeto, uma vez que pode servir de base para o desenvolvimento de outros sistemas robóticos ou para o estabelecimento de arquiteturas de referência para outros tipos de robô. Além disso, uma outra contribuição no contexto deste trabalho foi a apresentação de um panorama geral e detalhado das arquiteturas de referência, aplicáveis ao desenvolvimento de sistemas robóticos, disponíveis na literatura. Tal panorama foi estabelecido por meio de uma revisão sistemática, o que viabiliza sua atualização e replicação futura.

De uma maneira geral, buscou-se com o desenvolvimento deste trabalho contribuir para a comunidade de Robótica Móvel com uma arquitetura que seja base para o desenvolvimento de sistemas multirrobóticos de serviço. Buscou-se também contribuir para a comunidade de Arquitetura de Software, com a apresentação de um panorama sobre arquiteturas de referência para sistemas robóticos.

\subsection{Dificuldades e Limitações}

Uma das dificuldades encontradas durante o desenvolvimento deste trabalho foi falta de consenso na terminologia utilizada para definição de arquiteturas para sistemas robóticos, 
principalmente arquiteturas de referência, uma vez que a utilização, em maior escala, de técnicas provenientes da Engenharia de Software no domínio de Robótica Móvel, ainda é relativamente recente. Em solução a isso, foi necessário investigar de diferentes temas, de maneira relativamente aprofundada. Outra dificuldade encontrada foi a carência de padrões internacionais de software voltadas para sistemas robóticos. Com o crescimento da complexidade e da produção desses sistemas, tais padrões fazem-se necessários. Em solução a isso, foi realizada uma busca mais ampla por fontes de informação para esse domínio.

As limitações deste trabalho estão relacionadas, principalmente, à representação da arquitetura de referência proposta. Mais detalhes acerca das visões poderiam ser apresentadas, como por exemplo a relação entre visões e os stakeholders, podendo-se assim identificar mais pontos em que a arquitetura pode evoluir. Além disso, os pontos de variabilidade poderiam estar mais explícitos, o que poderia facilitar o uso da SiMuS no desenvolvimento de sistemas multirrobóticos de serviço. Por fim, uma vez que este trabalho foi desenvolvido em contexto acadêmico, não agregando a experiência que parceiros na indústria poderiam proporcionar, alguns conceitos relacionados ao domínio podem não ter sido previstos durante o estabelecimento. Entretanto, atualizações na arquitetura de referência poderão ser realizadas a medida que novos sistemas robóticos forem desenvolvidos, sendo essa uma prática prevista em estudos como o de Angelov et al. (2008).

\subsection{Trabalhos Futuros}

Visando a dar continuidade ao trabalho desenvolvido, a seguir, são apresentadas as principais perspectivas de trabalhos futuros relacionadas a este trabalho:

Evolução da Arquitetura de Referência com Base nas Avaliações: Com base nos resultados obtidos a partir da aplicação do checklist (Seção 4.5), a arquitetura de referência proposta poderá ser evoluída. Assim, objetiva-se então refinar e aprimorar a SiMuS quanto à capacidade de apoiar o desenvolvimento de sistemas multirrobóticos de serviço;

Reavaliação da Arquitetura de Referência Proposta: Visando a liberação de uma arquitetura de referência com maior qualidade, poderá ser conduzida uma nova avaliação após a evolução da arquitetura. Além do checklist já utilizado, métodos de avaliação arquitetural, como o SAAM e o ATAM, poderão ser adaptados e aplicados. A utilização de tais métodos de avaliação arquitetural têm por objetivo aprimorar a qualidade da arquitetura de referência proposta; 
Implementação do Sistema Descrito no Estudo de Caso e Outros: Como forma avaliação contínua da arquitetura de referência proposta tem-se, como trabalho futuro, a implementação do estudo de caso apresentado no Capítulo 5.1. Há a possibilidade de, inclusive, implementar variações do mesmo sistema descrito para que capacidades como a de reúso possam ser mais avaliadas. Além disso, poderiam ser pesquisados sistemas implementados por outros pesquisadores a fim de re-implementá-los utilizando a SiMuS, possibilitando-se assim uma forma de avaliação comparativa;

Elaboração de uma Análise Quantitativa: Baseado no desenvolvimento de diferentes sistemas multirrobóticos de serviço, uma análise quantitativa do aumento da capacidade de reúso e da diminuição do tempo de desenvolvimento proporcionado pelo uso da SiMuS poderá ser realizada. Por meio dessa análise, será possível se ter mais evidências dos benefícios da utilização da arquitetura de referência proposta no desenvolvimento de sistemas desse tipo; e

Elaboração de Ferramental de Apoio à Utilização da SiMuS: A fim de apoiar o desenvolvimento de sistemas multirrobóticos de serviço utilizando a SiMuS, e promover o reúso de artefatos construídos durante o desenvolvimento desses sistemas, poderão ser projetados e implementados ferramentas de apoio, tais como frameworks e bibliotecas que facilitem a utilização de determinadas tecnologias. 


\section{Referências}

Agmon, N.; Kraus, S.; Kaminka, G. Multi-robot perimeter patrol in adversarial settings. In: Proceedings of the IEEE International Conference on Robotics and Automation, Pasadena, USA, 2008, p. 2339-2345.

Albus, J. S. $\quad 4 \mathrm{~d} / \mathrm{rcs}$ - a reference model architecture for intelligent unmanned ground vehicles. Unmanned Ground Vehicle Technology, v. 4715, p. 303-310, 2002.

Álvarez, B.; Iborra, A.; Alonzo, A.; De la Puente, J. A. Reference architecture for robot teleoperation: Development details and practical use. Control Engineering Practice, v. 9, n. 4, p. 395-402, 2001.

Angelov, S.; Grefen, P. W. P. J.; Greefhorst, D. A classification of software reference architectures: Analyzing their success and effectiveness. In: Proceedings of the 8th Working IEEE/IFIP Conference on Software Architecture, Cambridge, UK, 2009, p. $141-150$.

Angelov, S.; Trienekens, J. J. M.; Grefen, P. Towards a method for the evaluation of reference architectures: Experiences from a case. In: Proceedings of the 2nd European Conference on Software Architecture, 2008, p. 225-240.

ANSI/IEEE Recommended practice for architectural description of software intensive systems (ANSI/IEEE 1471). American National Standards Institute (ANSI)/ Institute of Electric and Electronic Engineers (IEEE), 2000.

ANSI/UL Robots and robotic equipment (ANSI/UL 1740). American National Standards Institute (ANSI)/ Underwriters Laboratories (UL), 2007.

Arsanjani, A.; Zhang, L.-J.; Ellis, M.; Allam, A.; Channabasavaiah, K. S3: A service-oriented reference architecture. IT Professional, v. 9, n. 3, p. 10-17, 2007. 
AUTOSAR AUTOSAR (AUTomotive Open System ARchitecture). [On-line], World Wide Web, (Útimo acesso em 25/05/2012), 2011.

Disponível em http://www. autosar.org/

Bass, L.; Clements, P.; Kazman, R. Software architecture in practice. 2 ed. Addison-Wesley, 2003.

Bayer, J. View-based software documentation. Tese de Doutoramento, Fraunhofer IRB Verlag, Stuttgart, Germany, 2004.

Bekey, G.; Junku, Y. The status of robotics. IEEE Robotics \& Automation Magazine, v. 15, n. 1 , p. $80-86,2008$.

Biolchini, J.; Mian, P.; Natali, A.; Conte, T.; Travassos, G. Scientific research ontology to support systematic review in software engineering. Advanced Engeneering Informatics, v. 21, n. 2, p. 133-151, 2007.

Brooks, A.; Kaupp, T.; Makarenko, A.; Williams, S.; Orebäck, A. Orca: A component model and repository. In: Brugali, D., ed. Software Engineering for Experimental Robotics, v. 30 de Springer Tracts in Advanced Robotics, Springer Berlin/Heidelberg, p. 231-251, 2007.

Bunzel, S. Autosar - the standardized software architecture. Informatik Spektrum, v. 34, n. 1, p. 79-83, 2011.

Buschmann, F.; Meunier, R.; Rohnert, H.; Sommerlad, P.; Stal, M. Pattern-oriented software architecture: A system of patterns, v. 1. John Wiley \& Sons, 1996.

Chevaleyre, Y.; Sempe, F.; Ramalho, G. A theoretical analysis of multi-agent patrolling strategies. In: Proceedings of the 3rd International Joint Conference on Autonomous Agents and Multiagent Systems, New York, USA, 2004, p. $1524-1525$.

Clark, M. N. JAUS compliant systems offers interoperability across multiple and diverse robot platforms. In: AUVSI's Unmanned Systems North America, Baltimore, USA, 2005, p. 249-255.

Clements, P.; Bachmann, F.; Bass, L.; Garlan, D.; Ivers, J.; Little, R.; Nord, R.; Stafford, J. Documenting software architectures: Views and beyond. SEI series in software engineering, 2 ed. Boston, MA: Addison-Wesley, 2011.

Clements, P.; Kazman, R.; Klein, M. Evaluating software architectures: Methods and case studies. The SEI Series in Software Engineering. Addison-Wesley, 2002. 
Eickelmann, N. S.; Richardson, D. J. An evaluation of software test environment architectures. In: Proceedings of the 18th Internacional Conference on Software Engineering, Berlin, Germany, 1996, p. 353-364.

Eklund, U.; Örjan Askerdal; Granholm, J.; Alminger, A.; Axelsson, J. Experience of introducing reference architectures in the development of automotive electronic systems. SIGSOFT Software Engineering Notes, v. 30, n. 4, p. 1-6, 2005.

Fox, D.; Burgard, W.; Thrun, S. Markov localization for reliable robot navigation and people detection. In: Christensen, H. I.; Bunke, H.; Noltemeier, H., eds. Proceedings of the International Workshop on Sensor Based Intelligent Robots, Dagstuhl Castle, Germany: Springer-Verlag, 1999, p. 1-20 (Lecture Notes in Computer Science, v.1724).

Garlan, D. Software architecture: A roadmap. In: Proceedings of the Conference on The Future of Software Engineering, New York, USA: ACM Press, 2000, p. 91-101.

Graaf, B.; Lormans, M.; Toetenel, H. Embedded software engineering: The state of the practice. IEEE Software Engineering, v. 20, n. 6, p. 61-69, 2003.

Hayes-Roth, B.; Pfleger, K.; Lalanda, P.; Morignot, P.; Balabanovic, M. A domain-specific software architecture for adaptive intelligent systems. IEEE Transactions on Software Engineering, v. 21, n. 4, p. 288-301, 1995.

Haykin, S. S. Redes neurais. 2 ed. Bookman, 2001.

ISO/IEC Recommended practice for architectural description of software-intensive systems (ISO/IEC 42010). International Organization for Standardization (ISO)/ International Electrotechnical Commission (IEC), 2007.

ISO/TC 184 Automation systems and integration. International Organization for Standardization (ISO), 1983.

JAUS JAUS (Joint Architecture for Unmanned Systems). [On-line], World Wide Web, (Último acesso em 17/12/2012), 2012.

Disponível em http://www.openjaus.com/

Jung, C. R.; Osório, F. S.; Kelber, C.; Heinen, F. Computação embarcada: Projeto e implementação de veículos autônomos inteligentes. In: Anais do 29o Congresso da Sociedade Brasileira de Computação, São Leopoldo, Brasil, 2005, p. 1358-1406 (Jornada de Atualização em Informática da $S B C, \mathrm{v} .1)$.

Kazman, R.; Klein, M.; Barbacci, M.; Longstaff, T.; Lipson, H.; Carriere, J. The architecture tradeoff analysis method. In: Proceedings of the 4 th IEEE International 
Conference on Engineering of Complex Computer Systems, Monterey, USA, 1998, p. 68-78.

Kitchenham, B. Procedures for performing systematic reviews. Relatório Técnico TR/SE-0401, Keele University, 2004.

Kruchten, P. The $4+1$ view model of architecture. IEEE Software, v. 12, n. 6, p. 42-50, 1995.

Kwon, D.-S.; Kwak, Y. K.; Park, J.; Chung, M. J.; Jee, E.-S.; Park, K.-S.; Kim, H.-R.; Kim, Y.-M.; Park, J.-C.; Kim, E. H.; Hyun, K. H.; Min, H.-J.; Lee, H. S.; Park, J. W.; Jo, S. H.; Park, S.-Y.; Lee, K.-W. Emotion interaction system for a service robot. In: Proceedings of the 16th IEEE International Symposium on Robot and Human Interactive Communication, Jeju Island, Korea, 2007, p. 351-356.

Land, R. A brief survey of software architecture. Relatório Técnico, Department of Computer Engineering, Mälardalen University, Sweden, 2002.

Medvidovic, N.; Rosenblum, D. S.; Redmiles, D. F.; Robbins, J. E. Modeling software architectures in the unified modeling language. ACM Transactions on Software Engineering and Methodology, v. 11, n. 1, p. 2-57, 2002.

Medvidovic, N.; Taylor, R. N. A classification and comparison framework for software architecture description languages. IEEE Transactions on Software Engineering, v. 26, n. 1, p. 70-93, 2000.

Mendes, A. Arquitetura de software, desenvolvimento orientado para arquitetura. Campus, 2002.

Merson, P. Como documentar arquiteturas de software. Software Engineering Institute (SEI), Carnegie Mellon University, material de Apoio, mini-curso do 19o Simpósio Brasileiro de Engenharia de Software, 2005.

Mirisola, L. G. B. Orca complementary tutorial. Curso sobre ORCA - Instituto de Ciências Matemáticas e de Computação (ICMC/USP), 2009.

Mondada, F.; Gambardella, L. M.; Floreano, D.; Dorigo, M. The cooperation of swarm-bots: Physical interactions in collective robotics. IEEE Robotics and Automation Magazine, v. 12, p. 21-28, 2005.

Muller, G. A reference architecture primer. Relatório Técnico, Eindhoven University of Technology, whitepaper, 2008. 
Nakagawa, E. Y. Uma contribuição ao projeto arquitetural de ambientes de engenharia de software. Tese de doutorado, Instituto de Ciências Matemáticas e de Computação - ICMC/USP, São Carlos, Brasil, 2006.

Nakagawa, E. Y.; ao, A. S. S.; Ferrari, F.; Maldonado, J. C. Towards a reference architecture for software testing tools. In: Proceedings of the 19th International Conference on Software Engineering and Knowledge Engineering, Boston, USA, 2007, p. 157-162.

Nakagawa, E. Y.; Barbosa, E. F.; Maldonado, J. C. Exploring ontologies to support the establishment of reference architecture: An example on software testing. In: Proceedings of the IEEE/IFIP Conference on Software Architecture 2009, European Conference on Software Architecture 2009, Cambridge, UK, 2009a, p. 1-4.

Nakagawa, E. Y.; Ferrari, F.; Sasaki, M. M. F.; Maldonado, J. C. An aspect-oriented reference architecture for software engineering environments. Journal of Systems and Software, v. 84, n. 10, p. 1670-1684, 2011.

Nakagawa, E. Y.; Maldonado, J. C. Architectural requirements as basis to quality of software engineering environments. IEEE Latin America Transactions, v. 6, n. 3, p. 260-266, 2008.

Nakagawa, E. Y.; Martins, R.; Felizardo, K.; Maldonado, J. C. Towards a process to design aspect-oriented reference architectures. In: Proceedings of the 35rd Latin American Informatics Conference, Pelotas, Brazil, 2009b, p. 1-10.

OASIS Reference model for service oriented architecture 1.0. Relatório Técnico, OASIS Standard, 2006.

ORCA Robotics Orca: Components for robotics. [On-line], World Wide Web, (Último acesso em 20/11/2012), 2009.

Disponível em http://orca-robotics.sourceforge.net/

Ortiz, F.; Alonso, D.; Alvarez, B.; Pastor, J. A reference control architecture for service robots implemented on a climbing vehicle. In: Proceedings of the 10th International Conference on Reliable Software Technologies, York, UK, 2005, p. 13-24 (Lecture Notes in Computer Science, v.3555).

Osagie, P. Distributed control for networked autonomous vehicles. Dissertação de Mestrado, KTH Computer Science and Communication, Royal Institute of Technology, Sweden, 2006. 
Peters, L.; Pauly, M.; Arghir, A. Servicebots - a scalable architecture for autonomous service robots. In: Proceedings of the 9th IEEE International Conference on Fuzzy Systems, San Antonio, USA, 2000, p. 1013-1016.

Pfeifer, R.; Iida, F.; Bongard, J. New robotics: Design principles for intelligent systems. Artificial Life, v. 11, p. 1-2, 2005.

Player About player and features of player. [On-line], World Wide Web, (Último acesso em 30/12/2012), 2006.

Disponível em http://playerstage. sourceforge . net/index .php?src=player

Sandkuhl, K.; Messer, B. Towards reference architectures for distributed groupware applications. In: Proceedings of the 8th Euromicro Workshop on Parallel and Distributed Processing, Rhodos, Greece, 2000, p. 135-141.

Siegwart, R.; Nourbakhsh, I. R. Introduction to autonomous mobile robots. Scituate, USA: Bradford Company, 2004.

Silveira, R. A. Introdução a sistemas multiagente. 2006.

Software Engineering Institute How do you define software architecture? [On-line], World Wide Web, (Último acesso em 03/12/2012), 2009.

Disponível em http://www.sei.cmu.edu/architecture/definitions.html

Software Engineering Institute Community software architecture definitions. [On-line], World Wide Web, (Último acesso em 03/12/2012), 2010.

Disponível em http://www.sei.cmu.edu/architecture/start/community.cfm

Stone, P.; Veloso, M. Multiagent systems: A survey from a machine learning perspective. Autonomous Robots, v. 8, p. 345-383, 2000.

Thrun, S.; Burgard, W.; Fox, D. Probabilistic robotics (intelligent robotics and autonomous agents series). Intelligent robotics and autonomous agents. The MIT Press, 667 p., 2005.

UniversAAL Project The UniversAAL Reference Architecture. [On-line], World Wide Web, (Último acesso em 12/11/2012), 2012.

Disponível em http://www. universaal.org/

Vahid, F.; Givargis, T. Embedded system design - a unified hardware/software introduction. 1 ed. Wiley-VCH, 1-324 p., 2002. 
Wasserman, A. I. Towards a discipline of software engineering. IEEE Software, v. 13, n. 6, p. 23-31, 1996.

Weyns, D.; Holvoet, T. A reference architecture for situated multiagent systems. In: Proceedings of the 3rd International Workshop Environments for Multi-Agent Systems, Hakodate, Japan, 2006, p. 1-40 (Lecture Notes in Computer Science, v.4389).

Wolf, D. F.; Osório, F. S.; Simões, E.; Trindade Jr., O. Robótica inteligente: Da simulação às aplicações no mundo real. In: Anais do 29o Congresso da Sociedade Brasileira de Computaćão, Rio de Janeiro, Brasil, 2009, p. 279-330 (Jornada de Atualização em Informática da $S B C, \mathrm{v} .1)$.

Wolf, P.; Schmidt, A.; Otte, J. P.; Klein, M.; Rollwage, S.; König-Ries, B.; Dettborn, T.; Gabdulkhakova, A. openaal - the open source middleware for ambient-assisted living (AAL). In: Proceedings of the AALIANCE Conference, Malaga, Spain, 2010, p. 1-5.

Zhang, T.; Yuan, Y.; Ueno, H. A knowledge model-based intelligent coordinative network platform for service robot system. In: Proceedings of the 4th IEEE International Conference on Robotics and Biomimetics, 2007, p. 233-238. 